\title{
Review
}

\section{Advances in ultra-high temperature ceramics, composites, and coatings}

\author{
Dewei NI ${ }^{a, \dagger}$, Yuan $\mathrm{CHENG}^{b, \dagger}$, Jiaping ZHANG ${ }^{c, \dagger}$, Ji-Xuan $\mathrm{LIU}^{d, \dagger}$, \\ Ji ZOU ${ }^{e, \dagger}$, Bowen $\mathrm{CHEN}^{a, f}$, Haoyang $\mathrm{WU}^{e}$, Hejun $\mathrm{LI}^{c}$,

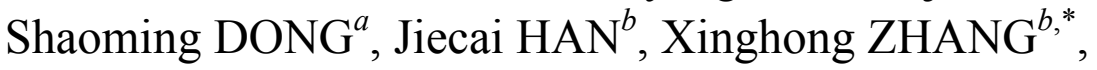 \\ Qiangang $\mathrm{FU}^{c,}$, Guo-Jun ZHANG ${ }^{d, *}$
}

${ }^{a}$ State Key Laboratory of High Performance Ceramics \& Superfine Microstructure, Structural Ceramics and Composites Engineering Research Center, Shanghai Institute of Ceramics,

Chinese Academy of Sciences, Shanghai 200050, China

${ }^{b}$ National Key Laboratory of Science and Technology on Advanced Composites in Special Environments, Center for Composite Materials and Structures, Harbin Institute of Technology, Harbin 150001, China

${ }^{c}$ Shaanxi Key Laboratory of Fiber Reinforced Light Composite Materials, Northwestern Polytechnical University, Xi'an 710072, China

${ }^{d}$ State Key Laboratory for Modification of Chemical Fibers and Polymer Materials, Institute of Functional Materials, Donghua University, Shanghai 201620, China

${ }^{e}$ State Key Laboratory of Advanced Technology for Materials Synthesis and Processing, Wuhan University of Technology, Wuhan 430070, China

${ }^{f}$ University of Chinese Academy of Sciences, Beijing 100049, China

Received: September 9, 2021; Revised: October 12, 2021; Accepted: October 16, 2021

(C) The Author(s) 2021.

\begin{abstract}
Ultra-high temperature ceramics (UHTCs) are generally referred to the carbides, nitrides, and borides of the transition metals, with the Group IVB compounds ( $\mathrm{Zr} \& \mathrm{Hf}$ ) and $\mathrm{TaC}$ as the main focus. The UHTCs are endowed with ultra-high melting points, excellent mechanical properties, and ablation resistance at elevated temperatures. These unique combinations of properties make them promising materials for extremely environmental structural applications in rocket and hypersonic vehicles, particularly nozzles, leading edges, and engine components, etc. In addition to bulk UHTCs, UHTC coatings and fiber reinforced UHTC composites are extensively developed and applied to avoid the intrinsic brittleness and poor thermal shock resistance of bulk ceramics. Recently, highentropy UHTCs are developed rapidly and attract a lot of attention as an emerging direction for ultra-high temperature materials. This review presents the state of the art of processing approaches, microstructure design and properties of UHTCs from bulk materials to composites and coatings, as well as the future directions.
\end{abstract}

\footnotetext{
$\dagger$ Dewei Ni, Yuan Cheng, Jiaping Zhang, Ji-Xuan Liu, and Ji Zou contributed equally to this work.

* Corresponding authors.

E-mail: G.-J. Zhang, gjzhang@dhu.edu.cn;

X. Zhang, zhangxh@hit.edu.cn;

Q.Fu, fuqiangang@nwpu.edu.cn
} 
Keywords: ultra-high temperature ceramics (UHTCs); coatings; composites; high-entropy ultra-high temperature ceramics

\section{Introduction}

Ultra-high temperature ceramics (UHTCs) refer to a number of special materials which are chemically stable at ultra-high temperatures (above $2000{ }^{\circ} \mathrm{C}$ ) and in reactive atmosphere (i.e., atomic oxygen environment), usually including borides, carbides, and nitrides of transition metals, and other high-melting point compounds [1-5]. The UHTCs generally have melting points higher than $3000{ }^{\circ} \mathrm{C}$ and excellent oxidation ablation resistance [1-3], which can maintain non-ablative properties and structural integrity in an oxidizing environment above $1800{ }^{\circ} \mathrm{C}$ for longer period. This makes them very promising for applications in extreme conditions. Existing high-temperature alloy materials have poor oxidation resistance and their application temperatures are generally lower than $1200{ }^{\circ} \mathrm{C}$; long-term application temperature of $\mathrm{C} / \mathrm{SiC}$ composites could not exceed $1650{ }^{\circ} \mathrm{C}$ due to the active oxidation of the $\mathrm{SiC}$ matrix; $\mathrm{C} / \mathrm{C}$ composites begin to be oxidized sharply above $500{ }^{\circ} \mathrm{C}$ without a protective layer. Therefore, the previous thermal protection material system could no longer meet the needs of hypersonic vehicle thermal protection. Due to the excellent combined properties, UHTCs are considered as the candidates for a new generation of high-temperature thermal protection materials. In more specific terms, transition-metal diborides are characterized by tuneable densities (4.5-12.5 $\left.\mathrm{g} \cdot \mathrm{cm}^{-3}\right)$, moderate coefficient of thermal expansion (CTE; $6.3 \times 10^{-6}-8.6 \times 10^{-6} \mathrm{~K}^{-1}$ ), high thermal conductivity $\left(60-120 \mathrm{~W} \cdot \mathrm{m}^{-1} \cdot \mathrm{K}^{-1}\right)$, low electrical resistivity $(10-30 \mu \Omega \cdot \mathrm{cm})$, relatively good mechanical properties, and oxidation resistance. Compared to borides, carbide-based UHTCs, such as HfC, have similar CTE, but higher electrical resistivity $(109 \mu \Omega \cdot \mathrm{cm})$ and slightly lower mechanical properties. However, carbide-based UHTCs are easier to be oxidized at low temperatures in oxygen containing environment, limiting their application to some extent. Compared with carbides or borides, the mechanical properties of nitride-based UHTCs are lower. They normally possess high CTE $\left(7 \times 10^{-6}-10 \times 10^{-6} \mathrm{~K}^{-1}\right)$ and low thermal conductivity $\left(19-23 \mathrm{~W} \cdot \mathrm{m}^{-1} \cdot \mathrm{K}^{-1}\right)$.

\section{1 History of UHTC studies}

The earliest research on UHTCs can be traced back to the $1950 \mathrm{~s}$. $\mathrm{HfB}_{2}$ and $\mathrm{ZrB}_{2}$ have been attracted and used as nuclear reactor materials because of their excellent high-temperature corrosion resistance [6-8]. Incrementally, potentials of UHTCs as the high-temperature thermal protection materials have been recognized. In the 1960s and 1980s, there was an upsurge in the research relating to hypersonic aircraft in USA. In order to develop new ultra-high temperature materials, which meet the thermal protection requirements of nose cone and fuselage front edge, Air Force Materials Laboratory (AFRL) funded the ManLabs laboratory to explore the potential of ultra-high temperature ceramic materials in anti-oxidation and ablation resistance [9-13]. In the 1990s, NASA Ames Glenn Research Center further carried out systematic basic research on the mechanical properties and oxidation resistance of $\mathrm{HfB}_{2}-\mathrm{SiC}$ and $\mathrm{ZrB}_{2}-\mathrm{SiC}$ [14-17]. By the end of the 1990s and the beginning of the 21st century, the Ames Glenn Research Center together with Sandia National Laboratory and the Air Force Space Command, carried out flight demonstration test of the thermal protection structure of UHTCs. Although it exposed the intrinsic brittleness of UHTCs, this flight test proved the great potential of UHTCs in extreme environments, from the viewpoint of ablation resistance $[18,19]$. The Ames Glenn Research Center led the follow-up research, and continuously invested in the research on the strengthening and toughening technology for UHTCs.

The design and implementation of strengthening and toughening have therefore become research hotspots in the field of UHTCs. With particulate, whisker, or platelet as reinforcements, the fracture toughness of bulk UHTCs was improved to a certain extent, even though the intrinsic brittleness could not be eliminated completely. A better solution to toughen the UHTCs is to introduce continuous fibers into their matrix. Continuous fiber-reinforced UHTC matrix composites (UHTCMCs) overcome the inherent brittleness and poor thermal shock resistance of bulk UHTCs [20-23]. Compared to the traditional aerospace composites of $\mathrm{C}$ or SiC matrices, the UHTCMCs seek to provide higher- 
temperature capability and enhanced ablation resistant performance. As shown in Fig. 1, the publications about UHTCMCs appear in $\sim 2005$, on the development of 2.5D-C $\mathrm{C}_{\mathrm{f}}$-reinforced $\mathrm{HfC}$ and $2.5 \mathrm{D}-\mathrm{C}_{\mathrm{f}}$-reinforced $\mathrm{ZrB}_{2}-\mathrm{SiC}$ composites [24,25]. Since then, UHTCMCs have stirred up a spree of researches, with a rapid increase in the number of relevant publications every year.

\section{2 Challenges}

Thermal environments for hypersonic vehicles include ultra-high temperatures $\left(>2000{ }^{\circ} \mathrm{C}\right)$, large thermal gradients and stresses, highly chemically active airflows $\left(>10 \mathrm{MW} \cdot \mathrm{m}^{-2}\right)$, and complex thermal-mechanical loads [26]. As mentioned above, monolithic UHTCs are susceptible to catastrophic failure during their services. Various approaches have been applied to improve the fracture toughness and thermal shock resistance of UHTCs.

(1) Particulate [27-29], chopped fiber, and whisker reinforced UHTCs

The effects of particles on the reinforcing of UHTCs are rather limited [30]. For this concern, carbon nanotubes, chopped fibers, and whiskers have been adopted as reinforcing elements to improve the fracture toughness of UHTCs. The previous work demonstrated that $\mathrm{HfB}_{2}$ matrix incorporated with carbon nanotube exhibited excellent fracture toughness of $7.8 \mathrm{MPa} \cdot \mathrm{m}^{1 / 2}$ and strength of $894 \mathrm{MPa}$ [31]. Nevertheless, the reaction between carbon nanotube and oxide impurities in the UHTCs might be a problem as it can deteriorate the mechanical performance. The homogenization of these additives in the UHTCs was also challenging [32]. $\mathrm{SiC}$ whiskers $\left(\mathrm{SiC}_{\mathrm{w}}\right)$ showed a better role in hardening and toughening of $\mathrm{ZrB}_{2}$-based composites, compared to $\mathrm{SiC}$ particulates [33]. Investigations demonstrate that $\mathrm{SiC}_{\mathrm{w}}$ exhibited greater degradation than $\mathrm{SiC}$ fibers, as the easy conversion of $\mathrm{SiC}_{\mathrm{w}}$ into $\mathrm{SiC}$ particles during the sintering process [34]. During sintering, strong interactions between fibers and matrix are occurred inevitably, limiting the degree of fiber pullout during failure. The problem could be solved either by introducing a soft interphase layer on the fibers or by developing new technologies to manufacture UHTCs in which sintering is no longer needed.

(2) Continuous fiber-reinforced UHTC matrix composites (UHTCMCs)

The poor thermal shock resistance of bulk UHTCs could be improved by loading UHTCs into the fiber preforms. Carbon fibers are the most used fibers for UHTCMCs, and it has been suggested that the effects of carbon fiber types on the fracture toughness of UHTCMCs are rather limited [35]. Various processing methods, such as chemical vapor infiltration (CVI), precursor infiltration and pyrolysis (PIP), slurry infiltration (SI), and reactive melt infiltration (RMI), have been developed for the fabrication of UHTCMCs. Denser UHTCMCs could be obtained by combining these approaches with a further heat treatment with pressure.

\section{(3) UHTC coatings}

An alternative approach to avoid the catastrophic failure of large monolithic UHTC component is to deposit them on tough and heat resistant substrates [36-42], i.e., carbon fiber-reinforced composites and graphite. Since the 2000 s, especially after X-43A completed its flight test, interests on UHTC ceramic coatings have become one of the research focuses. To survive in harsh aerothermal heating, the basic requirements of UHTC coatings are as follows: good expansion coefficient match with the substrate; good integrity/uniformity and strong interface bonding. In real working conditions, the preparation of UHTC

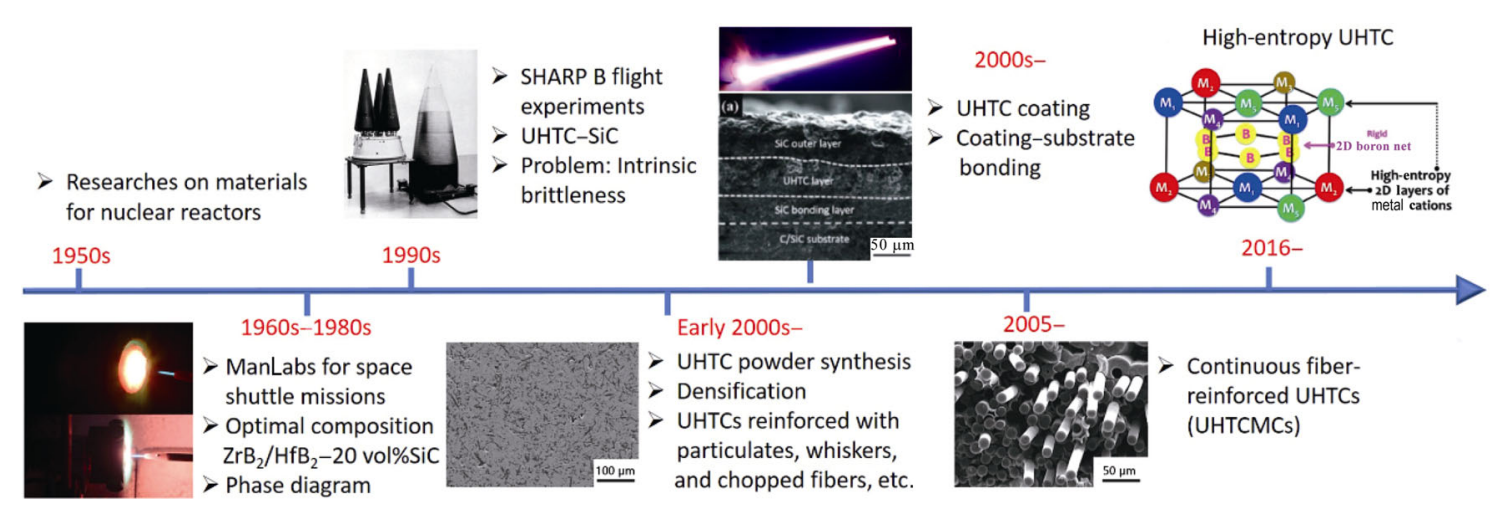

Fig. 1 Historical perspective on research related to ultra-high temperature ceramics and composites. 
coating necessarily involves a mechanism which can coordinate the usage of the aforementioned requirements. Therefore, the reported UHTC coatings usually present different compositions and structures.

In this review, processing and properties of bulk UHTCs will be first detailed, followed by the processing of UHTCMCs. The focus here would be limited to processing routes of these composites with particular discussion on their mechanical behavior and ablation resistance. In the coating section, the UHTC coatings are divided according to their composition and structure differences, and their performances are discussed based on the design rules of the coating. By applying the entropy-stabilization concept to UHTCs, a number of multicomponent carbide/borides were recently fabricated, as an emerging direction for the development of ultra-high temperature ceramics and composites. The recent progresses on the processing and properties of high-entropy UHTCs are also included in this review. By combining the progress on ceramics, composites, and coatings, this review tries to provide guidelines for the researchers to design, select, and manufacture suitable forms of ultra-high temperature materials for demanding environments.

\section{Bulk UHTCs: Composition, microstructure, and performance}

\section{1 Lattice structure of UHTCs}

UHTCs all exhibit strong covalent bonding which gives them structural stability at high temperatures. Metal carbides are brittle due to the strong bonds between carbon atoms. The largest class of carbides, including $\mathrm{Hf}, \mathrm{Zr}$, Ti, and Ta carbides have high melting points due to covalent carbon networks although carbon vacancies often exist in these materials [60]. Nitrides such as $\mathrm{ZrN}$ and $\mathrm{HfN}$ have similarly strong covalent bonds [59] but their refractory nature makes them especially difficult to synthesize and process. The stoichiometric nitrogen content can be varied in these complexes and relates to their synthetic techniques [63-65]. Boride UHTCs, such as $\mathrm{HfB}_{2}$ and $\mathrm{ZrB}_{2}$, benefit from very strong bonding between boron atoms as well as strong metal to boron bonds; the hexagonal close-packed structure with alternating two-dimensional (2D) boron and metal sheets gives these materials high and anisotropic strength as single crystals (Fig. 2) [66]. The crystal structures, and basic physical and mechanical properties of the main UHTCs are shown in Table 1.

Table 1 Basic physical and mechanical properties of boride, carbide, and nitride-based UHTCs

\begin{tabular}{|c|c|c|c|c|c|c|c|c|c|c|}
\hline \multirow{2}{*}{ Material } & \multirow{2}{*}{$\begin{array}{l}\text { Crystal } \\
\text { structure }\end{array}$} & \multirow{2}{*}{$\begin{array}{l}\text { Melting } \\
\text { temperature } \\
\left({ }^{\circ} \mathrm{C}\right)\end{array}$} & \multirow{2}{*}{$\begin{array}{l}\text { Density } \\
\left(\mathrm{g} \cdot \mathrm{cm}^{-3}\right)\end{array}$} & \multirow{2}{*}{$\begin{array}{c}\text { CTE, } \alpha \\
\left(10^{-6} \mathrm{~K}^{-1}\right)\end{array}$} & \multirow{2}{*}{$\begin{array}{c}\text { Thermal } \\
\text { conductivity } \\
\left(\mathrm{W} \cdot \mathrm{m}^{-1} \cdot \mathrm{K}^{-1}\right)\end{array}$} & \multirow{2}{*}{$\begin{array}{c}\text { Electrical } \\
\text { resistivity } \\
(\mu \Omega \cdot \mathrm{cm})\end{array}$} & \multicolumn{2}{|c|}{$\begin{array}{l}\text { Elastic modulus } \\
\quad(\mathrm{GPa})\end{array}$} & \multirow{2}{*}{$\begin{array}{l}\text { Hardness } \\
\quad(\mathrm{GPa})\end{array}$} & \multirow{2}{*}{ Ref. } \\
\hline & & & & & & & Cal. & Exp. & & \\
\hline \multicolumn{11}{|l|}{ Boride } \\
\hline $\mathrm{TaB}_{2}$ & $\mathrm{HCP}$ & 3040 & 12.5 & $8.2-8.8$ & $10.9-16.0$ & 33 & 497 & 551 & 19.6 & {$[18,43-50]$} \\
\hline $\mathrm{TiB}_{2}$ & $\mathrm{HCP}$ & 3225 & 4.5 & $7.6-8.6$ & 64.4 & $16-28.4$ & 583 & 575 & 24.0 & {$[17,18,47,50-55]$} \\
\hline $\mathrm{ZrB}_{2}$ & $\mathrm{HCP}$ & 3245 & 6.1 & $5.5-8.3$ & 57.9 & 9.2 & 523 & 489 & 23.0 & {$[17,18,46,50-52,56]$} \\
\hline $\mathrm{HfB}_{2}$ & $\mathrm{HCP}$ & 3380 & 11.2 & $6.3-7.6$ & 51.6 & $8.8-11$ & 535 & 451 & 28.0 & {$[17,18,50-52,57,58]$} \\
\hline \multicolumn{11}{|l|}{ Carbide } \\
\hline $\mathrm{TiC}$ & FCC & 3100 & 4.9 & $7.5-7.7$ & $17-21$ & 52.5 & 455 & 437 & 30.0 & {$[44,51,52,59-62]$} \\
\hline $\mathrm{ZrC}$ & FCC & 3530 & 6.6 & 6.82 & 20.61 & 68.0 & 436 & 387 & 25.0 & {$[51,52,59,61,63-65]$} \\
\hline $\mathrm{TaC}$ & FCC & 3800 & 14.5 & $6.6-8.4$ & 22.2 & $30-42.1$ & 550 & 537 & 17.0 & {$[44,51,52,59,66-68]$} \\
\hline $\mathrm{HfC}$ & FCC & 3900 & 12.8 & 6.3 & 22.2 & 45.0 & 537 & 461 & 24.2 & {$[17,44,51,52,59,61,69,70]$} \\
\hline \multicolumn{11}{|l|}{ Nitride } \\
\hline TaN & FCC & 2900 & 13.4 & 3.2 & 8.3 & $128-135$ & 490 & 490 & 10.8 & {$[43,44,51,52,71-73]$} \\
\hline TiN & FCC & 2950 & 5.4 & 9.35 & 29.1 & 21.7 & 463 & 400 & 18.6 & {$[51,52,72,74-79]$} \\
\hline $\mathrm{ZrN}$ & FCC & 2950 & 7.3 & 7.24 & 20.9 & 13.6 & 390 & 384 & 15 & {$[51,52,64,78,80,81]$} \\
\hline $\mathrm{HfN}$ & FCC & 3385 & 13.9 & 6.5 & 21.6 & 33 & 411 & 398 & 16.1 & {$[12,51,52,72,76,78,80,82]$} \\
\hline
\end{tabular}



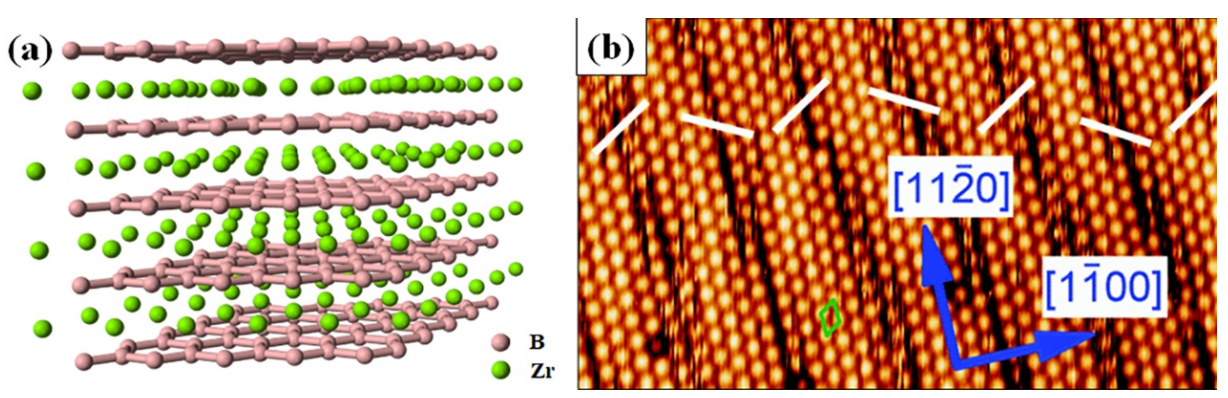

Fig. 2 Hexagonal close-packed structure (a) and STM image (b) of the (2×2)-reconstructed $\mathrm{ZrB}_{2}(0001)$ surface. Reproduced with permission from Ref. [66], (C) The American Physical Society 2012.

\section{2 Processing technology of bulk UHTCs}

Bulk ceramics are the initial application form for UHTCs, which can be densified by various methods, including hot pressing (HP) [67-72], spark plasma sintering (SPS) $[73,76,79]$, reactive hot-pressing (RHP) $[74,75,77,78]$, and pressureless sintering (PLS) [80-85], etc. The following part focuses on the various densification processes, as well as the sintering aids on the densification behavior of UHTCs.

(1) Hot pressing (HP)

Due to the strong covalent bonds, low volume, and grain boundary diffusion rates, UHTCs generally need to be sintered at a very high temperature assisted with pressure. HP has been the dominant method for the densification of UHTCs. For single-phase $\mathrm{ZrB}_{2}$, high temperature $\left(\geqslant 2100{ }^{\circ} \mathrm{C}\right)$ and low pressure $(20-30 \mathrm{MPa})$ or lower temperature $\left(\sim 1800{ }^{\circ} \mathrm{C}\right)$ and extremely high pressure $(>800 \mathrm{MPa})$ are usually needed to achieve densification [4]. Besides the inherent properties of its own crystal structure, the surface oxide impurities of UHTC powder also limit its densification to some extent. Studies have shown that oxide impurity layer can be formed on the surface of $\mathrm{ZrB}_{2}$ powder when exposed to air, including $\mathrm{B}_{2} \mathrm{O}_{3}$ and $\mathrm{ZrO}_{2}$ [86]. During sintering, the $\mathrm{B}_{2} \mathrm{O}_{3}$ with low melting point will turn to liquid or gas phase, which promotes the surface diffusion of $\mathrm{ZrB}_{2}$, resulting in coarsening of the grains. At the same time, the presence of $\mathrm{B}_{2} \mathrm{O}_{3}$ and $\mathrm{ZrO}_{2}$ will reduce the activity of $\mathrm{B}$ atoms to some extent and hinder the densification of $\mathrm{ZrB}_{2}$ [87]. To promote the densification of UHTCs, it is usually necessary to introduce appropriate sintering aids, which mainly include deoxidizing aids, liquid phase aids, solid solution aids, etc. The main deoxidizing aids are $\mathrm{Si}_{3} \mathrm{~N}_{4}$, AlN, WC, $\mathrm{VC}, \mathrm{B}_{4} \mathrm{C}$, etc. [88,89]. The chemical reaction between the sintering aids and the oxide impurities can realize deoxidization. The liquid phase aids are mainly composed of metals such as $\mathrm{Fe}$ and $\mathrm{Ni}$, which turn into liquid phase and promote the rearrangement and mass transfer of $\mathrm{ZrB}_{2}$ particles during sintering. The solid solution aids are mainly composed of Mo and other elements. During sintering, the solid solution of Mo and $\mathrm{ZrB}_{2}$ particles occurs, which activates the lattice to enhance the sintering driving force and promote densification [90]. The introduction of sintering aids can significantly reduce the $\mathrm{HP}$ temperature of $\mathrm{ZrB}_{2}$ ceramics.

$\mathrm{SiC}$ is the most commonly used second phase additive for UHTCs particularly for borides. The addition of $\mathrm{SiC}$ can improve the sinterability and inhibit grain growth of UHTCs. Plastic deformation of $\mathrm{SiC}$ at high temperatures can promote the slip and rearrangement of $\mathrm{ZrB}_{2}$ particles and fill the voids left by $\mathrm{ZrB}_{2}$ particles' slip and rearrangement, thus promoting the densification of $\mathrm{ZrB}_{2}$. The addition of $\mathrm{SiC}$ can also improve the oxidation and ablation resistance of UHTCs. Table 2 lists the densification behavior of $\mathrm{ZrB}_{2}$-based UHTCs prepared by HP under different conditions [91-100].

Table 2 Densification behavior of $\mathrm{ZrB}_{2}$-based UHTCs by HP

\begin{tabular}{cccc}
\hline Material & $\begin{array}{c}\text { HP conditions } \\
\left({ }^{\circ} \mathrm{C}, \mathrm{MPa}, \text { min }\right)\end{array}$ & $\begin{array}{c}\text { Relative } \\
\text { density }(\%)\end{array}$ & Ref. \\
\hline $\mathrm{ZrB}_{2}$ & $2000, \sim 17,260$ & 99 & {$[100]$} \\
$\mathrm{ZrB}_{2}$ & $1900,30,30$ & 86.5 & {$[99]$} \\
$\mathrm{ZrB}_{2}-25 \mathrm{Nb}$ & $1800,30,60$ & 99.1 & {$[91]$} \\
$\mathrm{ZrB}_{2}-5 \mathrm{Si}_{3} \mathrm{~N}_{4}$ & $1700,30,15$ & 98 & {$[98]$} \\
$\mathrm{ZrB}_{2}-5 \mathrm{AlN}$ & $1850,30,60$ & 97.2 & {$[95]$} \\
$\mathrm{ZrB}_{2}-20 \mathrm{MoSi}_{2}$ & $1850,30,60$ & 98.5 & {$[94]$} \\
$\mathrm{ZrB}_{2}-20 \mathrm{ZrSi}_{2}$ & $1550,30,15$ & 99.1 & {$[96]$} \\
$\mathrm{ZrB}_{2}-10 \mathrm{Mo}$ & $1950,20,60$ & 98.9 & {$[92]$} \\
$\mathrm{ZrB}_{2}-20 \mathrm{SiC}$ & $1900,30,60$ & 98 & {$[97]$} \\
$\mathrm{ZrB}_{2}-20 \mathrm{SiC}_{\text {nano }}$ & $1900,30,60$ & $\sim 100$ & {$[93]$} \\
\hline
\end{tabular}


With the development of sintering technology in recent years, SPS technology has begun to be widely used for the densification of UHTCs. SPS is a rapid sintering technology in which sintering current and pressure are applied to ceramic powder through electrodes to generate high temperature and pressure in a short time. SPS is also a pressure assisted high-temperature sintering method, but compared with traditional HP, SPS has a faster heating rate, which can effectively avoid grain growth and obtain dense and fine-grained ceramic materials in a very short time.

(2) Pressureless sintering (PLS)

PLS is a traditional sintering method for ceramic materials. It can produce near-net ceramics with complex shapes. Therefore, it is a low-cost producing technology for bulk UHTCs. However, full densification is difficult to be achieved for UHTCs by PLS. Sintering aids are usually introduced during the PLS, which mainly include two types. The first is low melting point phases, such as metals $\mathrm{Ni}, \mathrm{Fe}$, Mo, etc. [101-103] and transition metal disilicides $\mathrm{MoSi}_{2}, \mathrm{ZrSi}_{2}$, etc. $[104,105]$. They can form a liquid phase during sintering to promote the densification of $\mathrm{ZrB}_{2}$-based UHTCs. The second category can react with oxide impurities on the surface of UHTC particles. For the first time, Zhang et al. [86] realized that oxide impurities on the surface of $\mathrm{ZrB}_{2}$ powder will cause rapid growth of grains at the initial stage of sintering and hinder the densification. This kind of sintering aid can consume the oxide impurities on the powder surface and improve the sintering activity of powders [106-108]. Nitrides (such as AlN and $\mathrm{Si}_{3} \mathrm{~N}_{4}$ ) can consume $\mathrm{B}_{2} \mathrm{O}_{3}$ impurities on the surface of $\mathrm{ZrB}_{2}$ powder; carbon and boron compounds (such as $\mathrm{B}, \mathrm{B}_{4} \mathrm{C}$, $\mathrm{C}$, WC, and phenolic resin) can consume $\mathrm{ZrO}_{2}$ impurities on the surface of $\mathrm{ZrB}_{2}$ powder [85,109-111]. $\mathrm{B}_{4} \mathrm{C}$ can react with $\mathrm{ZrO}_{2}$ above $1200{ }^{\circ} \mathrm{C}$ [86,112], which not only promotes the densification of $\mathrm{ZrB}_{2}$, but also keeps the high-temperature strength of $\mathrm{ZrB}_{2}$, and the microstructure is shown in Fig. 3. So, it is widely used as a sintering aid for PLS of $\mathrm{ZrB}_{2}$. The introduction of carbon (granular or precursor) can also significantly improve the sintering performance of $\mathrm{ZrB}_{2}$. Adding $2 \mathrm{wt} \% \mathrm{~B}_{4} \mathrm{C}+1 \mathrm{wt} \% \mathrm{C}$ mixed sintering aid to micron $\mathrm{ZrB}_{2}$ powder, it can realize the densification at $1900{ }^{\circ} \mathrm{C}$ by PLS [106]. Jafari et al. [113] found that using part of $\mathrm{HfB}_{2}$ to replace $\mathrm{ZrB}_{2}$ in the $\mathrm{ZrB}_{2}-\mathrm{SiC}$ system is conducive to promote the densification during PLS.

(3) Reactive sintering (RS)

RS has been identified as an effective approach to produce UHTCs with high density and low impurity at relatively low temperatures. Generally, two processes are involved in RS, in-situ reactions of raw materials and densification, which are completed simultaneously during heating and subsequent holding.

The reactive sintering of UHTCs is first realized and reported by Zhang et al. [114] in 2004. Using Zr/Hf and $\mathrm{B} / \mathrm{C}$ powders as raw materials, monolithic $\mathrm{ZrB}_{2}$, $\mathrm{HfB}_{2}$, HfC, and $\mathrm{ZrC}$ ceramics can be produced by RS. $\mathrm{ZrB}_{2}$-based composites with $\mathrm{SiC}$ and/or $\mathrm{ZrC}$ can be produced by using $\mathrm{Zr}, \mathrm{B}_{4} \mathrm{C}$, and $\mathrm{Si}$ as raw materials, and the related reaction is shown below [114-116]:

$$
\begin{aligned}
& x \mathrm{Zr}+y \mathrm{~B}_{4} \mathrm{C}+(3 y-x) \mathrm{Si} \rightarrow \\
& \quad 2 y \mathrm{ZrB}_{2}+(x-2 y) \mathrm{ZrC}+(3 y-x) \mathrm{SiC}
\end{aligned}
$$

It can be seen that the composition of the product can be tailored by designing the ratio of the original powders. Figure 4 shows the typical microstructure of $\mathrm{ZrB}_{2}-\mathrm{ZrC}-\mathrm{SiC}$ produced by $\mathrm{RS}$ at $1800{ }^{\circ} \mathrm{C}$. The improvement of densification by RS process can be attributed to the formation of nano-sized particles during the reactive process. As the densification is generally driven by minimization of the surface free

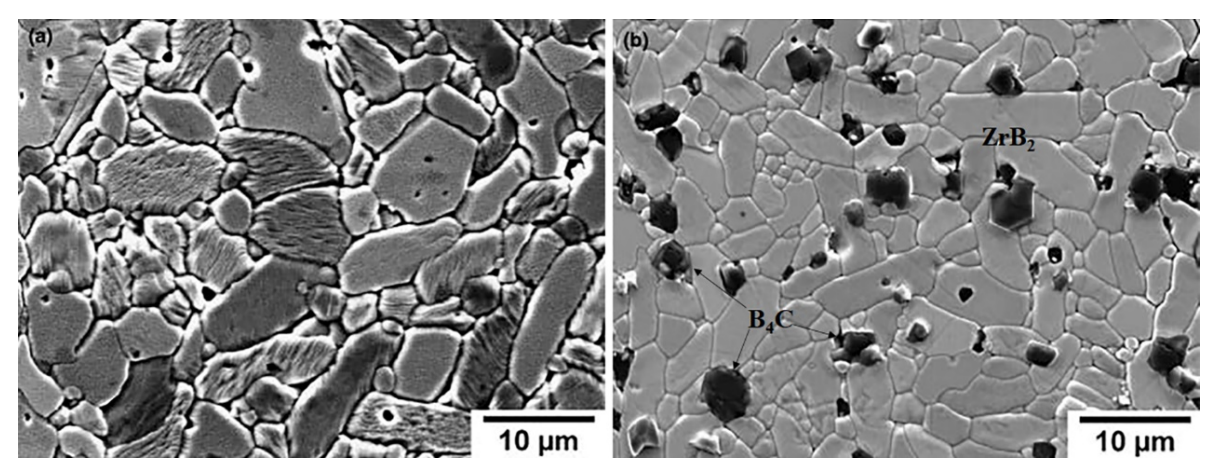

Fig. 3 Microstructures of pressureless sintered $\mathrm{ZrB}_{2}$ with $\mathrm{B}_{4} \mathrm{C}$ addition at $1850{ }^{\circ} \mathrm{C} / 1 \mathrm{~h}$ in vacuum: 2 wt $\% \mathrm{~B}_{4} \mathrm{C}$ (a) and $4 \mathrm{wt} \% \mathrm{~B}_{4} \mathrm{C}$ additions (b). Reproduced with permission from Ref. [86], (c) The American Ceramic Society 2006. 


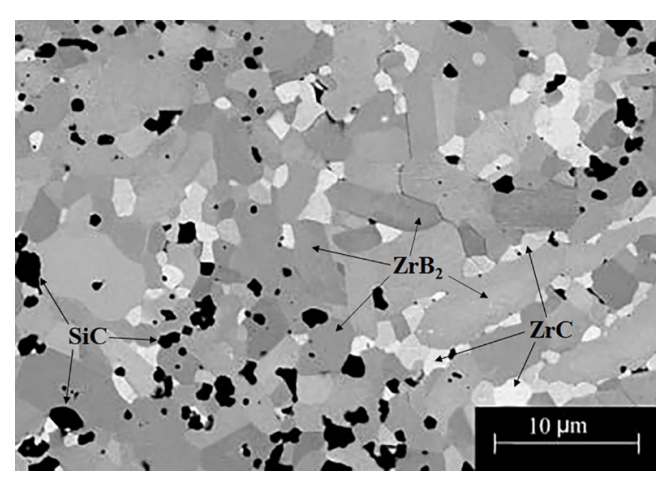

Fig. 4 Typical microstructure of $\mathrm{ZrB}_{2}-\mathrm{ZrC}-\mathrm{SiC}$ produced by reactive sintering. Reproduced with permission from Ref. [115], (c) The American Ceramic Society 2006.

energy, the fine crystalline size can enhance the driving force for densification accordingly. Carbothermal reduction method is also applied for preparing $\mathrm{ZrB}_{2}$ ceramics by RS. $\mathrm{ZrO}_{2}, \mathrm{~B}_{4} \mathrm{C}$, and $\mathrm{C}$ are used as raw materials to produce $\mathrm{ZrB}_{2}$ by $\mathrm{RS}$ [117]. However, due to the formation of gaseous byproduct during the reaction process, the ceramics prepared by carbothermal reduction reaction have low densification and poor mechanical properties. The UHTC materials prepared by reactive sintering are generally characterized with fine grain size. Kannan and Rangaraj [118] used $\mathrm{Zr}$ and $\mathrm{B}_{4} \mathrm{C}$ powders with different proportions, to obtain $\mathrm{ZrB}_{2}-\mathrm{ZrC}_{x}$ UHTCs through reactive sintering. The sintering temperature was reduced to $1200{ }^{\circ} \mathrm{C}$ by using this process. The material exhibits excellent mechanical properties.

\section{3 Mechanical properties and thermal shock resistance of bulk UHTCs}

(1) Mechanical properties of bulk UHTCs

Mechanical properties are the key indicators for the use of UHTCs. Table 3 lists the mechanical properties of typical UHTCs at room temperature [119]. The elasticity and hardness of $\mathrm{ZrB}_{2}$ and $\mathrm{HfB}_{2}$ based ceramics are closely related to the samples' density. The room-temperature flexural strength is strongly related to the grain size, which in turn depends on the initial powder particle size, reinforcement phase content, and sintering parameters. Refinement of the matrix $\left(\mathrm{ZrB}_{2}\right.$ or $\left.\mathrm{HfB}_{2}\right)$ and reinforcement phase (such as $\mathrm{SiC}$ ) particles are beneficial to the densification and mechanical properties of the material. The reduction of the original particle size is conducive to the refinement

Table 3 Mechanical properties of typical UHTCs at room temperature [119]

\begin{tabular}{|c|c|c|c|c|c|c|c|c|c|}
\hline \multirow{2}{*}{$\begin{array}{l}\text { Composition } \\
\text { (vol\%) }\end{array}$} & \multirow{2}{*}{$\begin{array}{c}\text { Sintering } \\
\text { conditions } \\
\left({ }^{\circ} \mathrm{C}, \mathrm{MPa}, \mathrm{min}\right)\end{array}$} & \multicolumn{2}{|c|}{$\begin{array}{l}\text { Original particle } \\
\text { size }(\mu \mathrm{m})\end{array}$} & \multirow{2}{*}{$\begin{array}{c}\text { Elastic } \\
\text {-modulus }(\mathrm{GPa})\end{array}$} & \multirow{2}{*}{$\begin{array}{l}\text { Hardness } \\
(\mathrm{GPa})\end{array}$} & \multirow{2}{*}{$\begin{array}{c}\text { Flexural } \\
\text { strength (MPa) }\end{array}$} & \multirow{2}{*}{$\begin{array}{c}\text { Fracture } \\
\text { toughness } \\
\left(\mathrm{MPa} \cdot \mathrm{m}^{1 / 2}\right)\end{array}$} & \multicolumn{2}{|c|}{$\begin{array}{c}\text { Grain size after } \\
\text { sintering }(\mu \mathrm{m})\end{array}$} \\
\hline & & $\mathrm{Zr}(\mathrm{Hf}) \mathrm{B}_{2}$ & $\mathrm{SiC}$ & & & & & $\mathrm{Zr}(\mathrm{Hf}) \mathrm{B}_{2}$ & $\mathrm{SiC}$ \\
\hline $\mathrm{ZrB}_{2}$ & $1900,30,30$ & 6.0 & - & 346 & $8.7 \pm 0.4$ & $351 \pm 31$ & $3.5 \pm 0.3$ & 6.0 & - \\
\hline $\mathrm{ZrB}_{2}$ & $1900,32,45$ & 2.0 & - & 489 & $23 \pm 0.9$ & $565 \pm 53$ & $3.5 \pm 0.3$ & 6.0 & - \\
\hline $\mathrm{ZrB}_{2}-10 \% \mathrm{SiC}$ & $1900,32,45$ & 2.0 & 0.7 & 450 & $24 \pm 0.9$ & $713 \pm 48$ & $4.1 \pm 0.3$ & 3.0 & - \\
\hline $\mathrm{ZrB}_{2}+15 \% \mathrm{SiC}+4.5 \% \mathrm{ZrN}$ & $1900,50,20$ & 2.0 & 0.45 & $467 \pm 4$ & $15.6 \pm 0.3$ & $635 \pm 60$ & $5.0 \pm 0.1$ & 3.0 & 0.8 \\
\hline $\mathrm{ZrB}_{2}-20 \% \mathrm{SiC}$ & $1900,32,45$ & 2.0 & 0.7 & 466 & $24 \pm 2.8$ & $1003 \pm 94$ & $4.4 \pm 0.2$ & 3.0 & 1.0 \\
\hline $\mathrm{ZrB}_{2}-20 \% \mathrm{SiC}-6 \% \mathrm{ZrC}(\mathrm{HP})$ & $1850,30,60$ & 2.0 & 1.0 & - & $19.4 \pm 0.4$ & $681 \pm 67$ & $5.7 \pm 0.2$ & 3.0 & 1.5 \\
\hline $\mathrm{ZrB}_{2}-20 \% \mathrm{SiC}-6 \% \mathrm{ZrC}$ (RHP) & $1850,30,60$ & - & - & - & $19.9 \pm 0.3$ & $652 \pm 21$ & $7.3 \pm 0.3$ & 3.0 & 1.5 \\
\hline $\mathrm{ZrB}_{2}-30 \% \mathrm{SiC}$ & $1900,32,45$ & 2.0 & 0.7 & 484 & $24 \pm 0.7$ & $1089 \pm 152$ & $5.3 \pm 0.5$ & 3.0 & 1.0 \\
\hline $\mathrm{ZrB}_{2}-30 \% \mathrm{SiC}$ & $1850,32,45$ & 2.0 & 0.7 & $516 \pm 3$ & $20 \pm 2$ & $1063 \pm 91$ & $5.5 \pm 0.3$ & 2.2 & 1.2 \\
\hline $\mathrm{ZrB}_{2}-30 \% \mathrm{SiC}$ & $1950,32,45$ & 2.0 & 0.7 & $507 \pm 3$ & $22 \pm 2$ & $1060 \pm 59$ & $5.2 \pm 0.4$ & 2.5 & 1.7 \\
\hline $\mathrm{ZrB}_{2}-30 \% \mathrm{SiC}$ & $2050,32,45$ & 2.0 & 0.7 & $505 \pm 2$ & $23 \pm 1$ & $854 \pm 88$ & $4.3 \pm 0.2$ & 3.5 & 2.0 \\
\hline $\mathrm{ZrB}_{2}-30 \% \mathrm{SiC}$ & $2050,32,180$ & 2.0 & 0.7 & $505 \pm 1$ & $22 \pm 1$ & $804 \pm 73$ & $4.5 \pm 0.2$ & 4.7 & 2.7 \\
\hline $\mathrm{ZrB}_{2}-30 \% \mathrm{SiC}$ & $1850,32,45$ & 6.0 & 0.7 & $503 \pm 6$ & $22 \pm 2$ & $888 \pm 151$ & $3.9 \pm 0.1$ & 2.1 & 1.5 \\
\hline $\mathrm{ZrB}_{2}-30 \% \mathrm{SiC}$ & $1950,32,45$ & 6.0 & 0.7 & $501 \pm 1$ & $22 \pm 2$ & $770 \pm 133$ & $4.0 \pm 0.2$ & 3.3 & 2.5 \\
\hline $\mathrm{ZrB}_{2}-30 \% \mathrm{SiC}$ & $2050,32,45$ & 6.0 & 0.7 & $503 \pm 1$ & $23 \pm 2$ & $720 \pm 38$ & $4.3 \pm 0.2$ & 3.7 & 3.1 \\
\hline $\mathrm{ZrB}_{2}-30 \% \mathrm{SiC}$ & $1900,32,45$ & 6.0 & 0.45 & $520 \pm 7$ & $20.7 \pm 1.0$ & $909 \pm 136$ & $4.5 \pm 0.1$ & 1.2 & 1.0 \\
\hline $\mathrm{ZrB}_{2}-30 \% \mathrm{SiC}$ & $1900,32,45$ & 6.0 & 10.0 & $479 \pm 5$ & $17.5 \pm 0.4$ & $389 \pm 45$ & $4.6 \pm 0.1$ & 3.0 & 6.3 \\
\hline $\mathrm{ZrB}_{2}-20 \% \mathrm{SiC}-15 \% \mathrm{G}$ & $1900,30,60$ & 3.0 & 2.0 & - & - & $481 \pm 28$ & $6.11 \pm 0.24$ & 3.0 & 2.0 \\
\hline $\mathrm{HfB}_{2}-20 \% \mathrm{SiC}$ & $2200,32,45$ & 4.1 & 1.6 & $549 \pm 8$ & $17 \pm 0.7$ & $453 \pm 46$ & $4.1 \pm 0.2$ & 7.0 & 5.0 \\
\hline $\mathrm{HfB}_{2}-30 \% \mathrm{SiC}-2 \% \mathrm{TaSi}_{2}$ & $1900,42,35$ & 1.7 & 1.0 & $489 \pm 4$ & - & $665 \pm 75$ & $3.6 \pm 0.5$ & 2.0 & 2.0 \\
\hline
\end{tabular}


of UHTC grains and the strength of the materials follows the Hall-Petch relationship with the grain size [120]. Moreover, refinement of the reinforcement phase (SiC particles) has a more significant impact on the mechanical properties. The study by Zhang et al. [121] noticed that reducing the size of the starting $\mathrm{SiC}$ particles decreased the $\mathrm{ZrB}_{2}$ grain size and changed the morphology of the final $\mathrm{SiC}$ grains from equiaxed to whisker-like. The highest flexure strength is obtained for the $\mathrm{ZrB}_{2}-\mathrm{SiC}$ prepared from middle starting powder with an equiaxed $\mathrm{SiC}$ grain morphology, compared with ceramics prepared from finer or coarser SiC powders. In certain content, too fine $\mathrm{SiC}$ particle will be over a threshold and cause elongated morphology of $\mathrm{SiC}$ second phase and worsen the mechanical properties. It is indicated that the addition of $\mathrm{SiC}$ has a significant inhibitory effect on the grain growth of the matrix $\mathrm{ZrB}_{2}$ and $\mathrm{HfB}_{2}$. When the volume content of $\mathrm{SiC}$ reaches $20 \%$, the inhibitory effect on grain growth is obvious. Further addition of $\mathrm{SiC}$ has little effect on the grain growth and strength.

On the contrary, the refinement of grain size has a very limited positive effect on the improvement of toughness, while grain morphologies of UHTCs have a significant effect on the fracture toughness. Compared with the equiaxed $\mathrm{ZrB}_{2}$ obtained by hot-pressing, the fracture toughness of the long rod-shaped $\mathrm{ZrB}_{2}$ by RHP is significantly improved up to $7.3 \mathrm{MPa} \cdot \mathrm{m}^{1 / 2}$ [122]. To improve the fracture toughness of UHTCs, there are generally two main approaches. One is to introduce toughening phases (such as $\mathrm{SiC}$ whiskers [123], graphite [124], $\mathrm{ZrO}_{2}$ [125], and ductile metals [126]), and the other is microstructure design (such as layered structure [127], and fiber monolithic structure [128]). The effect of the former is limited, and its fracture toughness is generally difficult to get $8 \mathrm{MPa} \cdot \mathrm{m}^{1 / 2}$, while the latter can exceed $10 \mathrm{MPa} \cdot \mathrm{m}^{1 / 2}$.

The high-temperature mechanical properties and fracture modes of UHTCs are very important research focus. High-temperature mechanical properties of UHTCs are mainly determined by the material composition, purity, and grain size. The hightemperature fracture mode is mainly intergranular fracture [129], which is different from that at room temperature. Therefore, the high-temperature flexural strength of the material is strongly dependent on the characteristics of grain boundaries. The improvement of material density and room-temperature mechanical properties could be realized by introducing low melting point substances (such as $\mathrm{Fe}, \mathrm{Ni}, \mathrm{ZrSi}_{2}, \mathrm{Al}_{2} \mathrm{O}_{3}$, and $\mathrm{Y}_{2} \mathrm{O}_{3}$ ) into UHTCs matrix; however, it has a significant negative impact on the high-temperature mechanical properties, where the performance degradation is generally severe above $1000{ }^{\circ} \mathrm{C}$. The room-temperature flexural strength of UHTCs based on highly pure raw material powder can be maintained to $1500{ }^{\circ} \mathrm{C}$ with almost no reduction [130]. Using tungsten carbide to remove the oxide impurities in borides, $\mathrm{ZrB}_{2}-20 \% \mathrm{SiC}-5 \% \mathrm{WC}, \mathrm{HfB}_{2}-20 \% \mathrm{SiC}-5 \% \mathrm{WC}$ with flexure strength up to $670 \mathrm{MPa}$ could be achieved when they were tested at $1600{ }^{\circ} \mathrm{C}[88,131,132]$. The materials with $\mathrm{WC}$ addition remained transgranular at $1600{ }^{\circ} \mathrm{C}$, while the others become fully intergranular fracture mode (Fig. 5). Apart from much less oxide contamination in the unique ceramic body, the high strength at elevated temperatures was also considered to be a result from the following two characteristics in $\mathrm{ZSW}: 1)$ the $\mathrm{ZrB}_{2}$ grains with core-shell structure and 2) the tungsten segregation at the $\mathrm{ZrB}_{2} / \mathrm{ZrB}_{2}$ grain boundary $[133,134]$. Both of them might act as the barriers for the dislocation movement during fracture, therefore avoiding the strength degradation of ZSW at higher temperatures [133]. First-principles calculations by Dai et al. $[135,136]$ also support such experimental observations, which suggest that the short equilibrium W-B bonds induce local contractions around the core-shell interface and the grain boundaries, therefore strengthening the grain boundaries.

In addition, SPS is beneficial to obtain UHTCs with excellent high-temperature flexural strength. This is because the low melting point impurities on the surface of the particles can be partially removed at the initial stage of SPS, thereby improving the grain boundary characteristics [137]. The refinement of grain size is beneficial to the room-temperature strength, but it is harmful to the high-temperature strength. The flexural strength of the $\mathrm{ZrB}_{2}(2 \mu \mathrm{m})-15$ vol\% $\% \mathrm{SiC}(0.5 \mu \mathrm{m})$ material at $1800{ }^{\circ} \mathrm{C}$ is $112 \mathrm{MPa}$, and the flexural strength retention rate is only $12.9 \%$. While the $\mathrm{ZrB}_{2}(5 \mu \mathrm{m})-$ $15 \mathrm{vol} \% \mathrm{SiC}(2 \mu \mathrm{m})$ material at this temperature is 217 $\mathrm{MPa}$, and the flexural strength retention rate is $43.4 \%$ [129].

Li et al. [138] assumed that breaking down the entire structure of a material can be considered as severing all the bonds between its atoms either by applying work or by heat transfer. Because bondbreaking is indifferent to either means, there is a kind of equivalence between heat energy and strain energy. 

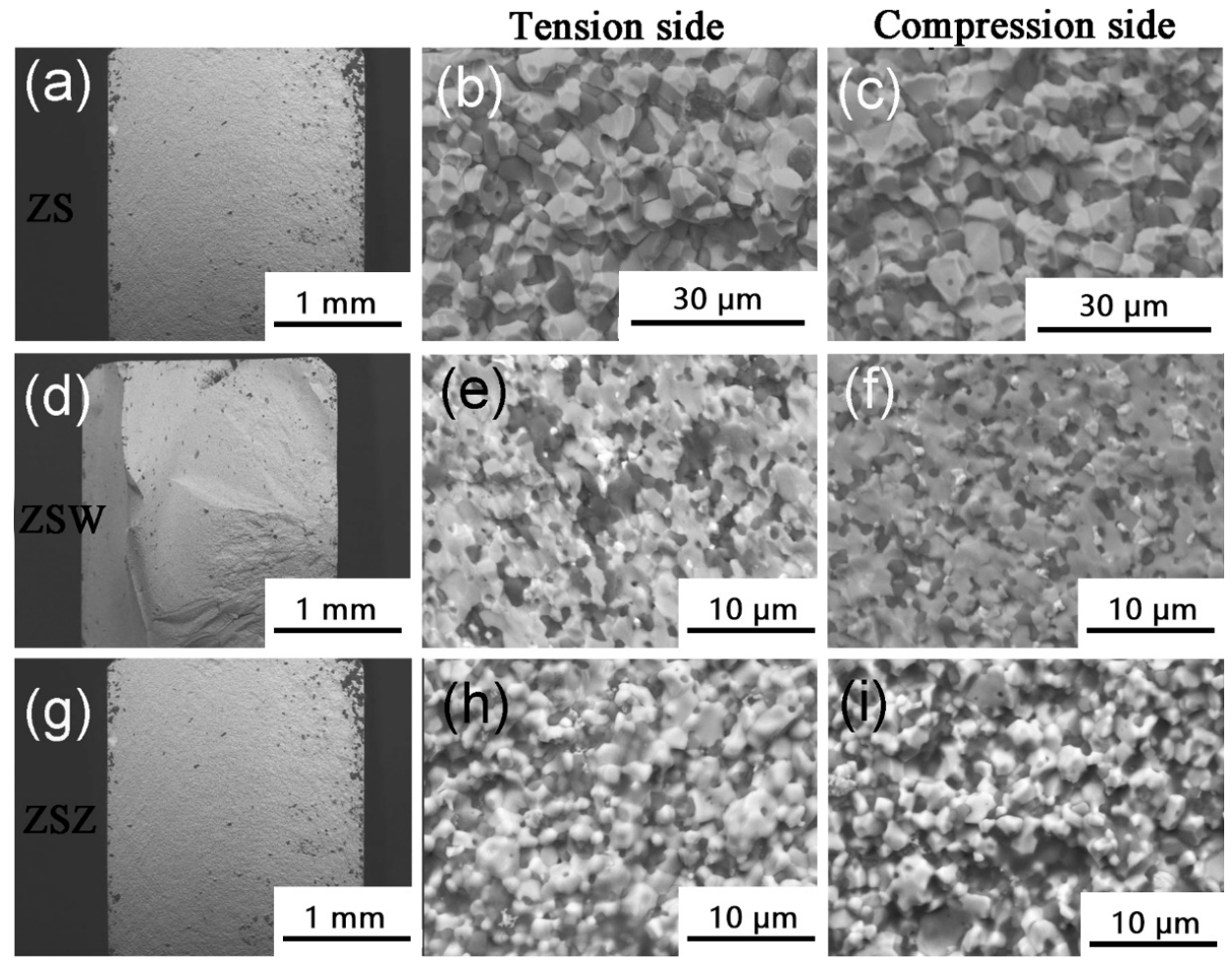

Fig. 5 Flexural surfaces of $\mathrm{ZrB}_{2}-\mathrm{SiC}(\mathrm{ZS})(\mathrm{a}-\mathrm{c}), \mathrm{ZrB}_{2}-\mathrm{SiC}-\mathrm{WC}(\mathrm{ZSW})(\mathrm{d}-\mathrm{f})$, and $\mathrm{ZrB}{ }_{2}-\mathrm{SiC}-\mathrm{ZrC}(\mathrm{ZSZ})(\mathrm{g}-\mathrm{i})$ at $1600{ }^{\circ} \mathrm{C}$. Reproduced with permission from Ref. [131], (C) The American Ceramic Society 2012.

Accordingly, there should be the existence of a constant maximum storage of energy for a particular material that includes both the strain energy and the corresponding equivalent heat energy. Based on this assumption, a temperature dependent fracture strength model is developed for UHTCs. Model predictions for $\mathrm{HfB}_{2}$, TiC, and $\mathrm{ZrB}_{2}$ single-phase UHTCs are largely consistent with experimental results. Based on this temperature dependent fracture surface energy model and the traditional Griffith fracture theories, a temperature dependent fracture strength model is further developed for $\mathrm{ZrB}_{2}-\mathrm{SiC}$ composites [139,140]. The combined effects of temperature, grain size, micro-flaw size, and residual stress on the strength of $\mathrm{ZrB}_{2}-\mathrm{SiC}$ composites are included in this model. According to the model, the temperature dependent fracture strength of materials can be easily predicted using some basic material parameters. The model is verified with excellent agreement at different temperatures by comparison with experimental data of different $\mathrm{ZrB}_{2}-\mathrm{SiC}$ composites. The developed model offers a mechanism of monitoring the strength of UHTCs at different temperatures by testing the change of flaw size, which provides a quantitative tool for design, evaluation, and monitoring of the fracture properties of UHTCs at high temperatures.
(2) Thermal shock resistance of bulk UHTCs

Bulk UHTCs are a typical brittle material, and it is prone to thermal shock failure under extreme heating environment, leading to catastrophic damage, so it is particularly important to improve its thermal shock resistance. For bulk UHTCs, we concern about crack initiation and crack propagation mostly, which can be expressed by thermal shock fracture parameters $\left(R^{\prime \prime \prime \prime}\right)$ and thermal shock damage parameters $(R)$ [141-143]:

$$
\begin{aligned}
& R^{\prime \prime \prime \prime}=\frac{E \gamma_{\mathrm{s}}}{\sigma_{\mathrm{f}}^{2}(1-v)}=\frac{K_{\mathrm{IC}}^{2}}{2 \sigma_{\mathrm{f}}^{2}(1-v)} \\
& R=\frac{\sigma_{\mathrm{f}}(1-v)}{E \alpha}
\end{aligned}
$$

where $\sigma_{\mathrm{f}}$ is the fracture strength of the material, $v$ is the Poisson's ratio, $E$ is the elastic modulus of the material, $\alpha$ is the thermal expansion coefficient of the material, $\gamma_{\mathrm{s}}$ is the fracture surface energy, and $K_{\text {IC }}$ is the fracture toughness of the material. It can be seen from Eq. (2) that under the condition that the elastic modulus, thermal expansion coefficient, and Poisson's ratio remain unchanged, increasing the flexural strength of UHTCs is beneficial to improve its thermal shock resistance. Since the thermal expansion coefficients of $\mathrm{ZrB}_{2}, \mathrm{HfB}_{2}$, and $\mathrm{SiC}$ are quite different, 
huge thermal tension stress will be generated on $\mathrm{ZrB}_{2} / \mathrm{HfB}_{2}$ grains after high-temperature sintering, which will adversely affect the thermal shock resistance. Therefore, the material design needs to consider reducing thermal stress, by adding a high melting point soft phase such as graphite, etc. The thermal shock resistance of bulk UHTCs can be greatly improved by microstructure design, such as layered structure and fiber monolithic structure. $\mathrm{ZrB}_{2}$-based fibrous monolithics have a critical thermal shock temperature difference of $1400{ }^{\circ} \mathrm{C}$ compared with $\mathrm{ZrB}_{2}$ and $\mathrm{ZrB}_{2}-30$ vol\% $\% \mathrm{SiC}$ material, which increased by $250 \%$ [144].

\section{4 Microstructure design and performance regulation of bulk UHTCs}

Symmetrically distributed strong covalent bonds lead to intrinsic brittleness and low damage tolerance of UHTCs, which has always been the core problem and bottleneck of bulk UHTCs. Research on the strengthening and toughening technology of UHTCs has become the most concerned topic when discussing the performance regulation of UHTCs. In the traditional sense, the strengthening and toughening technology of UHTCs has evolved to find the best balance between strength and toughness, considering the oxidation ablation resistance. Figure 6(a) shows the Ashby diagram of the yield strength and fracture toughness of typical engineering materials [145]. By tailoring the composition of the material, the fracture toughness can be gradually improved along the direction indicated by the white arrow. Figure 6(b) shows the effects of intrinsic ductility (plasticity) and non-intrinsic ductility (shielding against cracks) of the material on the strength and toughness behavior of the

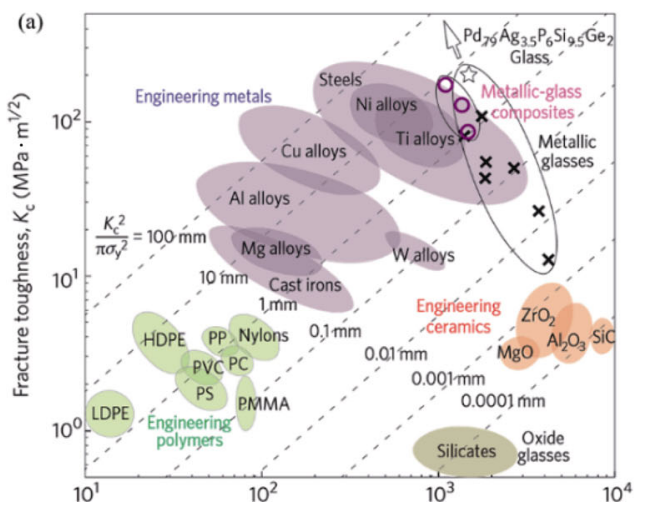

material during crack propagation [145]. Intrinsic toughening mainly comes from the plasticity of the material itself, where the damage tolerance of the material is improved by affecting the crack initiation and propagation. Non-intrinsic toughening relies on the suppression of crack propagation after crack initiation. In this case, the toughness of the material is improved by reducing the local stress and strain field at the crack tip. For the toughening of UHTCs, the toughening phases such as particles, whiskers, carbon nanotubes, and graphene are introduced to induce crack deflection and bifurcation by pulling out and bridging the ductile phases, thereby inhibiting the forward transfer of the crack tip, and thus achieving the toughening effect, which is extrinsic toughening as shown in Fig. 6(b). The microstructure design and performance regulation of UHTCs will be described in detail in the following section.

\section{(1) Particle toughening}

The method of improving mechanical properties, impact resistance, and corrosion resistance of composites by addition of second-phase dispersion particles is called particle toughening.

The strength and fracture toughness of UHTCs can be improved by particle toughening, and the common additive is silicon-containing compounds. Among these silicon-containing compounds, the addition of $\mathrm{SiC}$ can maximize the comprehensive properties of UHTCs. The addition of SiC can effectively hinder grain growth, and improve the sintering activity and fracture toughness of the UHTCs. By controlling the size of $\mathrm{SiC}$ particles, the maximum strength and toughness of the material can be achieved. Generally speaking, Vickers hardness and tensile strength gradually

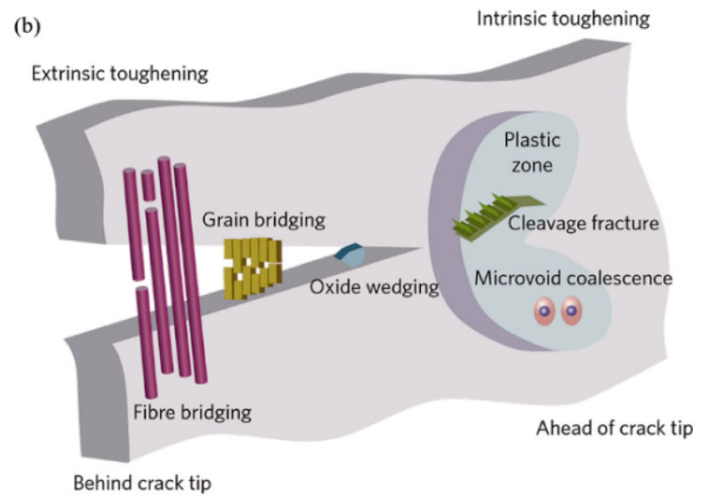

Fig. 6 Conflicts of strength versus toughness: Ashby plot showing strength-toughness relationships for engineering materials (a); schematic of intrinsic versus extrinsic toughening (b). Reproduced with permission from Ref. [145], (C) Nature Publishing Group, a division of Macmillan Publishers Limited 2011. 
decrease with the increase of grain size [146]. The content of reinforcement is also an important factor affecting the toughening effect. Asl et al. [147] studied the effect of $\mathrm{SiC}_{\mathrm{p}}$ content on the relative densities and mechanical properties of $\mathrm{ZrB}_{2}-\mathrm{SiC}_{\mathrm{p}}$ prepared by hot-pressing $\left(2000{ }^{\circ} \mathrm{C} / 30 \mathrm{~min} / 10 \mathrm{MPa}\right)$. When the content of $\mathrm{SiC}_{\mathrm{p}}$ increases from $10 \mathrm{vol} \%$ to $30 \mathrm{vol} \%$, the grain growth of $\mathrm{ZrB}_{2}$ is inhibited, and the relative density increases from $98.3 \%$ to $99.8 \%$. At the same time, the mechanical properties show an increasing trend and the fracture toughness increases from $3.5 \pm 0.1$ to $3.8 \pm 0.2 \mathrm{MPa} \cdot \mathrm{m}^{1 / 2}$, which is mainly attributed to the coupling toughening mechanisms such as transgranular fracture and crack deflection. Figure 7 shows a typical crack propagation path in $\mathrm{ZrB}_{2}-\mathrm{SiC}$ after indentation, showing crack deflection near $\mathrm{SiC}$ particles and predominantly transgranular fracture for $\mathrm{ZrB}_{2}$ grains [148].

(2) Whisker toughening

As a kind of fibrous single crystal material, whiskers have small diameter, large aspect ratio, high tensile strength, and elastic modulus due to few surface defects, so they have wide application prospects in ceramic toughening [149]. SiC whisker has a cubic lattice structure, which has the highest hardness, maximum modulus, maximum tensile strength, and the highest heat resistance temperature. As a result, $\mathrm{SiC}$ whiskers are widely used as toughening phase. Due to its large aspect ratio, it can effectively inhibit the grain growth when it is evenly distributed around the ceramic grains, thus refining the grains and improving the mechanical properties of the materials [150]. Zhang et al. [151] studied the effect of the addition of $\mathrm{SiC}_{\mathrm{w}}$ on the mechanical properties of $\mathrm{ZrB}_{2}$. The results show that the fracture toughness of $\mathrm{ZrB}_{2}-20 \mathrm{vol} \% \mathrm{SiC}_{\mathrm{w}}$ ceramic is as high as $5.97 \pm 0.3 \mathrm{MPa} \cdot \mathrm{m}^{1 / 2}$. It is much higher than traditional $\mathrm{ZrB}_{2}$ ceramic $\left(2.3-3.5 \mathrm{MPa} \cdot \mathrm{m}^{1 / 2}\right)$ and $\mathrm{ZrB}_{2}-\mathrm{SiC}$ ceramic $\left(4.0-4.5 \mathrm{MPa} \cdot \mathrm{m}^{1 / 2}\right)$. From study of the micro-morphology of crack propagation after nano-indentation, it can be seen that the whisker pull-out and whisker bridging phenomenon during the crack propagation process are promoted due to the whisker self-height aspect ratio and moderate interface bonding with $\mathrm{ZrB}_{2}$ matrix, and the crack deflection is accompanied around the whiskers. The synergistic effect of these toughening mechanisms can absorb a large amount of crack propagation energy, and improve the fracture toughness of the materials.

(3) Carbon nanotube toughening

Carbon nanotubes (CNTs) have attracted the attention of many scientists since their unique structure and excellent mechanical, electrical, and chemical properties were discovered by Dr. Iijima from the NEC corporation in 1991 [152]. The fracture toughness of UHTCs can be improved by adding a small amount of carbon nanotubes. The study by Tian et al. [153] indicated that the addition of $2 \mathrm{wt} \%$ CNTs into $\mathrm{ZrB}_{2}-20$ vol\% $\mathrm{SiC}$ increases the fracture toughness by about $15 \%$. Lin et al. [154] systematically studied the effect of sintering temperature $\left(1600-1800{ }^{\circ} \mathrm{C}\right)$ on $\mathrm{ZrB}_{2}-10$ vol\%CNTs prepared by SPS (Fig. 8). The results show that the maximum fracture toughness of $\mathrm{ZrB}_{2}-\mathrm{CNT}$ ceramic material $\left(7.2 \mathrm{MPa} \cdot \mathrm{m}^{1 / 2}\right)$ is achieved at the sintering temperature of $1650{ }^{\circ} \mathrm{C}$, which is much higher than that of single-phase $\mathrm{ZrB}_{2}$ ceramic material $\left(3.3 \mathrm{MPa} \cdot \mathrm{m}^{1 / 2}\right)$. The synergistic effect of carbon nanotube pull-out and crack deflection mechanisms greatly increases the damage tolerance of $\mathrm{ZrB}_{2}$ ceramics.

(4) Graphene toughening

Graphene is a 2D carbon nanomaterial whose carbon atoms form hexagonal lattices with $\mathrm{sp}^{2}$ hybrid

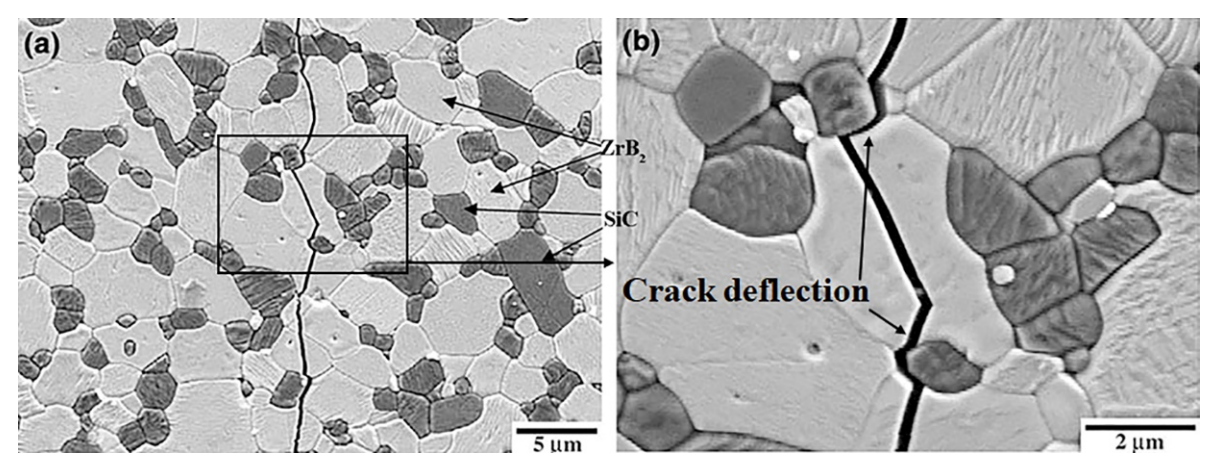

Fig. 7 Typical crack propagation path of $\mathrm{ZrB}_{2}-\mathrm{SiC}$ after indentation at low (a) and high (b) magnification showing crack deflection near $\mathrm{SiC}$ particles and predominantly transgranular fracture for $\mathrm{ZrB}_{2}$ grains. Reproduced with permission from Ref. [148], (C) Springer Science Business Media, LLC 2007. 

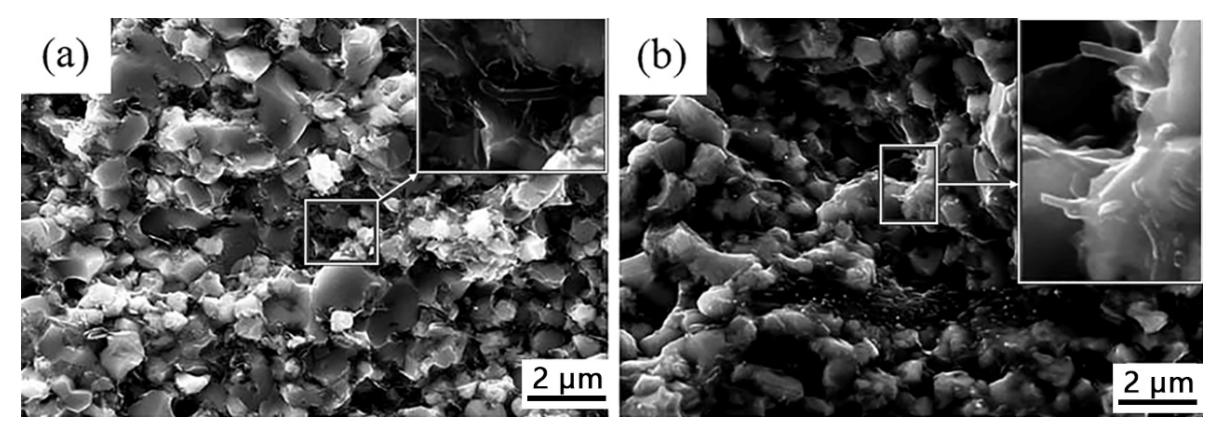

Fig. 8 Fracture morphologies of $\mathrm{ZrB}_{2}-\mathrm{CNT}$ ceramics sintered at $1600{ }^{\circ} \mathrm{C}$ (a) and $1650{ }^{\circ} \mathrm{C}$ (b). Reproduced with permission from Ref. [154], (C) Maney Publishing 2016.

orbitals [155]. Ocak et al. [156] introduced graphene nano-sheets (GNP) with different volume contents from 0 vol $\%$ to 9 vol $\%$ into $\mathrm{TiC}-\mathrm{ZrC}$ ceramics by SPS. The results show that the relative density of $3 \mathrm{vol} \%$ GNP-TiC-ZrC is higher than $99 \%$, and the maximum fracture toughness is $5.17 \mathrm{MPa} \cdot \mathrm{m}^{1 / 2}$. Cheng et al. [157] reported $\mathrm{ZrC}-\mathrm{SiC}$-graphene composites preparing by mud impregnation into macroporous graphene network structure, followed by SPS. The microstructure is shown in Fig. 9. The graphene lamella is parallel to the compressed surface, and the fracture toughness of the material is improved from 3.82 to $4.26 \mathrm{MPa} \cdot \mathrm{m}^{1 / 2}$, although the flexural strength of $\mathrm{ZrC}-\mathrm{SiC}$ ceramics with graphene decreases from 416 to $220 \mathrm{MPa}$. This is mainly due to crack deflection and bridging induced by macroporous graphene (Fig. 9).

Overall, the above-mentioned toughening designs can improve the toughness and thermal shock resistance of UHTCs to some extent. However, the reliability of bulk UHTCs still cannot match the requirements of engineering applications. Generally, the practical applications of UHTCs are in forms of fiber-reinforced UHTC composites or coatings, which will be discussed in Sections 3 and 4 in detail.
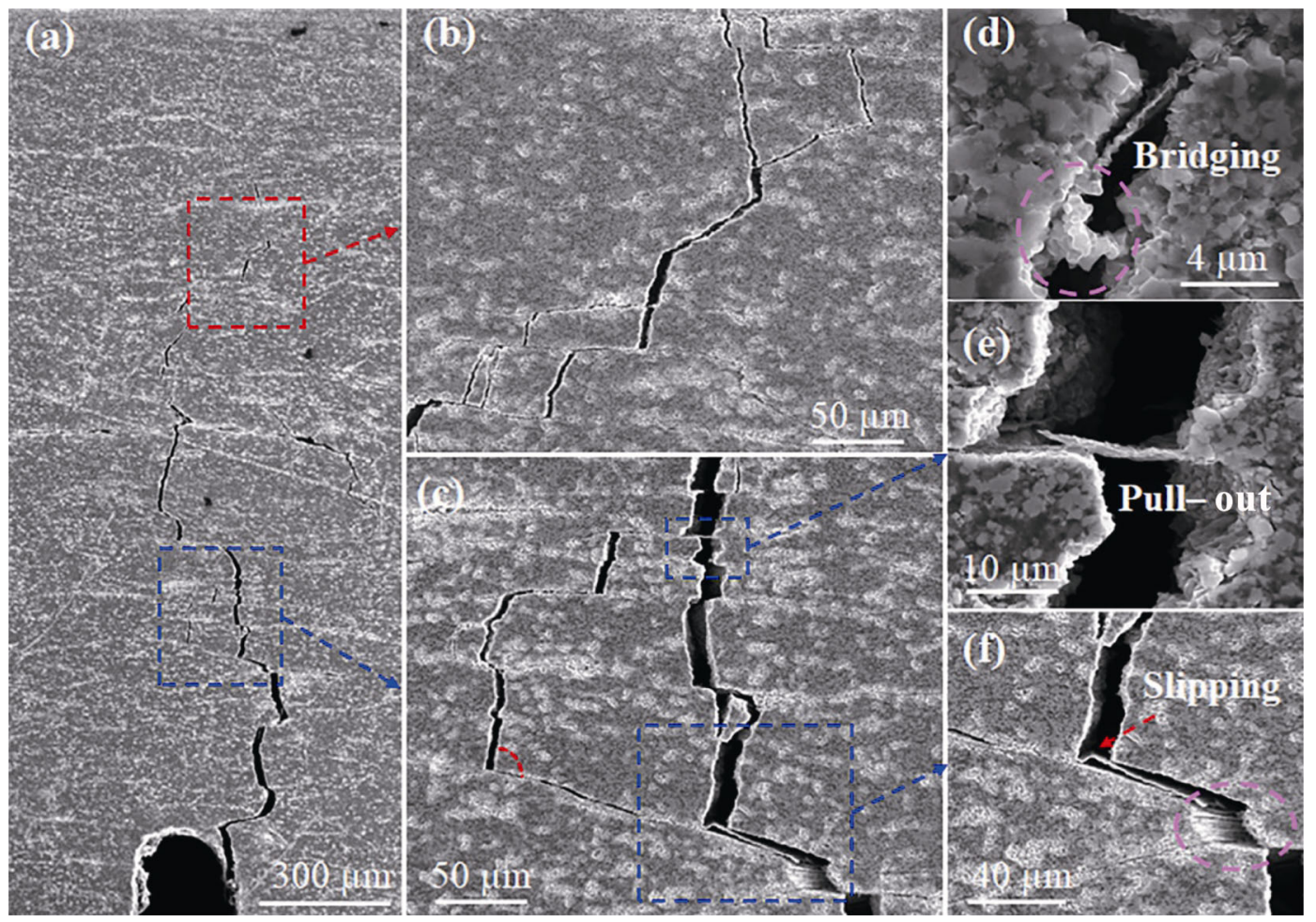

Fig. 9 Crack propagation of $\mathrm{ZrC}-\mathrm{SiC}$-graphene composites (a); crack deflection and crack branching in the partially enlarged view of the red (b) and blue (c) square dashed frames in (a); bridging (d), pull-out (e), and slipping (f) of graphene sheets. Reproduced with permission from Ref. [157], C Elsevier Ltd. 2018. 


\section{5 Thermal response, oxidation/ablation behavior, and mechanisms of bulk UHTCs}

Thermal response, oxidation/ablation behavior, and mechanisms are also complicated but play an important role in the characterization and evaluation of UHTCs. There are many factors related to the thermal response of UHTCs such as thermal conductivity, volumetric heat capacity, catalytic efficiency, emissivity, and oxidation characteristic. The surface temperature rising rate of UHTCs during initial heating stage and temperature gradient strongly depends on the thermal conductivity and volumetric heat capacity. The surface temperature evolution and the maximum surface temperature are closely associated with environmental parameters, oxidation reaction models, and physicochemical properties of the oxidation products. Oxidation of UHTCs is a comprehensive process in which oxygen diffuses inward and gaseous or liquid oxidation products diffuses outward. The oxidation/ablation performance and mechanisms of UHTCs system are not the same for different components and environmental conditions. Therefore, it is required to fully understand the oxidation and ablation process of UHTCs, before we can design and control the composition, microstructure, and key properties of UHTCs according to the requirements of different service environments. In the following section, oxidation/ablation process and mechanisms of typical UHTC materials are introduced to lay the foundation for the design of ultra-high temperature thermal protection materials.

For carbide UHTCs, the oxidation process is mainly characterized by the outward diffusion of inner metal atom $\mathrm{Me}$ (metal) and the inward diffusion of outer oxygen atom [158]. A large number of oxygen atoms diffuse into the $\mathrm{MeC}$ lattice and form an oxide layer in the interior, which is composed of a loose outer layer and a dense inner layer. Figure 10 shows the mechanistic model for the oxidation of $\mathrm{ZrC}$ to $\mathrm{ZrO}_{2}$.

Voitovich and Pugach [159] focused on the static oxidation behavior of $\mathrm{ZrC}$ and $\mathrm{HfC}$ in the temperature range of $500-1200{ }^{\circ} \mathrm{C}$, and the involved oxidation reactions are as follows:

$$
\begin{aligned}
& \mathrm{MeC}+\mathrm{O}_{2} \rightarrow \mathrm{Me}_{x} \mathrm{O}_{y}+\mathrm{CO}_{2} \\
& \mathrm{MeC}+\mathrm{O}_{2} \rightarrow \mathrm{Me}_{x} \mathrm{O}_{y}+\mathrm{CO} \\
& \mathrm{MeC}+\mathrm{O}_{2} \rightarrow \mathrm{Me}_{x} \mathrm{O}_{y}+\mathrm{C} \\
& 2 \mathrm{MeC}+\mathrm{N}_{2} \rightarrow 2 \mathrm{MeN}+2 \mathrm{C}
\end{aligned}
$$

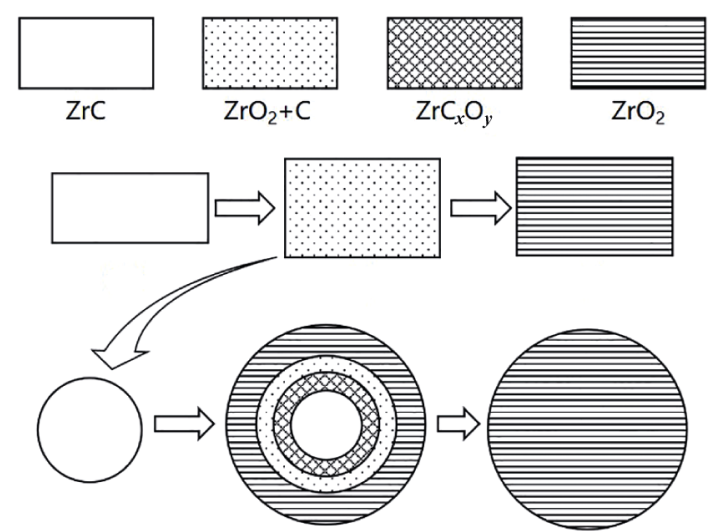

Fig. 10 Mechanistic model for the oxidation of $\mathrm{ZrC}$ to $\mathrm{ZrO}_{2}$. Reproduced with permission from Ref. [158], (C) Elsevier B.V. 1994.

Voitovich and Pugach [159] found that the occurrence of reactions closely related to oxygen partial pressure and temperature. At the initial stage of oxidation, the Reaction (4) occurs on the surface of the materials due to the sufficient oxygen partial pressure. With the diffusion of oxygen into the material, the Reactions (5) and (6) start. At higher temperatures, $\mathrm{N}_{2}$ in the air can also combine with Me, which is Reaction (7). Under oxidation at $900{ }^{\circ} \mathrm{C}$, an oxide layer with a higher sintering degree can be formed on the surface of $\mathrm{ZrC}$ [160], which is closely bound to the substrate, and the vacancy concentration of the oxidized phase $\mathrm{ZrC}_{x} \mathrm{O}_{y}$ formed inside is low. At low temperature oxidation stage, the oxidation resistance of $\mathrm{ZrC}$ is slightly better than that of HfC. It is revealed that the oxide layer thickness of $\mathrm{HfC}$ at $1400{ }^{\circ} \mathrm{C}$ increases linearly with time. However, the oxide layer thickness of HfC shows a parabola relationship with time at $1400-2100{ }^{\circ} \mathrm{C}$, and the oxide layer structure evolves into a complex multi-layer structure: the outer layer of porous $\mathrm{HfO}_{2}$, the middle layer of dense $\mathrm{HfC}_{x} \mathrm{O}_{y}$, and the inner layer of residual carbon. The dense structure of the intermediate $\mathrm{HfC}_{x} \mathrm{O}_{y}$ layer can well prevent the inward oxygen diffusion. Below $1500{ }^{\circ} \mathrm{C}$, the oxidation layer of HfC has a poor sintering degree and easily peels off from the substrate. At temperatures above $1800{ }^{\circ} \mathrm{C}$, $\mathrm{HfO}_{2}$ can be sintered to form a dense oxide film, showing good oxidation resistance. The oxidation resistance mechanisms of $\mathrm{MeC}$ mainly depend on the formation of dense oxidation layer with good adhesion to the substrate by sintering of the oxide phase at high temperatures. Since the oxide phase sintering behavior of $\mathrm{MeC}$ is closely related to temperature, the practical applications of $\mathrm{MeC}$ are limited, such as insufficient 
oxidation performance caused by the mismatch between the actual temperature and the service temperature. Many studies have shown that the introduction of $\mathrm{SiC}$ into the UHTCs can improve the mechanical properties, thermal shock resistance, and oxidation ablation resistance [161-164]. The introduced $\mathrm{SiC}$ can form silicate glass phase covering material with high viscosity, high melting point, low oxygen diffusion velocity, and low vapor pressure at high temperature, which prevents the further invasion of oxygen and can play a good protective role below $1600{ }^{\circ} \mathrm{C}$ [165]. UHTCs-SiC have become the focus of current research. By introducing the $\mathrm{SiC}$ phase, the oxidation resistance of $\mathrm{MeC}$ ceramics can be effectively improved [166].

Boride UHTCs have excellent oxidation resistance at low temperatures, but their oxidation resistance mechanism is completely different from that of carbides [167]. $\mathrm{ZrB}_{2}$ begins to oxidize obviously at $700{ }^{\circ} \mathrm{C}$, and the formed oxide layer $\left(\mathrm{B}_{2} \mathrm{O}_{3}\right)$ has good oxidation resistance below $1100{ }^{\circ} \mathrm{C}$. However, $\mathrm{B}_{2} \mathrm{O}_{3}$ will volatilize due to high vapor pressure when the temperature is higher than $1200{ }^{\circ} \mathrm{C}$, and the oxidation resistance will gradually lose. Parthasarathy et al. [168] developed a mechanistic model to interpret the oxidation behavior of the diborides of $\mathrm{Zr}$, $\mathrm{Hf}$, and $\mathrm{Ti}$ in the temperature range of $1000-1800{ }^{\circ} \mathrm{C}$ (Fig. 11). Good correspondence was obtained between the theory and experiments for weight gain, recession, and scale thickness as functions of temperature and oxygen partial pressure. It is revealed that at temperatures below about $1400{ }^{\circ} \mathrm{C}$, the rate-limiting step is the diffusion of dissolved oxygen through a film of liquid $\mathrm{B}_{2} \mathrm{O}_{3}$ in capillaries at the base of the oxidation product. While at higher temperatures, the $\mathrm{B}_{2} \mathrm{O}_{3}$ is lost by evaporation, and the oxidation rate is limited by Knudsen diffusion of molecular oxygen through the capillaries between nearly columnar blocks of the oxide, $\mathrm{MO}_{2}$.

For $\mathrm{ZrB}_{2}-\mathrm{SiC}$, the main reactions involved during oxidation are as follows:

$$
\begin{aligned}
\mathrm{ZrB}_{2}(\mathrm{~s})+\frac{5}{2} \mathrm{O}_{2}(\mathrm{~g}) & \rightarrow \mathrm{ZrO}_{2}(\mathrm{~s})+\mathrm{B}_{2} \mathrm{O}_{3}(\mathrm{l}) \\
\mathrm{SiC}(\mathrm{s})+\frac{3}{2} \mathrm{O}_{2}(\mathrm{~g}) & \rightarrow \mathrm{SiO}_{2}(\mathrm{~s}, \mathrm{l})+\mathrm{CO}(\mathrm{g}) \\
\mathrm{SiC}(\mathrm{s})+\mathrm{O}_{2}(\mathrm{~g}) & \rightarrow \mathrm{SiO}(\mathrm{g})+\mathrm{CO}(\mathrm{g}) \\
\mathrm{B}_{2} \mathrm{O}_{3}(\mathrm{l}) & \rightarrow \mathrm{B}_{2} \mathrm{O}_{3}(\mathrm{~g})
\end{aligned}
$$

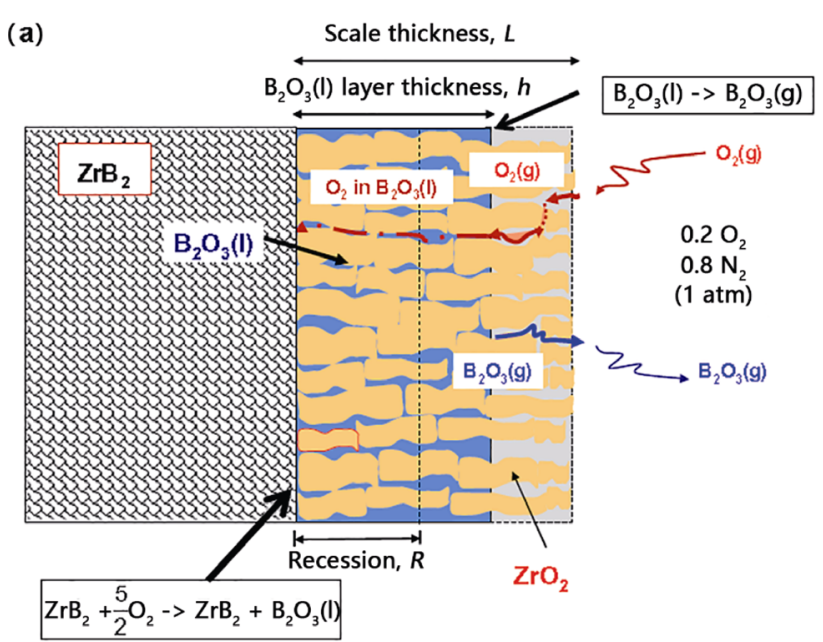

(b)

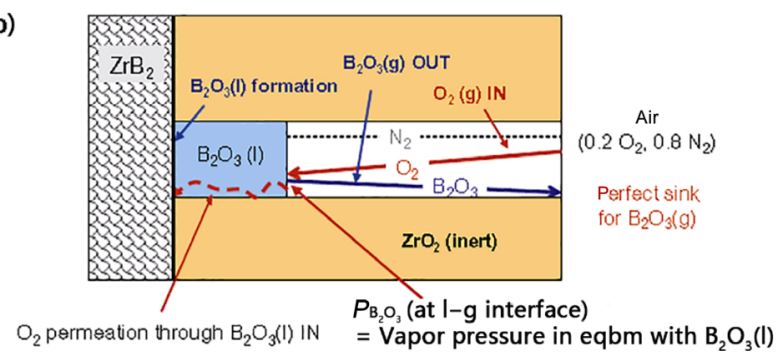

Fig. 11 Schematic diagram of mechanisms involved oxidation of $\mathrm{ZrB}_{2}$ in air in the temperature range of 1000-1800 ${ }^{\circ} \mathrm{C}$ (a); schematic of the mechanistic steps considered in the oxidation model (b) developed by Parthasarathy et al. Reproduced with permission from Ref. [168], (C) Acta Materialia Inc. Published by Elsevier Ltd. 2007.

$$
\begin{gathered}
\mathrm{SiO}_{2}(\mathrm{~s}, \mathrm{l}) \rightarrow \mathrm{SiO}_{2}(\mathrm{~g}) \\
\mathrm{ZrO}_{2}(\mathrm{~s}) \rightarrow \mathrm{ZrO}_{2}(\mathrm{~g})
\end{gathered}
$$

The oxidation reactions of $\mathrm{SiC}$ are relatively complex [169], and the transition temperature of $\mathrm{SiC}$ from passive to active oxidation in air is $\sim 1734{ }^{\circ} \mathrm{C}$, which decreases significantly with the decrease of oxygen partial pressure. $\mathrm{SiO}_{2}$ generated by passive oxidation has good antioxidant protection ability below $1850{ }^{\circ} \mathrm{C}$, and $\mathrm{SiO}_{2}$ will fail because of rapid volatilization at a higher temperature. The introduction of 10-30 vol\% $\mathrm{SiC}$ can significantly improve the oxidation resistance of UHTCs [170,171]. The refinement of grain size will lead to the improvement of the distribution uniformity of $\mathrm{SiC}$, thus improving the oxidation resistance of the materials. In this way, $\mathrm{SiO}_{2}$ can fill the pores more effectively and bridge the defects to block the entry of oxygen, thus improving the oxidation resistance of the material [172].

Fahrenholtz [164] developed a thermodynamic model to explain the formation of a SiC-depleted layer 


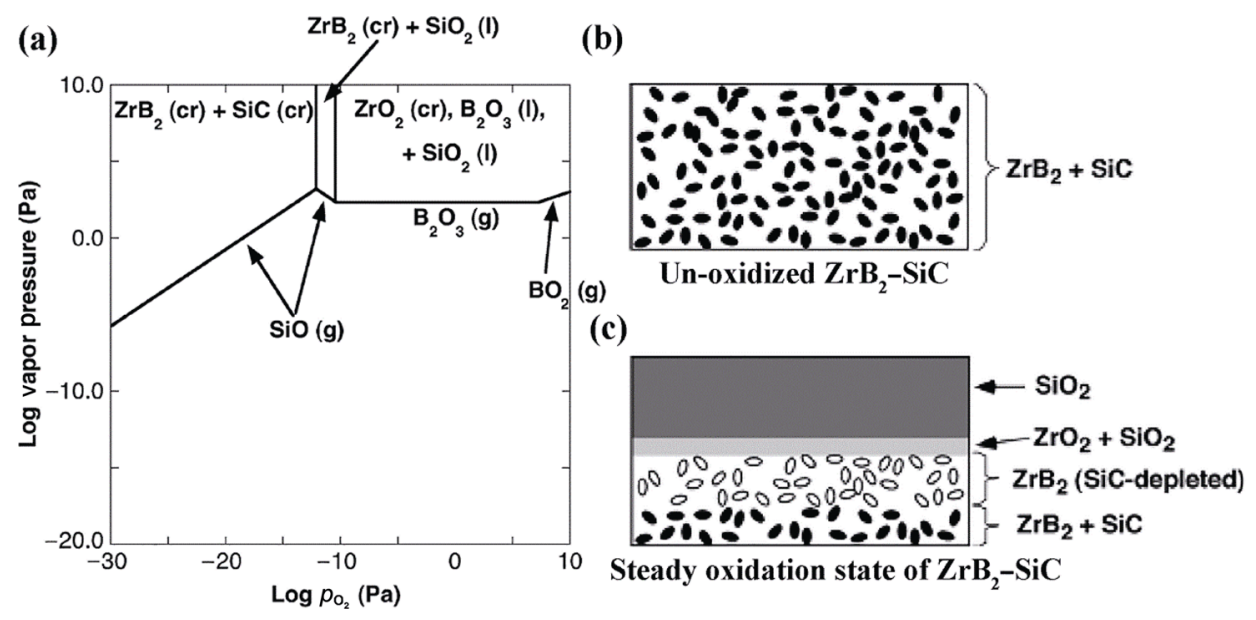

Fig. 12 Volatility diagram of $\mathrm{ZrB}_{2}-\mathrm{SiC}$ at $1500{ }^{\circ} \mathrm{C}$ (a), schematic diagram of un-oxidized $\mathrm{ZrB}_{2}-\mathrm{SiC}$ (b), and the steady oxidation state of $\mathrm{ZrB}_{2}-\mathrm{SiC}$ at $1500{ }^{\circ} \mathrm{C}$ (c). Reproduced with permission from Ref. [164], (C) The American Ceramic Society 2007.

during $\mathrm{ZrB}_{2}-\mathrm{SiC}$ oxidation in air at $1500{ }^{\circ} \mathrm{C}$. Based on the volatility diagrams (Fig. 12(a)), a thermodynamically stable structure (Fig. 12(c)) consisting of 1) a silica-rich layer, 2) a Zr-rich oxidized layer, and 3) a $\mathrm{SiC}$-depleted zirconium diboride layer, was proposed to form for $\mathrm{ZrB}_{2}-\mathrm{SiC}$ during oxidation. This is consistent with the experimental results very well. The SiC-depleted layer developed due to active oxidation of $\mathrm{SiC}$. Diffusion of oxygen through the $\mathrm{SiO}_{2}$-rich scale and the $\mathrm{ZrO}_{2}-\mathrm{SiO}_{2}$ layer is the rate limiting step of the overall process. Accordingly, the thickness of the outer scale should continue to increase with time due to the continued oxidation of $\mathrm{SiC}$, which, in turn, increases the thickness of the SiC-depleted region in the underlying $\mathrm{ZrB}_{2}-\mathrm{SiC}$. The experimental research by $\mathrm{Ni}$ et al. [173] revealed that the formation of the $\mathrm{SiC}$-depleted layer during oxidation is resulted from the active oxidation of $\mathrm{SiC}$ with $\mathrm{C}$ as an initial product. Lu et al. [174] further developed the volatility diagram of a ternary $\mathrm{ZrB}_{2}-\mathrm{SiC}-\mathrm{ZrC}$ (ZSZ) system to interpret the oxidation behavior of ZSZ ceramics. Based on the volatility diagram, the formation of $\mathrm{ZrC}$-corroded and SiC-depleted layers and the oxidation sequence of each component in ZSZ during oxidation and ablation were well understood.

At ultra-high temperature oxidation environment $\left(\sim 2200{ }^{\circ} \mathrm{C}\right)$, the oxide layer formed on $\mathrm{ZrB}_{2}-\mathrm{SiC}$ shows a multi-layered structure [175] (Fig. 13). It includes: 1) oxidized outer layer, 2) dense $\mathrm{ZrO}_{2}$ recrystallization layer, 3) porous oxide layer, 4) $\mathrm{SiC}$ depletion layer, and 5) unreacted bulk material. The outer layer is a porous $\mathrm{ZrO}_{2}$ layer, and the second layer is a dense $\mathrm{ZrO}_{2}$ layer formed by the recrystallization and sintering of $\mathrm{ZrO}_{2}$ grains at high temperatures, which can effectively prevent the entry of oxygen and protect the inner bulk material from rapid oxidation. The third layer is a porous oxide layer, which is caused by the generation of high vapor pressure gas. The generated gas cannot be discharged in time, when its pressure exceeds the ambient pressure, it will form pores. This layer is the transition layer between the $\mathrm{ZrO}_{2}$ recrystallization layer (the second layer) and the $\mathrm{SiC}$ depletion layer (the fourth layer). Due to the existence of a large number of pores and high vapor pressure gaseous oxides, coupled with the mismatch of thermal expansion coefficient between $\mathrm{ZrO}_{2}$ and $\mathrm{ZrB}_{2}$, the bonding strength between this layer and the $\mathrm{SiC}$ depletion layer is the weakest among all layers, and it is easy to crack and delaminate here. Therefore, this layer plays a key role in the high-temperature oxidation performance of the material. Below this layer, it is the $\mathrm{SiC}$ depletion layer, which is mainly composed of unreacted $\mathrm{ZrB}_{2}$. During the oxidation process, its structure does not change significantly, and the original continuity does not change. The fifth layer is the unoxidized $\mathrm{ZrB}_{2}-\mathrm{SiC}$ bulk material $[163,176,177]$.

$\mathrm{HfB}_{2}$ has higher melting point and thermal conductivity than $\mathrm{ZrB}_{2}$, and the melting point of its oxidation product $\mathrm{HfO}_{2}$ is also higher than that of $\mathrm{ZrB}_{2}$ oxidation product $\mathrm{ZrO}_{2}$. Accordingly, $\mathrm{HfB}_{2}$ shows good oxidation resistance under ultra-high temperature environment [178]. Similar to $\mathrm{ZrB}_{2}$-based UHTCs, the introduction of $\mathrm{SiC}$ into $\mathrm{HfB}_{2}$ can effectively improve the mechanical properties and oxidation resistance of the materials $[179,180]$. Similar to $\mathrm{ZrB}_{2}-\mathrm{SiC}$ composites, $\mathrm{HfB}_{2}-\mathrm{SiC}$ and $\mathrm{HfB}_{2}-\mathrm{SiC}-\mathrm{AlN}$ after oxyacetylene test 


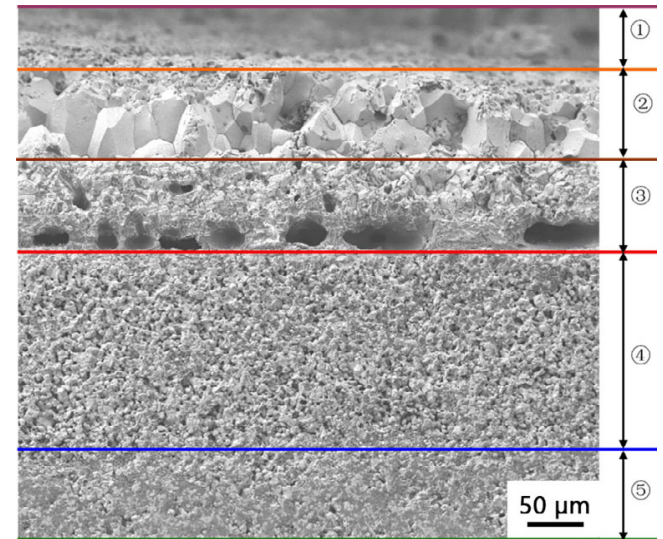

Fig. 13 Cross-section of $\mathrm{ZrB}_{2}-\mathrm{SiC}$ after oxidation at $2200{ }^{\circ} \mathrm{C}$ for $10 \mathrm{~min}$. Reproduced with permission from Ref. [175], (C) Elsevier Ltd. 2007.

also have an obvious layered structure: The entire oxide layer can be divided into three layers from surface: 1) outermost oxide layer, 2) oxide sub-layer, and 3) unreacted bulk [181]. Fahrenholtz et al. [18,164] pointed out that the oxygen atom transport into the $\mathrm{SiC}$ depletion layer is mainly by permeation, where active oxidation of $\mathrm{SiC}$ is occurred, with gaseous $\mathrm{CO}$ and $\mathrm{SiO}$ as the main products. Due to the existence of many pores, the structure of the $\mathrm{SiC}$ depletion layer is very loose, which is very easy to fall off under the action of external force, resulting in the absence of oxidation layer, adverse to the oxidation resistance of the materials [182].

The addition of AlN can promote the densification of $\mathrm{HfB}_{2}-\mathrm{SiC}$ by removing the oxide layer on the surface of $\mathrm{HfB}_{2}$ powders and inhibiting the grain growth of $\mathrm{HfB}_{2}$ during sintering [181]. AlN can be oxidized to $\mathrm{Al}_{2} \mathrm{O}_{3}$ with a higher melting point than $\mathrm{SiO}_{2}$, which can cover the surface of the material to play an oxidation resistance role at a higher temperature. Besides, $\mathrm{Al}_{2} \mathrm{O}_{3}$ and $\mathrm{SiO}_{2}$ can form an aluminosilicate melt to fill the pores in the oxide layer formed by $\mathrm{SiC}$ active oxidation. The study by Zhang et al. [183] revealed that the addition of a $\mathrm{W}$ compound (i.e., WC) can improve the oxidation resistance of $\mathrm{ZrB}_{2}$ remarkably. During oxidation, the presence of $\mathrm{WO}_{3}$ in the oxide scale resulted in liquid phase sintering of $\mathrm{ZrO}_{2}$, which modified the microstructure of the scale and increased its relative density. As a result, WC-containing $\mathrm{ZrB}_{2}$ had improved oxidation resistance compared with nominally pure $\mathrm{ZrB}_{2}$. This provides a new approach for UHTC design with improved oxidation resistance.

On the other hand, Ni et al. [184,185] developed highly textured $\mathrm{MB}_{2}$-based UHTCs based on strong magnetic field alignment, which present anisotropic oxidation resistant properties due to the intrinsic anisotropy of diborides. Better oxidation resistance is achieved on the sample surface perpendicular to the $c$-axis of $\mathrm{MB}_{2}$ [184-187]. Preliminary investigation suggests that mass transmission (such as oxygen and $\mathrm{SiO}$ ) anisotropy is an important factor for the anisotropic oxidation resistance. This provides a new selection for the design and application of UHTCs.

With the continuous improvement of hypersonic technology, the thermal protection systems and materials have become key factors restricting the further development of hypersonic vehicle. UHTCs are receiving more and more attention due to their excellent high-temperature comprehensive performance. However, in order to truly achieve engineering application, the inherent brittleness of UHTC is the core scientific problem that must be solved. The introduction of particles, whiskers, and short fibers cannot provide a stable toughened skeleton, and the toughening effect cannot meet the service requirements. The UHTCMCs combining UHTCs and continuous fibers are expected to fundamentally overcome the inherent brittleness of bulk UHTCs, and have become the main development trend and research hotspot at present and in the future, which is the focus of the subsequent section.

\section{Ultra-high temperature ceramic matrix composites (UHTCMCs): Components, processing, and properties}

Combining the unique properties of the UHTCs with the concepts of ceramic matrix composites, a new class of materials known as fiber reinforced UHTCMCs are developed. The UHTCMCs are endowed with excellent mechanical properties and ablation resistance at ultra-high temperatures, and furthermore, overcoming the inherent brittleness and poor thermal shock resistance of bulk UHTCs. Therefore, UHTCMCs are currently considered as the most potential candidates for applications in thermal structures and anti-ablation components of hypersonic vehicles, such as sharp noses, leading edges, and combustor of solid rockets.

\section{1 Components of the UHTCMCs}

Generally, UHTCMCs are composed of fiber reinforcements, interphase/interface, and UHTC matrix, which need to be selected and combined properly to 
achieve the desired properties. This section focuses on the properties and compatibility of fibers, interphase, and matrix for UHTCMCs.

(1) Fiber reinforcements

In fiber-reinforced UHTCMCs, fibers are designed to overcome the brittleness and poor thermal shock resistance of the monolithic UHTCs. Furthermore, the fibers must also be able to withstand the extremely high temperature and harsh environment, in which thermal and oxidation stability are required. The type of fiber reinforcements influences the mechanical properties significantly, especially fracture toughness, and it also affects the fabrication processing. Due to the relatively low cost and better ultra-high temperature properties, carbon fibers are the most commonly reinforcements for UHTCMCs currently. Very few works have also been conducted on the SiC fiberreinforced UHTCMCs. However, the poor oxidation resistance properties of carbon fibers and the limited high-temperature resistance of $\mathrm{SiC}$ fibers intrinsically restrict the performance of UHTCMCs under more extreme conditions. Developing UHTC fibers with superior thermal and oxidation stability becomes critical for further improving the properties of UHTCMCs $[188,189]$. Up to now, only the US Matech GSM (Matech Global Strategic Materials Inc., California, USA) has reported their development of UHTC fibers, such as HfC fibers, TaC fibers, and UHTC fibers reinforced UHTC matrix composites [190]. However, the commercially available UHTC fibers have rarely been reported.

Earlier research paid some attention to the chopped fiber-reinforced composites due to the simple fabrication process (Fig. 14). However, chopped fibers are vulnerable when mixing with ceramic powders. And, the poor dispersibility of fibers results in limited

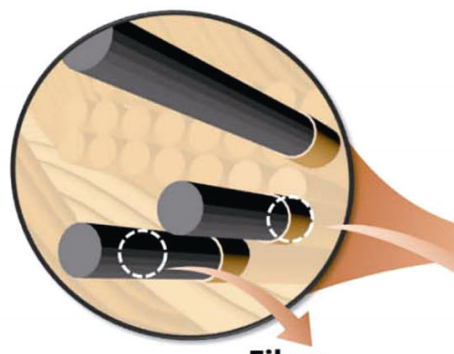

Fiber

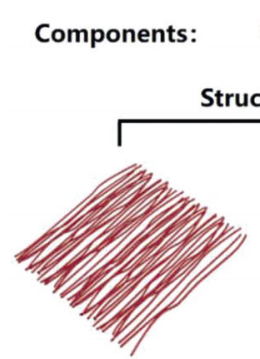

1D

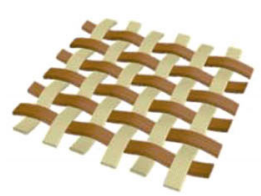

2D Plain

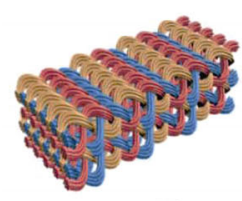

3D Braid

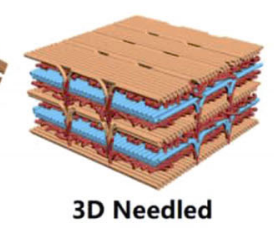

$\mathrm{C}_{\mathrm{f}}, \mathrm{SiC}_{\mathrm{f}}, \mathrm{UHTC}_{\mathrm{f}} \ldots$

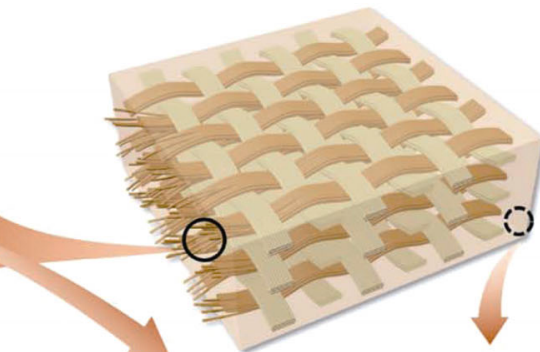

Interface

Matrix

PyC, BN, (PyC/SiC)n... UHTCs...
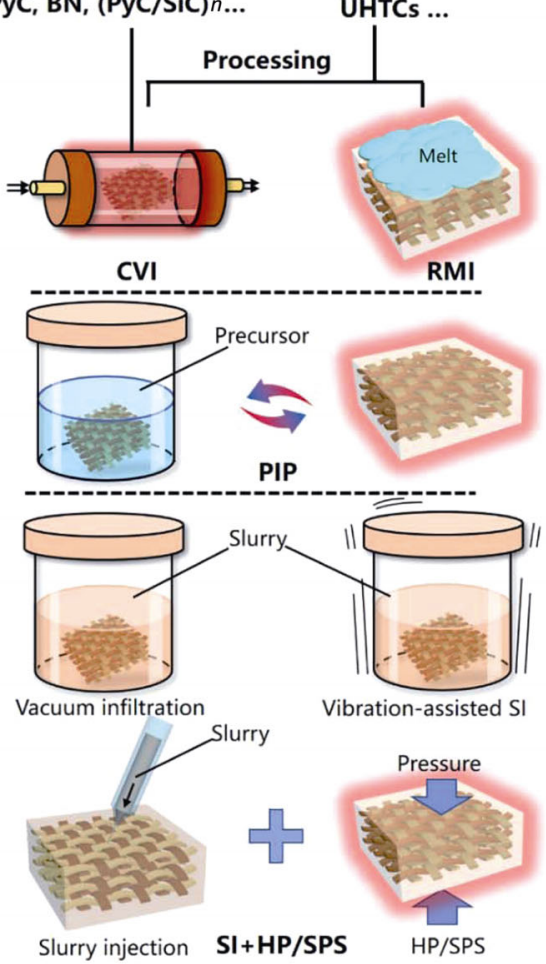

Fig. 14 Schematic diagram of the components and processing of UHTCMCs. 
mechanical properties of the composites [191-193]. Accordingly, continuous fiber reinforcements with different weaving modes are developed for highperformance UHTCMCs. The fibers in 2D preform are usually stacked in different directions. The composites with 2D fiber reinforcements present higher mechanical strength along the fiber directions but poor interlayer shear strength [163,194-198]. 3D fiber preforms, mainly contain needled, woven, braid fiber preforms, etc. (Fig. 14), exhibit better mechanical properties. Currently, 3D preforms are the most widely used reinforcements for UHTCMC fabrication [199203].

Even though the composites are reinforced with continuous fibers, the inter-bundle and the interlaminar matrix also show a brittle behavior at the micron scale. Accordingly, some research has been conducted by introducing one-dimensional nanostructure, such as carbon nanotubes (CNTs), boron nitride nanotubes (BNNTs), and $\mathrm{SiC}$ nanowire (SiCNWs), into the matrix to develop hierarchically reinforced composites [204,205].

(2) Interphase/interface

Interphase/interface between fibers and matrix is another key component of UHTCMCs, which determine the mechanical behavior and oxidation resistance properties of UHTCMCs to a certain extent. Generally, the interface on fibers is deposited by chemical vapor infiltration before introducing ceramic matrix. The vulnerable fibers can be protected by interphase. Moreover, weak interphase is necessary to toughen the composites by crack deflection, interface debonding, and fiber pull-out when the load is applied on the composites. Pyrolytic carbon (PyC) with layered structure and $\mathrm{PyC} / \mathrm{SiC}$ are the most widely used interphase for UHTCMCs, which play a critical role in damage tolerance of the composites [206]. h-BN has very similar layered structure, elasticity, and fracture properties to PyC. Recently, the $\mathrm{BN} / \mathrm{SiC}$ multilayer interphase has also been developed to improve the oxidation resistance of the composites by forming borosilicate glass which can seal the cracks and prevent the inward diffusion of oxygen in oxidized environment. However, the oxidized product of $\mathrm{BN}$, $\mathrm{B}_{2} \mathrm{O}_{3}$, volatilizes violently at temperatures higher than $1100{ }^{\circ} \mathrm{C}$, resulting in the decrease of oxidation resistance [207]. To further improve the oxidation resistance of the $\mathrm{BN}$ interphase, NASA modified $\mathrm{BN}$ with Si and fabricated Si-doped BN interphase [208].
More researchers prefer to fabricate multilayer interphase to improve the properties of composites. Take $\mathrm{PyC}$ and $\mathrm{PyC} / \mathrm{SiC}$ multilayer interphase in $\mathrm{C}_{\mathrm{f}} / \mathrm{SiBCN}$ composites as an example, PyC interface reacts with $\mathrm{SiBCN}$ matrix and forms ring-like defects at temperatures higher than $1600{ }^{\circ} \mathrm{C}$, leading to the serious degradation of mechanical properties (from $370 \mathrm{MPa}$ at room temperature to $92 \mathrm{MPa}$ at $1600{ }^{\circ} \mathrm{C}$ ). For the $\mathrm{C}_{\mathrm{f}} / \mathrm{SiBCN}$ composites with $(\mathrm{PyC} / \mathrm{SiC})_{3}$ multilayer interphase, the reactions can be retarded effectively and the intact interphase ensures the excellent properties of the composites. The flexural strength of the composites is maintained to $330 \pm 10 \mathrm{MPa}$ at $1600{ }^{\circ} \mathrm{C}$ [200,209]. In summary, the development of proper interphase is critical for performance optimization of UHTCMCs.

(3) UHTC matrix

UHTC matrix are the main components of UHTCMCs, where the carbides and borides of $\mathrm{Zr}$, Hf and $\mathrm{Ta}$ have been extensively studied. In particular, $\mathrm{Zr}$ and Hf-based UHTCs are the most used matrix due to the high melting points of themselves and their oxides. For Ta-based UHTCs, the low melting point of their oxides $\left(\sim 1800{ }^{\circ} \mathrm{C}\right.$ for $\left.\mathrm{Ta}_{2} \mathrm{O}_{5}\right)$ restrict their ultra-high temperature applications to some extent. The oxidation and ablation resistance of UHTCMCs not only depends on the composition of the matrix, but also depends on the microstructure of the formed oxide layer. Compared to the carbide UHTCs, borides possess better oxidation resistance in a wide temperature range below $1100{ }^{\circ} \mathrm{C}$ due to the formation of glassy $\mathrm{B}_{2} \mathrm{O}_{3}$ [195,210-215].

A dense oxide layer with limited oxygen diffusion rate is necessary to maintain an effective protection. Therefore, additives into the UHTC matrix to modify the oxide layers have been investigated. Based on the results of bulk UHTCs, SiC is the most used second phase to improve the oxidation and ablation resistance of the UHTCMCs, which can form a dense glassy $\mathrm{SiO}_{2}$ layer during oxidation and ablation. The glassy phase with a low viscosity can fill in the cracks or pores in oxide layer and prevent oxygen inward diffusion [198,216,217]. However, the vast evaporation of $\mathrm{SiO}_{2}$ at ablation temperature above $2200{ }^{\circ} \mathrm{C}$ results in failure of the oxide protective layer. In recent years, rare earth oxides and $\mathrm{TiC}$ are introduced into the matrix to stabilize the ablation oxides and increase the melting point of silica to further improve the ablation resistance of UHTCMCs [218-220]. In addition, SiBCN-based composites have also been studied for high-temperature 
structural applications. However, the ablation resistance is limited due to the lack of UHTC components [200,221-224]. Recently, a novel $\mathrm{C}_{\mathrm{f}} / \mathrm{Zr}_{0.8} \mathrm{Ti}_{0.2} \mathrm{C}_{0.74} \mathrm{~B}_{0.26}$ composite is reported with superior ablation resistance [210].

\section{2 Processing and microstructures of UHTCMCs}

Various processing methods have been developed for UHTCMC fabrication. Chemical vapor infiltration/ deposition (CVI/CVD), precursor infiltration and pyrolysis (PIP), slurry infiltration (SI), and reactive melt infiltration (RMI) are the most commonly used methods. Slurry infiltration combined with subsequent sintering treatment, such as HP and SPS, have also been developed recently to fabricate dense UHTCMCs. The advantages and disadvantages of the different processing routes are discussed in this section.

(1) Chemical vapor infiltration/deposition (CVI/CVD)

$\mathrm{CVI} / \mathrm{CVD}$ is a process which introduces reactive gases into porous fiber preforms to form the ceramic matrix of fiber-reinforced composites (Fig. 15). By introducing various reactive gases, $\mathrm{CVI} / \mathrm{CVD}$ can be widely applied to fabricate $\mathrm{C}, \mathrm{SiC}$, and other UHTC matrix, such as $\mathrm{HfC}, \mathrm{ZrC}$, and $\mathrm{ZrB}_{2}$ [5,225]. The $\mathrm{CVI} / \mathrm{CVD}$ process is generally a relatively low temperature (900-1400 ${ }^{\circ} \mathrm{C}$ ) and low-pressure densification processing route compared with other advanced manufacturing methods and can be very versatile, which prevents the heat damage to fibers [226]. The
CVI/CVD-derived ceramic matrix with high purity, high crystallinity, and near stoichiometry generally possesses more excellent mechanical, anti-oxidation and anti-ablation properties [227]. However, the CVI/CVD process typically takes $2-3$ months to achieve required densities and is therefore highly expensive $[228,229]$. As a result, almost no UHTCMCs fabricated completely by CVI/CVD have been reported, but it is a very common method for interphase and partial matrix fabrication.

(2) Precursor infiltration and pyrolysis (PIP)

PIP is a green-forming procedure to introduce UHTC matrix involving infiltration of a low viscosity liquid chemical precursor into fiber preforms and subsequent pyrolysis at elevated temperatures to yield ceramics (Fig. 16(a)). Compared with CVI, PIP has a larger infiltration depth and lower cost [230], and is the most widely used processing for UHTCMCs, particularly for large-size component fabrication. Due to the evolution of gaseous byproduct and volume shrinkage from precursor to ceramic, the formed ceramic matrix generally appears a porous structure (Figs. 16(b) and 16(c)) [231,232]. Generally, the infiltration and pyrolysis must be performed iteratively many times, until a matrix of the desired or otherwise limiting density is achieved [229]. Polycarbosilane (PCS) is the most common precursor used for $\mathrm{SiC}$ matrix [233]. Recently, the precursors for UHTCs matrix, such as zirconium butoxide for $\mathrm{ZrC}[234,235]$

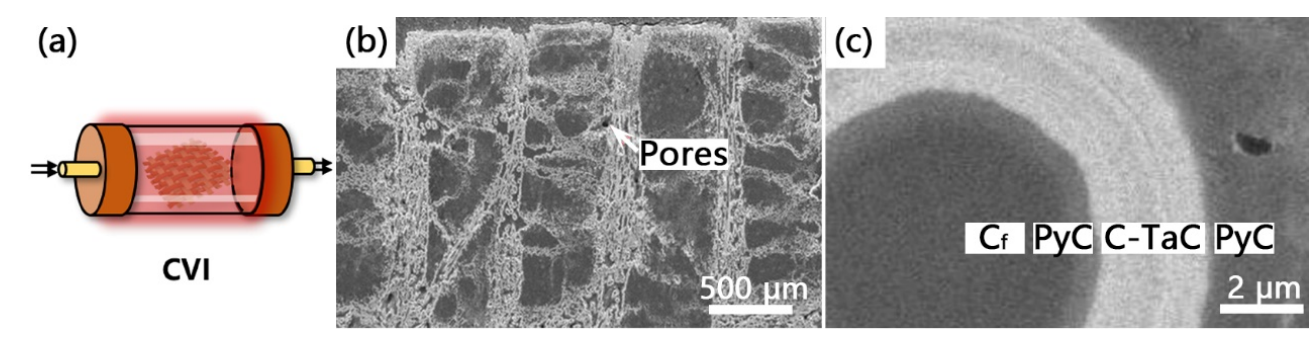

Fig. 15 Schematic diagram of CVI (a); microstructure of CVI- $\mathrm{C}_{\mathrm{f}} / \mathrm{C}-\mathrm{TaC}(\mathrm{b}, \mathrm{c})$. Reproduced with permission from Ref. [214], (C) Elsevier B.V. 2013.
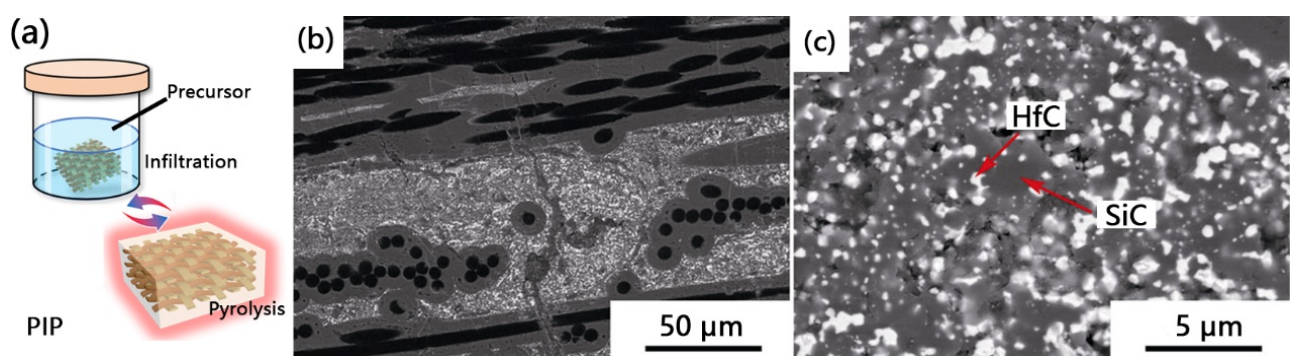

Fig. 16 Schematic diagram of PIP (a); microstructure of PIP- $\mathrm{C}_{\mathrm{f}} / \mathrm{HfC}-\mathrm{SiC}$ composites (b, c). Reproduced with permission from Ref. [232], (C) The Author(s) 2020. 
and organic zirconium-containing polymer for $\mathrm{ZrB}_{2}$ [236], have also been developed, which makes PIP more flexible to fabricate UHTCMCs. A high ceramic yield from precursors is important and the precursor choice is critical for PIP processing optimization.

(3) Slurry infiltration (SI)

For SI processing, slurry composed of ceramic powders, solvent, and dispersant is impregnated into the porous preform. Then, the solvent and organic components are removed during drying and de-binding. The quick and simple process makes SI the cheapest method for UHTCMC fabrication. However, due to the hindering effect of fibers, ceramic powders cannot be infiltrated uniformly into fiber preform and the infiltration depth of the powders is very limited. To improve the infiltration efficiency, slurry injection and vibration-assisted slurry impregnation were developed. Baker et al. [228] reported the slurry injection firstly (Fig. 17(a)), where the slurry penetrates much deeper in the preform than conventional vacuum impregnation (Figs. 17(b) and 17(c)). However, the injection process presents limited filling effect at the edges of the preform. Therefore, the joint process of vacuum impregnation and slurry injection can get a denser composite with homogenous matrix distribution. $\mathrm{Hu}$ et al. [176,237] reported vibration-assisted slurry impregnation for 3D needled-punched carbon fiber preforms (Fig. 18(a)). The process is conducted in a vacuum tank, and the vibrating frequency is $60 \mathrm{~Hz}$. The as-fabricated UHTCMCs show uniform component distribution and less open porosity (Figs. 18(b) and 18(c)). Consequently, the mechanical properties of composites fabricated by vibration-assisted slurry impregnation are improved as expected.

(4) Reactive melt infiltration (RMI)

RMI is another common method used to introduce UHTC matrix into porous preforms by infiltrating molten metals/alloys and in-situ reactions with the pre-matrix carbon or boron phase [238]. The process can get a near fully dense matrix with limited pores (Fig. 19). Therefore, composites usually perform better ablation resistance [209,239]. Compared with CVI and PIP methods, the RMI process is more efficient and costs less, which is beneficial for commercialization production [240,241]. Based on RMI processing route, mass production of $\mathrm{SiC}_{\mathrm{f}} / \mathrm{SiC}$ composite and components have been reported by General Electric for advanced CFM LEAP engine since 2016 [5]. However, fiber/interphase degradation is very common during RMI, which results in poor mechanical properties [242]. For the first time, Chen et al. [243] analyzed the interphase degradation behavior of RMI-UHTCMC systematically. It is revealed that chemical reaction and physical melting are the main interphase degradation
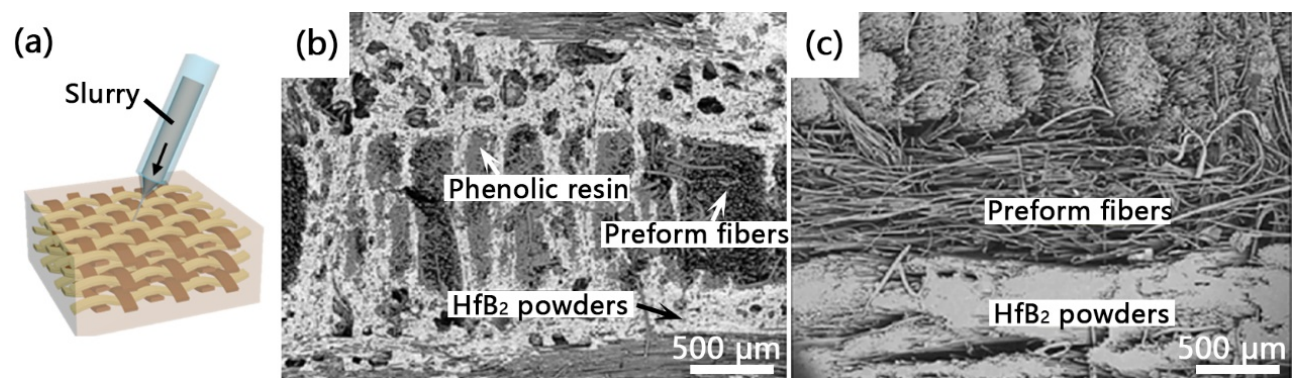

Fig. 17 Schematic diagram of slurry injection (a), microstructure of the $\mathrm{C}_{\mathrm{f}} / \mathrm{HfB}_{2}$ composites fabricated by slurry injection (b), and slurry impregnation (c). Reproduced with permission from Ref. [228], (c) Elsevier Ltd. 2019.
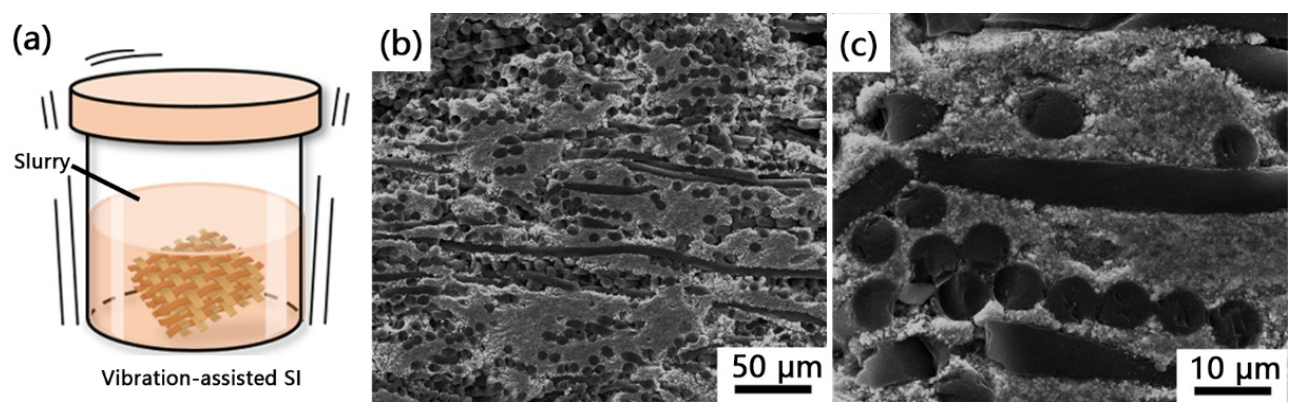

Fig. 18 Schematic diagram of vibration-assisted slurry impregnation (a); microstructures of the $\mathrm{C}_{\mathrm{f}} / \mathrm{ZrB}_{2}-\mathrm{SiC}$ composites fabricated by vibration-assisted slurry impregnation (b, c). Reproduced with permission from Ref. [176], C Elsevier Ltd. 2018. 


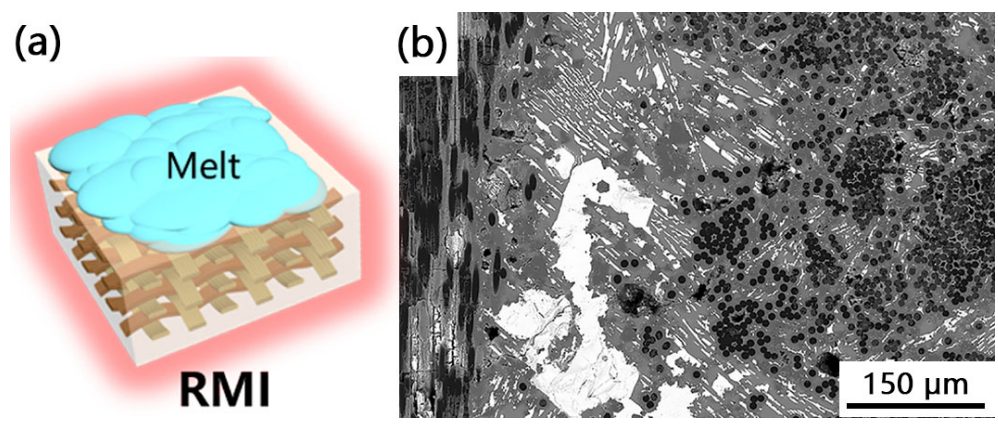

Fig. 19 Schematic diagram of RMI (a); typical microstructure of RMI- $\mathrm{C}_{\mathrm{f}} / \mathrm{ZrC}-\mathrm{SiC}$ composites (b). Reproduced with permission from Ref. [209], (C) The American Ceramic Society 2018.

mechanisms involved during RMI. Besides, residual metallic phase results in the decrease of mechanical and anti-ablation properties when the composites are operated at high temperatures [244].

The melt infiltration kinetics in terms of porous preform structure can be established to quantitively evaluate the microstructure evolution of the composites. Levenspiel [245] developed a mathematical model to express the relationship between pore size and infiltration time by assuming the reduction of pore size during RMI is a diffusion-limited process:

$$
t=\frac{M_{\mathrm{M}} \cdot \rho_{\mathrm{A}_{\mathrm{P}} \mathrm{B}_{\mathrm{M}}} \cdot r_{0}{ }^{2}}{6 \cdot M_{\mathrm{A}_{\mathrm{P}} \mathrm{B}_{\mathrm{M}}} \cdot \rho_{\mathrm{M}} \cdot D_{\mathrm{A}_{\mathrm{P}} / \mathrm{A}_{\mathrm{P}} \mathrm{B}_{\mathrm{M}}}}\left[1-3\left(\frac{r}{r_{0}}\right)^{2}+2\left(\frac{r}{r_{0}}\right)^{3}\right]
$$

where $M_{\mathrm{M}}, M_{\mathrm{A}_{\mathrm{P}} \mathrm{B}_{\mathrm{M}}}, \rho_{\mathrm{M}}$ and $\rho_{\mathrm{A}_{\mathrm{P}} \mathrm{B}_{\mathrm{M}}}$ are the molar weights of melt (M) and $A_{P} B_{M}$, densities of melt (M)

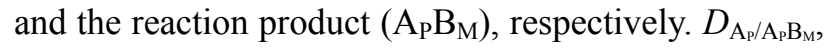
$t, r$, and $r_{0}$ are the diffusion coefficient of reaction atoms in reaction layer, reaction time, transient, and initial pore radius of the preform, respectively. $r_{0}$ is calculated based on Dullien formula:

$$
r_{0}=\frac{1}{3}\left(\sum_{i=1}^{k} r_{i}\right)^{2}\left[\sum_{i=1}^{k} r_{i} \sum_{j=1}^{k}\left(\frac{r_{i}}{r_{j}}\right)^{3}\right]^{-1}
$$

where $r_{i}(i=1,2, \ldots, k)$ is the characteristic pore radius measured by mercury porosimeter. The $r-t$ curves of the particular composites can be calculated by Eqs. (14) and (15). The critical time $\left(t_{\mathrm{c}}\right)$ is determined by $r-t$ curves at $r=0$. The longer the $t_{\mathrm{c}}$ is, the kinetically more favorable the melt infiltration is. Consequently, more sufficient melt can be infiltrated into the preform to form a more uniform phase distribution. Accordingly, the microstructure of the RMI-derived composites can be approximately predicted by $r-t$ curves [246].

(5) Slurry infiltration combined with subsequent sintering

Generally, UHTCMCs are not compulsorily required to sinter/consolidate like bulk ceramics. Recently, pressure assisted sintering processes like HP and SPS (Fig. 20(a)) are also used for the subsequent consolidation of UHTCMCs to improve their densification [247,248]. However, high temperature and pressure can lead to the damage of fibers and interphase (Figs. 20(b) and 20(c)) [248,249]. Zhang et al. [163] reduced the sintering temperature to $1450{ }^{\circ} \mathrm{C}$ by using nanosized ceramic powders and prevented the degradation of fibers to some extent. Zoli et al. [250] pointed out that the degradation of fibers caused by SPS can be alleviated by optimizing the interphase layer and the sintering parameters.

To avoid the disadvantages of the different processing methods, more researchers prefer to fabricate UHTCMCs using hybrid processing route. Servadei et al. [229]
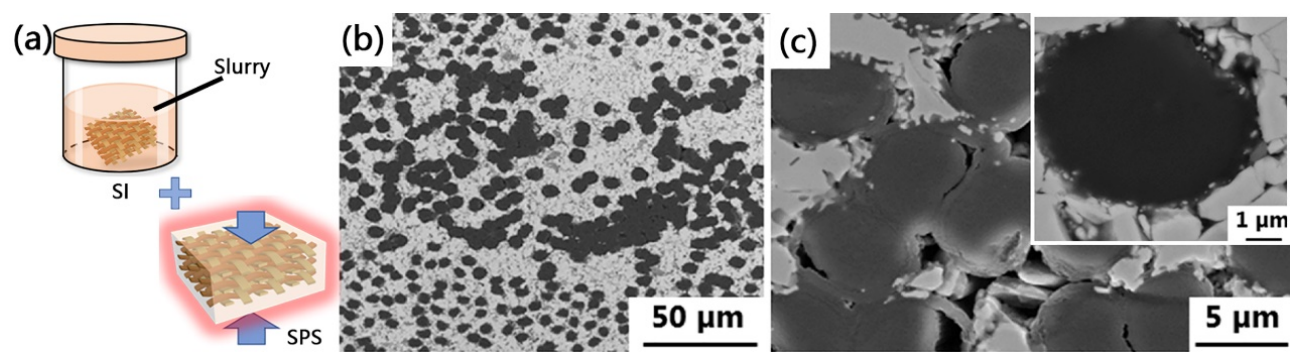

Fig. 20 Schematic diagram of vacuum slurry impregnation and SPS (a); microstructure of the polished $\mathrm{SPS}-\mathrm{C}_{\mathrm{f}} / \mathrm{ZrB} \mathrm{B}_{2}-\mathrm{SiC}$ composites (b, c). Reproduced with permission from Ref. [250], (c) Elsevier Ltd. 2019. 
fabricated dense $\mathrm{C}_{\mathrm{f}} / \mathrm{ZrB}_{2}-\mathrm{SiC}$ composites with low defectiveness by $\mathrm{ZrB}_{2}$ slurry infiltration coupled with polymer infiltration and pyrolysis. Yao et al. [251] fabricated $\mathrm{C}_{\mathrm{f}} / \mathrm{C}-\mathrm{SiC}-\mathrm{ZrC}$ composites by a joint $\mathrm{CVI}$ and PIP process, and the composites show better mechanical, anti-oxidation and anti-ablation properties. Zhang et al. [163,252,253] fabricated $\mathrm{C}_{\mathrm{f}} / \mathrm{ZrB}_{2}-\mathrm{SiC}$ composites by SI, PIP, and HP processes which avoid the fiber/matrix reactions and improve the fracture toughness. Ni et al. [209,239] fabricated $\mathrm{C}_{\mathrm{f}} / \mathrm{ZrC}-\mathrm{SiC}$ composites by sol-gel and RMI which effectively improves the mechanical and ablation resistance of the composites.

\section{3 Microstructure, mechanical and thermal properties of UHTCMCs}

Composites are toughened by fiber pull-out and crack deflection at the interphase. When the force is applied on the UHTCMCs, the load is transferred from the matrix to the fibers. For the $2 \mathrm{D}$ laminated $\mathrm{C}_{\mathrm{f}} / \mathrm{ZrB}_{2}-\mathrm{SiC}$, the special distribution of fibers and matrix induces higher residual stress in the matrix, which increases the number of cracks and reduces the matrix modulus [249]. Due to the weak bond among fiber layers, composites reinforced with 2D fiber preform generally show low interlaminar shear strength. This can be improved by adding vertical fibers or using $3 \mathrm{D}$ fiber preforms [254,255]. In addition, an intact interphase with suitable thickness is also required for excellent mechanical properties [256]. Multi-layer interphase has been proved beneficial for fibers protection and mechanical property improvement of the composites [257]. Typical properties of UHTCMCs fabricated by various processing routes are summarized in Table 4 .

Table 4 Typical properties of UHTCMCs fabricated by various processing routes

\begin{tabular}{|c|c|c|c|c|c|c|c|c|c|c|c|c|}
\hline \multirow{2}{*}{ Material } & \multirow{2}{*}{ Processing } & \multirow{2}{*}{$\begin{array}{l}\text { Density } \\
\left(\mathrm{g} \cdot \mathrm{cm}^{-3}\right)\end{array}$} & \multirow{2}{*}{$\begin{array}{l}\text { Open } \\
\text { porosity } \\
(\%)\end{array}$} & \multirow{2}{*}{$\begin{array}{l}\text { Flexural } \\
\text { strength } \\
(\mathrm{MPa})\end{array}$} & \multirow{2}{*}{$\begin{array}{c}\text { Elastic } \\
\text { modulus } \\
(\mathrm{GPa})\end{array}$} & \multirow{2}{*}{$\begin{array}{l}\text { Ablation } \\
\text { method }\end{array}$} & \multicolumn{2}{|c|}{ Temperature $\left({ }^{\circ} \mathrm{C}\right)$} & \multirow{2}{*}{$\begin{array}{c}\text { Ablation } \\
\text { time (s) }\end{array}$} & \multirow{2}{*}{$\begin{array}{l}\text { Heat flux } \\
\left(\mathrm{MW} \cdot \mathrm{m}^{-2}\right)\end{array}$} & \multirow{2}{*}{ Ablation rate } & \multirow{2}{*}{ Ref. } \\
\hline & & & & & & & Flame & Surface & & & & \\
\hline $3 \mathrm{D}-\mathrm{C}_{\mathrm{f}} / \mathrm{C}-\mathrm{TaC}$ & CVI & 5.48 & 5 & 196.8 & & & & & & & & [214] \\
\hline $3 \mathrm{D}-\mathrm{C}_{\mathrm{f}} / \mathrm{ZrB}_{2}-\mathrm{SiC}$ & $\mathrm{SI}+\mathrm{HP}$ & 2.93 & 3.7 & $169 \pm 12$ & & & & & & & & {$[176]$} \\
\hline $1 \mathrm{D}-\mathrm{C}_{\mathrm{f}} / \mathrm{ZrB}_{2}-\mathrm{SiC}$ & $\mathrm{SI}+\mathrm{HP}$ & 3.8 & 10 & $320 \pm 10$ & & & & & & & & \multirow{2}{*}{250} \\
\hline $1 \mathrm{D}-\mathrm{C}_{\mathrm{f}} / \mathrm{ZrB}_{2}-\mathrm{SiC}$ & $\mathrm{SI}+\mathrm{SPS}$ & 4.0 & 5 & $260 \pm 20$ & & & & & & & & \\
\hline $2.5 \mathrm{D}-\mathrm{C}_{\mathrm{f}} / \mathrm{HfB}_{2}-\mathrm{C}$ & $\begin{array}{l}\text { Slurry } \\
\text { injection } \\
+ \text { CVI }\end{array}$ & $3.2 \pm 0.16$ & 16 & $121.4 \pm 18.3$ & $28.3 \pm 3.2$ & & & & & & & [196] \\
\hline $2 \mathrm{D}-\mathrm{C}_{\mathrm{f}} / \mathrm{ZrB}_{2}-\mathrm{SiC}$ & $\mathrm{SI}+\mathrm{PIP}$ & 3.2 & 6 & $491 \pm 44$ & $220 \pm 9$ & & & & & & & [229] \\
\hline $3 \mathrm{D}-\mathrm{C}_{\mathrm{f}} / \mathrm{ZrB}_{2}-\mathrm{SiC}$ & $\begin{array}{c}\text { Vibration- } \\
\text { assisted } \\
\text { SI+HP }\end{array}$ & 4.10 & 2.6 & $204 \pm 18$ & & & & & & & & {$[176]$} \\
\hline $2.5 \mathrm{D}-\mathrm{C}_{\mathrm{f}} / \mathrm{C}-\mathrm{ZrC}-\mathrm{SiC}$ & CLVD & & & & & OAT & $\sim 3000$ & & 60 & 4.18 & $\begin{array}{l}1210 \mathrm{mg} \cdot \mathrm{s}^{-1} \\
1160 \mu \mathrm{m} \cdot \mathrm{s}^{-1}\end{array}$ & [258] \\
\hline $2 \mathrm{D}-\mathrm{C}_{\mathrm{f}} / \mathrm{C}-\mathrm{HfB}_{2}$ & $\mathrm{PIP}+\mathrm{CVI}$ & $1.77-1.84$ & & & & OAT & & $\sim 2150$ & 90 & 4.18 & $\begin{array}{c}2.75 \mathrm{~g} \cdot \mathrm{m}^{-2} \cdot \mathrm{s}^{-1} \\
3.14 \mu \mathrm{m} \cdot \mathrm{s}^{-1}\end{array}$ & [211] \\
\hline $2 \mathrm{D}-\mathrm{C}_{\mathrm{f}} / \mathrm{ZrB}_{2}-\mathrm{SiC}$ & $\mathrm{SI}+\mathrm{PIP}$ & 2.15 & $\sim 8.6$ & & & $\begin{array}{l}\text { Plasma } \\
\text { torch }\end{array}$ & & 2500 & 300 & & $\begin{array}{l}3.07 \mathrm{~g} \cdot \mathrm{m}^{-2} \cdot \mathrm{s}^{-1} \\
1.05 \mu \mathrm{m} \cdot \mathrm{s}^{-1}\end{array}$ & [259] \\
\hline $3 \mathrm{D}-\mathrm{C}_{\mathrm{f}} / \mathrm{C}-\mathrm{SiC}-\mathrm{ZrC}$ & PIP & 1.94 & 8.5 & & & $\begin{array}{l}\text { Plasma } \\
\text { torch }\end{array}$ & & 2300 & 60 & & $\begin{array}{l}0.56 \mathrm{mg} \cdot \mathrm{s}^{-1} \\
16.33 \mu \mathrm{m} \cdot \mathrm{s}^{-1}\end{array}$ & [260] \\
\hline $3 \mathrm{D}-\mathrm{C}_{\mathrm{f}} / \mathrm{ZrC}-\mathrm{SiC}$ & PIP & 2.11 & 15 & $136.0 \pm 13.1$ & $31.8 \pm 2.6$ & OAT & $\sim 3000$ & & 40 & 4.2 & $\begin{array}{c}8.8 \pm 0.4 \mathrm{mg} \cdot \mathrm{s}^{-1} \\
23 \pm 1 \mu \mathrm{m} \cdot \mathrm{s}^{-1}\end{array}$ & [230] \\
\hline $3 \mathrm{D}-\mathrm{C}_{\mathrm{f}} / \mathrm{ZrC}-\mathrm{SiC}$ & PIP & 2.13 & 18 & $142.4 \pm 17.5$ & $19.2 \pm 2.9$ & OAT & 3000 & & 80 & 4.2 & $\begin{array}{l}11.7 \mathrm{mg} \cdot \mathrm{s}^{-1} \\
31.8 \mu \mathrm{m} \cdot \mathrm{s}^{-1}\end{array}$ & [231] \\
\hline $3 \mathrm{D}-\mathrm{C}_{\mathrm{f}} / \mathrm{HfC}-\mathrm{SiC}$ & PIP & $3.18 \pm 0.04$ & $13.2 \pm 0.4$ & & & $\begin{array}{l}\text { Plasma } \\
\text { wind } \\
\text { tunnel }\end{array}$ & & $1706-2454$ & 600 & & $\begin{array}{l}0.87 \mathrm{mg} \cdot \mathrm{s}^{-1} \\
0.067 \mu \mathrm{m} \cdot \mathrm{s}^{-1}\end{array}$ & {$[232]$} \\
\hline $3 \mathrm{D}-\mathrm{C}_{\mathrm{f}} / \mathrm{ZrC}-\mathrm{SiC}$ & PIP & 2.18 & 4.9 & $749 \pm 15$ & $141 \pm 12$ & & & & & & & {$[233]$} \\
\hline $3 \mathrm{D}-\mathrm{C}_{\mathrm{f}} / \mathrm{ZrC}-\mathrm{SiC}$ & RMI & 2.64 & 3.5 & & & $\begin{array}{c}\text { Plasma } \\
\text { torch }\end{array}$ & & $\sim 1890$ & 60 & 4.02 & $\begin{array}{l}6.97 \mathrm{mg} \cdot \mathrm{s}^{-1} \\
0.29 \mu \mathrm{m} \cdot \mathrm{s}^{-1}\end{array}$ & [239] \\
\hline $3 \mathrm{D}-\mathrm{C}_{\mathrm{f}} / \mathrm{ZrC}-\mathrm{SiC}$ & RMI & 2.52 & 1.7 & 380 & 61 & & & & & & & [209] \\
\hline $3 \mathrm{D}-\mathrm{C}_{\mathrm{f}} / \mathrm{SiC}-\mathrm{ZrC}-\mathrm{TiC}$ & RMI & 3.25 & 9.7 & & & OAT & & 2500 & 60 & & $\begin{array}{l}0.008 \mathrm{mg} \cdot \mathrm{s}^{-1} \\
0.000 \mu \mathrm{m} \cdot \mathrm{s}^{-1}\end{array}$ & [219] \\
\hline $3 \mathrm{D}-\mathrm{C}_{\mathrm{f}} / \mathrm{C}-\mathrm{SiC}-\mathrm{ZrC}$ & RMI & 2.42 & 5.0 & $143.5 \pm 11.2$ & $13.4 \pm 3.3$ & OAT & & $\sim 2400$ & 60 & 4.18 & $\begin{array}{c}1.21 \pm 0.33 \mathrm{mg} \cdot \mathrm{s}^{-1} \\
5.90 \pm 0.90 \mu \mathrm{m} \cdot \mathrm{s}\end{array}$ & [240] \\
\hline
\end{tabular}


The microstructure and mechanical properties of UHTCMCs depend greatly on the processing methods and the form of the reinforcements. Introducing ceramic powders into fiber preforms does not always result in a homogeneous distribution of the UHTC phase. This is very common for the composites reinforced with $2 \mathrm{D}$ plain cloth or more complex fiber preform. UHTC powders prefer to concentrate among fiber bundles due to the poor infiltrating effect inside the fiber bundles. Therefore, composites fabricated by SI generally need to be further densified and the as-fabricated composites possess an inhomogeneous phase distribution in the matrix area. For example, 2D plain cloth infiltrated with $\mathrm{ZrB}_{2}$ slurry is densified by PIP process which results in the concentration of $\mathrm{ZrB}_{2}$ in inter-bundle area and $\mathrm{SiC}$ in intra-bundle area (Fig. 21) [198,261]. This particular microstructure results in weak interlaminar bonding strength and thermal mismatch between the fiber bundles and matrix.

The UHTC matrix formed by PIP experiences volume shrinkage combining with the gas release. As a result, pores and cracks are very common in the composites [237,262]. Take the $\mathrm{C}_{\mathrm{f}} / \mathrm{C}-\mathrm{ZrC}-\mathrm{SiC}-\mathrm{ZrB}_{2}$ composites fabricated by SI and PIP as an example. The CTE of PyC interphase is higher than that of carbon fibers. Carbon fibers are compressed by PyC interphase at ambient temperature and are stretched at the temperature above $1100{ }^{\circ} \mathrm{C}$ along the radial and axial directions. Therefore, the bond of fiber and interphase is enhanced at ambient temperature and weakened at the temperatures above $1100{ }^{\circ} \mathrm{C}$ (Fig. 22(a)).
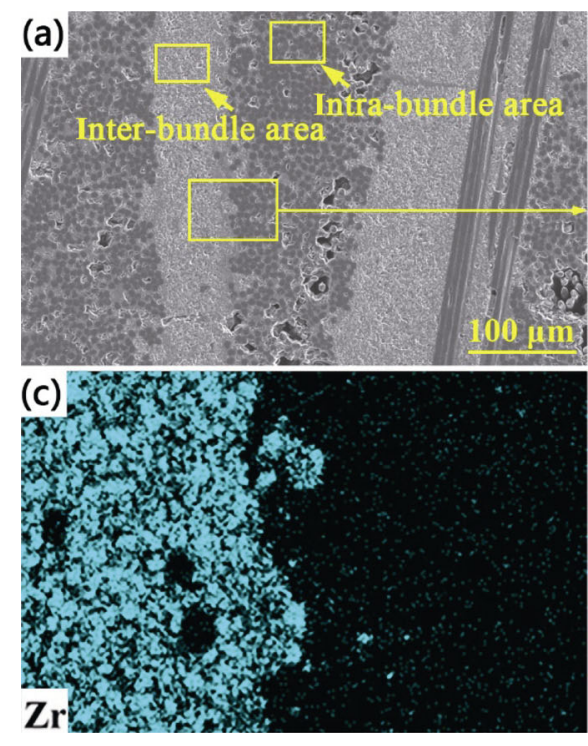

Fig. 21 Microstructures of $2 \mathrm{D}-\mathrm{C}_{\mathrm{f}} / \mathrm{ZrB}_{2}-\mathrm{SiC}$ composites $(\mathrm{a}, \mathrm{b})$, and the EDS analysis of $(\mathrm{b})(\mathrm{c}, \mathrm{d})$. Reproduced with permission from Ref. [198], (C) Elsevier Ltd. 2020.
The weaker bond of fiber-interphase at high temperatures benefits to the crack deflection, fiber breakage, and pull-out. Consequently, the tensile strength of the composites at $1700{ }^{\circ} \mathrm{C}$ is higher than that at ambient temperature (Figs. 22(b)-22(d)). However, the mechanical properties of the composites decrease above $1800{ }^{\circ} \mathrm{C}$ due to the fiber damage and looser matrix at elevated temperature [263].

The composites fabricated by SI and further densified by subsequent HP or SPS possess higher density and lower porosity [264-266]. Due to the high sintering temperature and pressure (up to $1900{ }^{\circ} \mathrm{C}$, $40 \mathrm{MPa}$ ), the reactions between oxide impurity on the powder surface and fibers cannot be ignored. Generally, the fibers react with oxide impurities and result in chemical etching. Strong bonding between fibers and matrix is formed (Fig. 20(c)), which results in the failure of fiber pull-out and crack deflection. As a result, the composites possess a low flexural strength and fracture toughness. Coating PyC interphase with a suitable thickness on the fibers is an effective way to mitigate the chemical etching and offers a weak bonding to improve the toughness [249,267,268]. On the other hand, the high sintering temperature and pressure result in high residual stress in the composites, which can be released at high temperatures. Therefore, the mechanical properties increase with the increase of temperature. Furthermore, the grain boundary of the ceramic matrix tends to slide at high temperatures, which results in the plastic deformation of the composite [265].
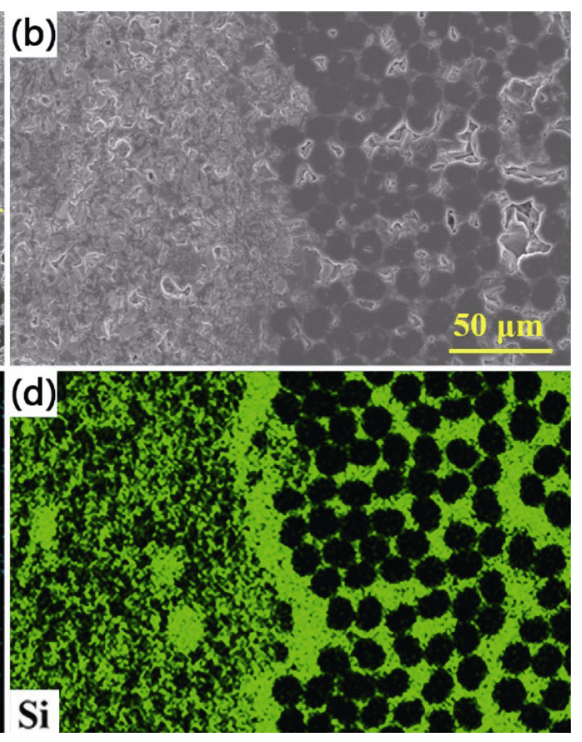


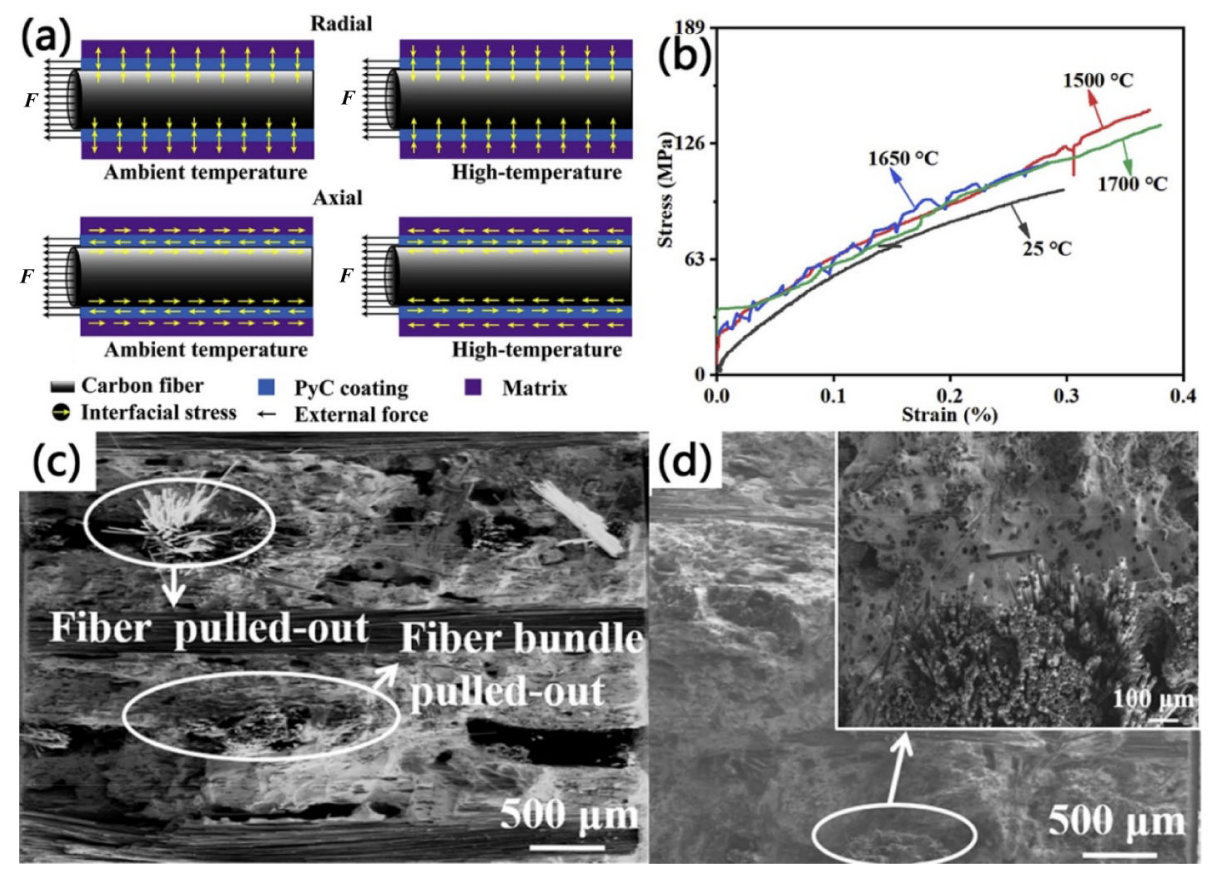

Fig. 22 Interphase stress distribution at ambient temperature and high temperature (a), stress-strain curves of $\mathrm{C}_{\mathrm{f}} / \mathrm{C}-\mathrm{ZrC}-$ $\mathrm{SiC}-\mathrm{ZrB}_{2}$ composites during tensile test at different temperatures (b), and fracture surfaces of $\mathrm{C}_{\mathrm{f}} / \mathrm{C}-\mathrm{ZrC}-\mathrm{SiC}-\mathrm{ZrB}{ }_{2}$ composites after tensile test at ambient temperature (c) and $1700{ }^{\circ} \mathrm{C}$ (d). Reproduced with permission from Ref. [263], (C) Elsevier B.V. 2019.

As discussed above, UHTCMCs fabricated by CVI are rarely reported. The limited infiltration depth results in large pores in the UHTCMCs (Fig. 15) [269,270]. For the UHTCMCs fabricated by RMI, they normally show high matrix density and low porosity. However, bulk metal and carbon residues generally exist in the composites due to kinetic factors. Moreover, the metal melt usually erodes fibers and interphase during RMI. As a result, the composites exhibit brittle fracture characteristics. Therefore, optimizing interphase structure and RMI kinetics are critical for enhanced mechanical properties of the UHTCMCs fabricated by RMI [271]. Ni et al. [209] developed a novel RMI route for $\mathrm{C}_{\mathrm{f}} / \mathrm{ZrC}-\mathrm{SiC}$ fabrication by infiltrating $\mathrm{Si}$ melt into nano-porous $\mathrm{C}_{\mathrm{f}} / \mathrm{ZrC}-\mathrm{C}$ preforms, where the nanoporous $\mathrm{C}_{\mathrm{f}} / \mathrm{ZrC}-\mathrm{C}$ preforms were prepared through a colloid process, with a $\mathrm{ZrC}$ "protective coating" formed surrounding the carbon fibers. The $\mathrm{ZrC}$ "coating" can protect the fibers and interphase to a certain extent from high-temperature Si melt erosion during RMI process (Fig. 23). Besides, the well distributed nano-porous structure is beneficial to forming a dense composite with limited Si residue during RMI process. Moreover, the needle-shaped $\mathrm{ZrSi}_{2}$ grains formed during the cooling stage which act as reinforcement of the matrix (Fig. 19(b)). Consequently, flexural strength of the composites is as high as $\sim 380 \mathrm{MPa}$, which is much higher than those UHTCMCs fabricated by conventional RMI method.

Chen et al. [272] fabricated $\mathrm{C}_{\mathrm{f}} / \mathrm{ZrC}$ composites by introducing $\mathrm{Zr}$ melt into $\mathrm{C}_{\mathrm{f}} / \mathrm{C}$ preform through $\mathrm{RMI}$. It is indicated that there is $\sim 4.2 \mathrm{vol} \%$ residual $\mathrm{Zr}$ is present
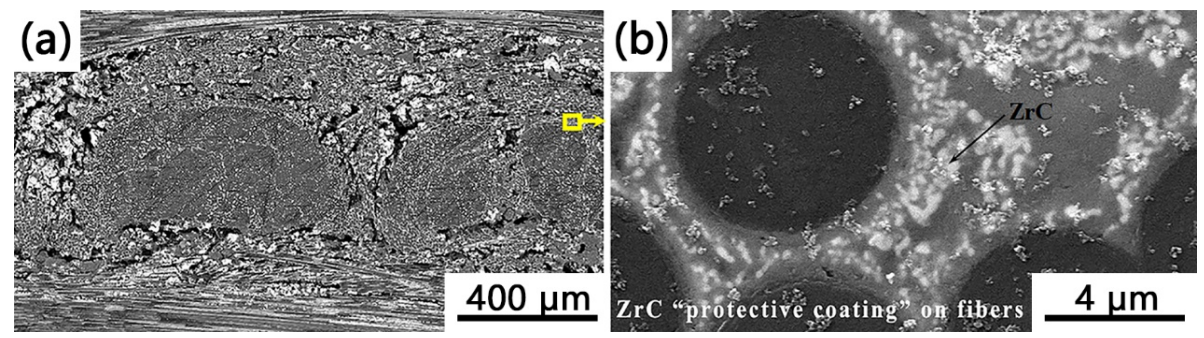

Fig. 23 Microstructure of the nano-porous $\mathrm{C}_{\mathrm{f}} / \mathrm{ZrC}-\mathrm{C}$ preforms, with a $\mathrm{ZrC}$ "protective coating" formed surrounding the carbon fibers: low magnification of $\mathrm{C}_{\mathrm{f}} / \mathrm{ZrC}-\mathrm{C}$ preform (a) and $\mathrm{ZrC}$ "protective coating" surrounding carbon fibers (b). Reproduced with permission from Ref. [209], (C) The American Ceramic Society 2018. 
in the $\mathrm{RMI}-\mathrm{C}_{\mathrm{f}} / \mathrm{ZrC}$, which is harmful to the hightemperature mechanical properties. Subsequent hightemperature annealing at $\sim 1600{ }^{\circ} \mathrm{C}$ can properly consume the residual $\mathrm{Zr}$ and get an optimum flexural strength of $192 \mathrm{MPa}$. However, at higher heat-treatment temperatures, fiber deterioration will become serious and lead to the decrease of strength.

Thermal properties, such as thermal expansion coefficient (CTE), thermal diffusivity, thermal conductivity, and specific heat, are critical to UHTCMCs and are significantly affected by phase content and microstructure of the composites. The vast difference of CTE between fibers and ceramic matrix induces residue stress and cracks in composites after the fabrication process. As a result, the strength and elastic modulus of conventional UHTCMCs are relatively lower than $\mathrm{SiC}_{\mathrm{f}} / \mathrm{SiC}$ composites. Chen et al. [273] designed a porous $\mathrm{SiC}$ coating in $\mathrm{C} / \mathrm{ZrC}$ to mitigate the CTE mismatch and thermal stress between $\mathrm{C}$ fibers and $\mathrm{ZrC}$ matrix, which effectively enhanced the mechanical properties of the composites. Carbon fibers have highly anisotropic thermal properties along different directions. Generally, the axial CTE of carbon fibers is negligible and the radial CTE is $\sim 10 \times 10^{-6}{ }^{\circ} \mathrm{C}^{-1}$. Due to the anisotropic $3 \mathrm{D}$ stacked structure in the fiber preforms, the thermal properties of the composites show significant differences among different directions. UHTCMCs with particular thermal properties can be designed by modifying microstructure and components [21].

\section{4 Oxidation and ablation behavior of UHTCMCs}

(1) Oxidation behavior and mechanisms of UHTCMCs Oxidation and ablation resistant properties are critical for the practical application of UHTCMCs. Generally, the oxidation and ablation resistance of UHTCMCs are dependent much on the composition and microstructure of the oxide layers formed on the surface, which might protect the composites from further oxidation/ablation damage. The UHTCMCs with $\mathrm{ZrB}_{2}-\mathrm{SiC}$ matrix show familiar oxidation behavior with bulk UHTCs which form a dense outside layer, $\mathrm{ZrO}_{2}-\mathrm{SiO}_{2}$ middle layer and $\mathrm{SiC}$ depleted layer [274]. Tang et al. [24] analyzed the oxidation behavior of $\mathrm{C}_{\mathrm{f}} / \mathrm{ZrB}_{2}-\mathrm{SiC}$ composites. It is indicated that $\mathrm{B}_{2} \mathrm{O}_{3}$ formed from the oxidation of $\mathrm{ZrB}_{2}$ matrix under $1000{ }^{\circ} \mathrm{C}$. The glassy $\mathrm{B}_{2} \mathrm{O}_{3}$ phase plays a positive role in oxidation resistance by covering the underneath composites and filling the pores and microcracks. However, the vast evaporation of $\mathrm{B}_{2} \mathrm{O}_{3}$ and limited $\mathrm{SiO}_{2}$ formation under $1200{ }^{\circ} \mathrm{C}$ result in the less protection capability of the oxide layer. With the increase of temperature, adequate glassy $\mathrm{SiO}_{2}$ with low viscosity formed which can also cover the composites, fill the pores and cracks to reduce the oxygen diffusivity of the oxide layer. Consequently, the oxidation resistance of the composites remains stable at $1200-1400{ }^{\circ} \mathrm{C}$ (Fig. 24) [24,275].

Vinci et al. [216] investigated the influence of $\mathrm{SiC}$ content on the oxidation behavior of $\mathrm{C}_{\mathrm{f}} / \mathrm{ZrB}_{2}-\mathrm{SiC}$
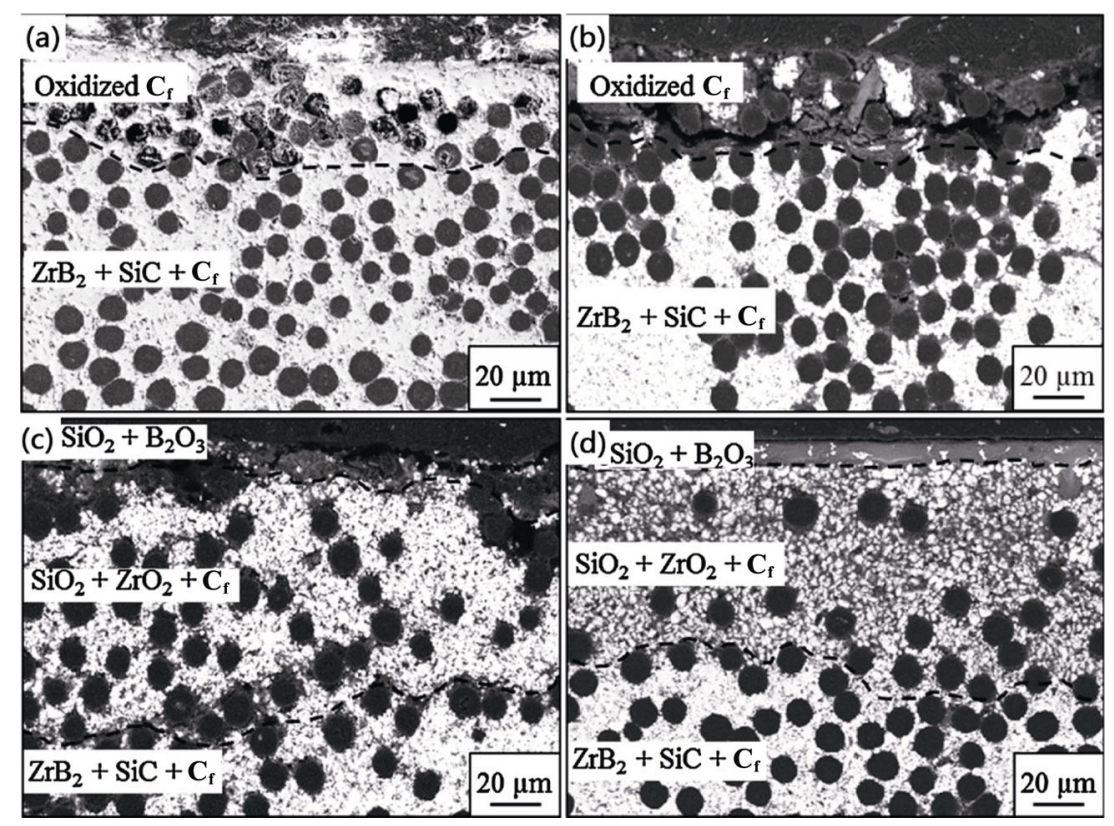

Fig. 24 Cross sections of $\mathrm{C}_{\mathrm{f}} / \mathrm{ZrB}_{2}-\mathrm{SiC}$ after 6-h oxidation in flowing air at $800{ }^{\circ} \mathrm{C}$ (a), $1000{ }^{\circ} \mathrm{C}$ (b), $1200{ }^{\circ} \mathrm{C}$ (c), and $1400{ }^{\circ} \mathrm{C}$ (d). Reproduced with permission from Ref. [275], (C) The Authors 2017. 
composites at higher temperature $\left(1500\right.$ and $\left.1650{ }^{\circ} \mathrm{C}\right)$. For the composites with the $\mathrm{SiC}$ content less than $5 \mathrm{vol} \%$, the formed oxide layer has limited glassy $\mathrm{SiO}_{2}$, leading to the excessive oxidation of the carbon fibers and rupture of the oxide layer. The porous oxide layer possesses a limited protective effect and results in the further oxidation of the underneath material. For the $\mathrm{C}_{\mathrm{f}} / \mathrm{ZrB}_{2}-\mathrm{SiC}$ with $\mathrm{SiC}$ content more than $15 \mathrm{vol} \%$, dense borosilicate layer could be formed to the whole composites, leading to the improvement of the oxidation resistance (Fig. 25). Accordingly, $\mathrm{C}_{\mathrm{f}} / \mathrm{ZrB}_{2}-\mathrm{SiC}$ composites with $\mathrm{SiC}$ content above $15 \mathrm{vol} \%$ is needed to get an ideal anti-oxidation property.

$\mathrm{Y}_{2} \mathrm{O}_{3}$ addition is expected to improve the oxidation resistance of $\mathrm{C}_{\mathrm{f}} / \mathrm{ZrB}_{2}-\mathrm{SiC}$ through enhancing the sintering process and forming a denser $\mathrm{ZrO}_{2}$ layer on the oxidation surface. The Y-based secondary phases promoted the growth of $\mathrm{ZrO}_{2}$ grains at $1500{ }^{\circ} \mathrm{C}$. The large $\mathrm{ZrO}_{2}$ grains are surrounded by yttrium borate on the surface, and the inner oxide layer is $\mathrm{ZrO}_{2} / \mathrm{SiO}_{2} /$ $\mathrm{YBO}_{2}$ phase. However, as the temperature rises to $1650{ }^{\circ} \mathrm{C}$, the outer oxide layer becomes porous due to the partial evaporation of low melting phases coupled with insufficient $\mathrm{SiO}_{2}$ protective layer (Fig. 26). As a result, oxidation resistance degrades after adding $\mathrm{Y}_{2} \mathrm{O}_{3}$. But, the influence of the $\mathrm{Y}_{2} \mathrm{O}_{3}$ content on the oxidation resistance has not been well investigated, which is of significance to be analyzed in the further research [276].

Compared with $\mathrm{ZrB}_{2}-\mathrm{SiC}$ matrix composites,
UHTCMCs with ZrC-SiC matrix have a similar oxidation behavior. However, due to the lack of glassy phase and the release of $\mathrm{CO}, \mathrm{CO}_{2}$ by $\mathrm{ZrC}$ oxidation, the UHTCMCs with $\mathrm{ZrC}-\mathrm{SiC}$ matrix have a more porous and less protective oxide layer below $1200{ }^{\circ} \mathrm{C}$. Therefore, $\mathrm{C}_{\mathrm{f}} / \mathrm{ZrC}-\mathrm{SiC}$ has worse oxidation resistance than $\mathrm{C}_{\mathrm{f}} / \mathrm{ZrB}_{2}-\mathrm{SiC}$ composites [5,251]. Adding $2 \mathrm{wt} \%$ $\mathrm{La}_{2} \mathrm{O}_{3}$ in $\mathrm{ZrB}_{2}-$ and $\mathrm{HfB}_{2}-20$ vol\% $\% \mathrm{SiC}$ matrix can increase the viscosity of glassy borosilicate melt and lower the oxygen diffusion coefficient at the temperature range of $1400-1600{ }^{\circ} \mathrm{C}$, leading to improved oxidation resistance [277].

$\mathrm{TaC}$ is another matrix component that is chosen to bear oxidation. Chen et al. [278] investigated the oxidation behavior of the $\mathrm{C}_{\mathrm{f}} / \mathrm{C}-\mathrm{TaC}$ composites. After 40 min oxidation at $1200-1600{ }^{\circ} \mathrm{C}$, a smooth oxide layer $\left(\mathrm{TaC}_{x} \mathrm{O}_{y}\right)$ with a large number of parallel self-healed cracks formed on the sample surface. Even the dense oxide layer has been formed, the oxidation process is controlled by surface kinetics of oxygen diffusion in the initial stage of $0-10 \mathrm{~min}$. After oxidation for $10 \mathrm{~min}$, the oxidation process is controlled by the diffusion of the oxygen in $\mathrm{TaC}_{x} \mathrm{O}_{y}$ layer.

In particular, composites show anisotropic oxidation behavior due to the existence of reinforcement fibers. Carbon fibers are vulnerable when exposed to oxidation environment and can be oxidized violently. When the oxidation takes place along the fiber layer, the fibers are consumed and left the holes as oxygen diffusion

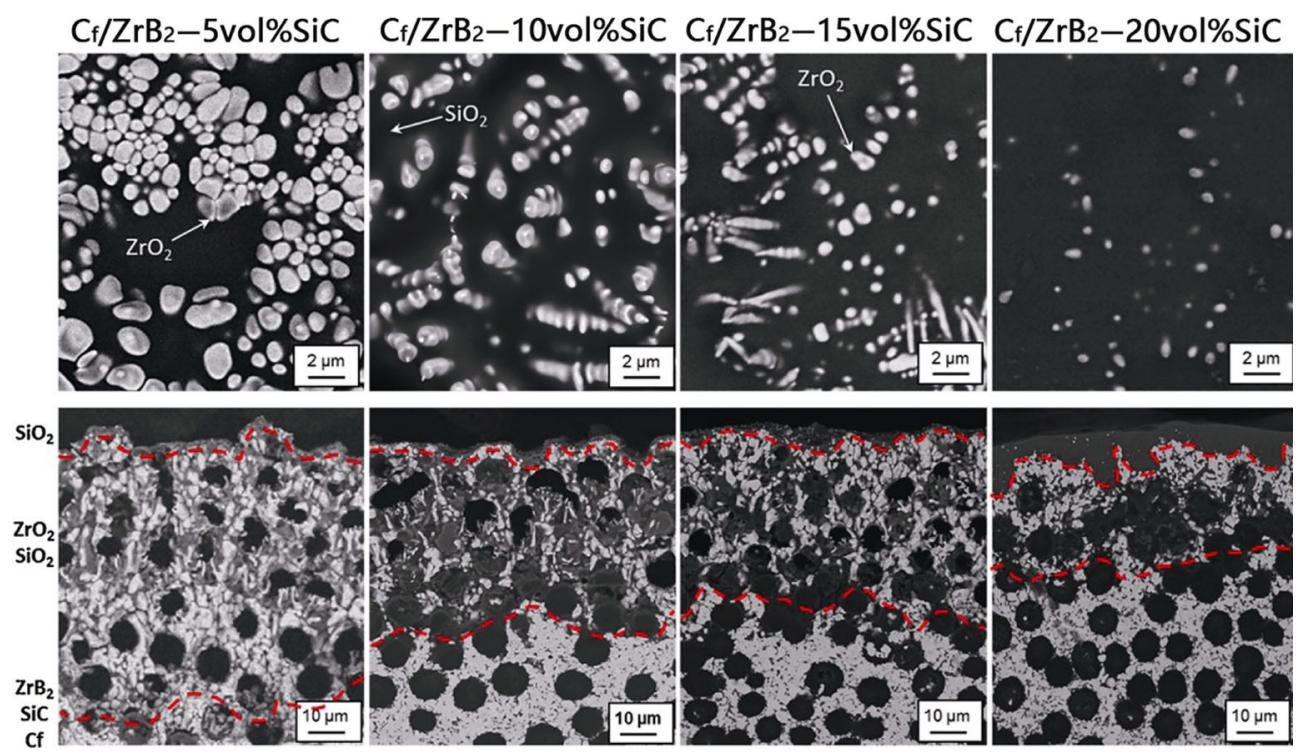

Fig. 25 Microstructure of the surface (top) and cross section (bottom) of $\mathrm{C}_{\mathrm{f}} / \mathrm{ZrB}_{2}-\mathrm{SiC}$ with different $\mathrm{SiC}$ contents after oxidation at $1650{ }^{\circ} \mathrm{C}$. Reproduced with permission from Ref. [216], (C) Elsevier Ltd. 2018. 

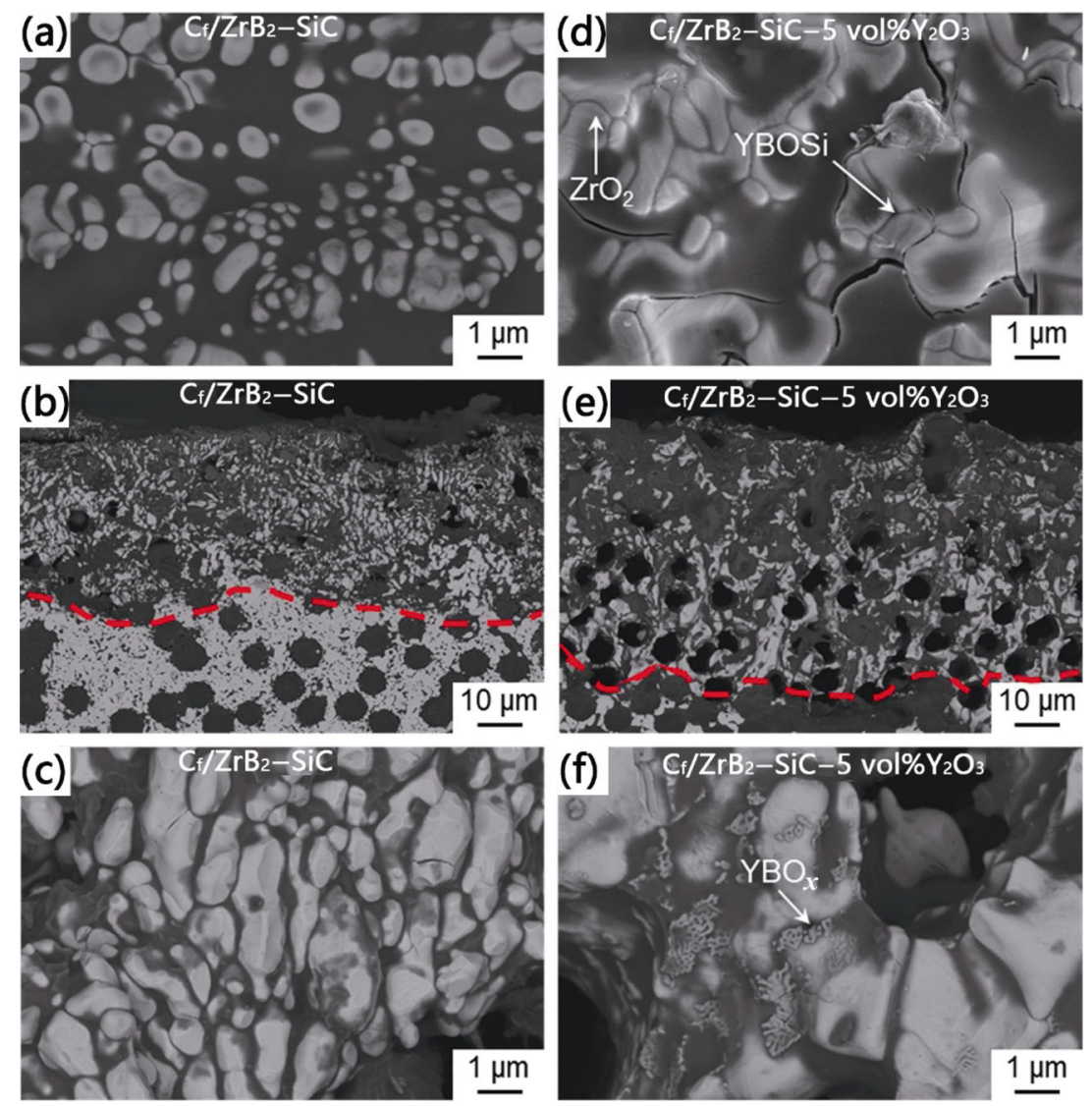

Fig. 26 Microstructures of $\mathrm{C}_{\mathrm{f}} / \mathrm{ZrB}_{2}-\mathrm{SiC}$ and $\mathrm{C}_{\mathrm{f}} / \mathrm{ZrB}_{2}-\mathrm{SiC}-5$ vol\% $\% \mathrm{Y}_{2} \mathrm{O}_{3}$ composites after oxidation at $1650{ }^{\circ} \mathrm{C}$ in air: surface morphology (a, d), cross-sections of the oxide layer (b, e), and detail of the oxide layer (c, f). Reproduced with permission from Ref. [276], C Elsevier Ltd. 2020.

channel which is negative to oxidation resistance. When the oxidation direction is perpendicular to the fibers layer, the fibers are oxidized fast and the ceramic matrix will be exposed. The ceramic matrix will be oxidized to denser oxide layer and resist the further oxidation [216].

(2) Ablation behavior and mechanisms of UHTCMCs

Partially due to temperature restriction of furnace, oxidation test mainly processed at a temperature below $2000{ }^{\circ} \mathrm{C}$. However, UHTCMCs are generally designed for applications at above $2000{ }^{\circ} \mathrm{C}$, which also need to withstand the vast scouring of corrosive/oxidative air. Therefore, more work is focused on the ablation behavior and mechanisms of UHTCMCs, which is closer to their service environments. The ablation test methods, such as oxyacetylene flame, oxypropane flame, plasma flame, arc jet, and wind tunnel, etc., are developed to simulate the service environments of UHTCMCs. Oxyacetylene and oxypropane tests are the most common and cheapest methods which provide similar temperature and heat flux conditions. However, the gas velocity is relatively slow. More researchers tend to use plasma flame test as it can provide more serious ablation conditions. In particular, arc jet and wind tunnel are the best methods to simulate the service environment of the UHTCMCs. However, these two techniques are quite expensive, which restrict their wide applications [257,279-282].

UHTCMCs show good ablation resistance and their ablation mechanisms are widely studied. Generally, the ablation resistance of UHTCMCs is realized by forming oxide layer with a high melting point [283-286]. Glassy phase is also needed to fill up the cracks and pores to form a dense oxide layer, which can prevent the inward diffusion of the oxygen. For the matrix with boride UHTCs, $\mathrm{B}_{2} \mathrm{O}_{3}$ evaporates violently during high-temperature ablation and cannot directly protect composites by forming borosilicate, due to the higher ablation temperature and the vast scouring of ablation flame. Some $\mathrm{B}_{2} \mathrm{O}_{3}$ may exist in the oxide scale due to the incomplete evaporation or the continued production of the $\mathrm{B}_{2} \mathrm{O}_{3}$ beneath the outer scale. It 
should be noted that the evaporation of $\mathrm{B}_{2} \mathrm{O}_{3}$ can dissipate heat accumulation and alleviated the damage to the composites induced by heat flux [282].

$\mathrm{SiC}$ addition can improve the ablation resistance at medium and high temperature by forming a glassy $\mathrm{SiO}_{2}$ phase. However, ablation resistance of the composites at ultra-high temperature will be degraded if the $\mathrm{SiC}$ volume fraction in the matrix is too high, where the glassy $\mathrm{SiO}_{2}$ phase cannot exist stably under ultra-high temperature combustion gas scouring [287]. High melting point oxides from the UHTCs matrix are the key anti-ablative components for the ablation resistance of UHTCMCs at ultra-high temperature extreme conditions. The as-formed solid skeleton of oxides with a high melting point supports and retains the glassy $\mathrm{SiO}_{2}$ phase. Taking $\mathrm{C}_{\mathrm{f}} / \mathrm{ZrB}_{2}-\mathrm{SiC}$ composites as an example, high melting point oxide grains $\left(\mathrm{ZrO}_{2}\right.$ grains) are precipitated from the glassy $\mathrm{SiO}_{2}$ phase, coarsened, and sintered via a quasi-liquid phase assisted route. The phase transition of $\mathrm{ZrO}_{2}$ induces the formation of cracks in the oxide layer and decreases the ablation resistance of composites with the increase of ablation temperature (Fig. 27) [198].

The addition of rare earth elements, such as $\mathrm{LaB}_{6}$, $\mathrm{La}_{2} \mathrm{O}_{3}$, and $\mathrm{Y}_{2} \mathrm{O}_{3}$, to $\mathrm{ZrB}_{2}$ matrix has been studied and expected to stabilize the $\mathrm{ZrO}_{2}$ and reduces the evaporation of the glass phase. High melting point $\left(\sim 2300{ }^{\circ} \mathrm{C}\right) \mathrm{La}_{2} \mathrm{Zr}_{2} \mathrm{O}_{7}$ is expected to form. However, $\mathrm{La}_{2} \mathrm{Zr}_{2} \mathrm{O}_{7}$ has not been detected after ablation at $\sim 2500{ }^{\circ} \mathrm{C}$. Moreover, the addition of $\mathrm{La}^{3+}$ with lower valence cation to $\mathrm{ZrB}_{2}$ increases the oxygen diffusion coefficient in the $\mathrm{ZrO}_{2}$ oxide layer and lowers the eutectic temperature of the oxide scale. As a result, the oxidation of the composites with $\mathrm{La}$ addition is accelerated during ablation [288]. Luo et al. [218] added $\mathrm{Y}_{2} \mathrm{O}_{3}$ into the $\mathrm{C}_{\mathrm{f}} / \mathrm{SiC}-\mathrm{ZrC}$ composites and tested the ablation properties by oxyacetylene torch under the heat flux of $4.2 \mathrm{MW} \cdot \mathrm{m}^{-2}$. Due to the high ablation temperature $\left(\sim 3000{ }^{\circ} \mathrm{C}\right)$, the glassy silica phase evaporates quickly during ablation and the $\mathrm{Y}_{2} \mathrm{O}_{3}$ and $\mathrm{ZrO}_{2}$ are left in the oxide layer. The reaction between $\mathrm{SiO}_{2}$ and $\mathrm{Y}_{2} \mathrm{O}_{3}$ may need long time or excessive silica. As a result, no trace of any reaction between $\mathrm{Y}_{2} \mathrm{O}_{3}$ and silica has been detected. $\mathrm{Y}_{2} \mathrm{O}_{3}$ neither reacted with $\mathrm{ZrO}_{2}$ nor the phase transformation during the cooling stage suppressed. The vast evaporation of $\mathrm{SiO}_{2}$ and the porous $\mathrm{ZrO}_{2}$ leads to the exposure and further ablation of the underneath composites.

Zeng et al. [219] added $\mathrm{TiC}$ into the $\mathrm{C}_{\mathrm{f}} / \mathrm{C}-\mathrm{SiC}-\mathrm{ZrC}$ composites and compared the ablation properties with $\mathrm{C}_{\mathrm{f}} / \mathrm{C}-\mathrm{SiC}$ and $\mathrm{C}_{\mathrm{f}} / \mathrm{C}-\mathrm{TiC}$. During ablation test at $2500{ }^{\circ} \mathrm{C}$, $\mathrm{Zr}_{1-x} \mathrm{Ti}_{x} \mathrm{O}_{2}$ with high viscosity and low volatility is formed. With the evaporation of glassy $\mathrm{SiO}_{2}$, the Ti-rich oxides can precipitate from the glassy $\mathrm{SiO}_{2}$ and rebuild the protective scale with lower volatility against the erosion by the ultra-high temperature. Besides, the precipitation of Zr-rich oxides can further improve the viscosity of the oxide layer to withstand the flushing by ablation flame. As a result, the $\mathrm{C}_{\mathrm{f}} / \mathrm{C}-\mathrm{SiC}-\mathrm{ZrC}-\mathrm{TiC}$ composites show a better ablation resistance than $\mathrm{C}_{\mathrm{f}} / \mathrm{C}-\mathrm{SiC}$ and $\mathrm{C}_{\mathrm{f}} / \mathrm{C}-\mathrm{TiC}$.

Generally, Hf-based UHTCMCs present better ablation resistance than $\mathrm{Zr}$-based composites as the $\mathrm{HfO}_{2}$ has a higher melting point than $\mathrm{ZrO}_{2}$. And $\mathrm{HfB}_{2}$ shows better anti-ablation properties than $\mathrm{HfC}$ as the oxidation products are adherent to the composites (Fig. 28) [287,288]. Compared with Zr-based and Hf-based composites, the composites with $\mathrm{TaC}$ matrix show poor ablation resistance as the formed $\mathrm{Ta}_{2} \mathrm{O}_{5}$ has a low melting point of $1872{ }^{\circ} \mathrm{C}$, which results in the intense

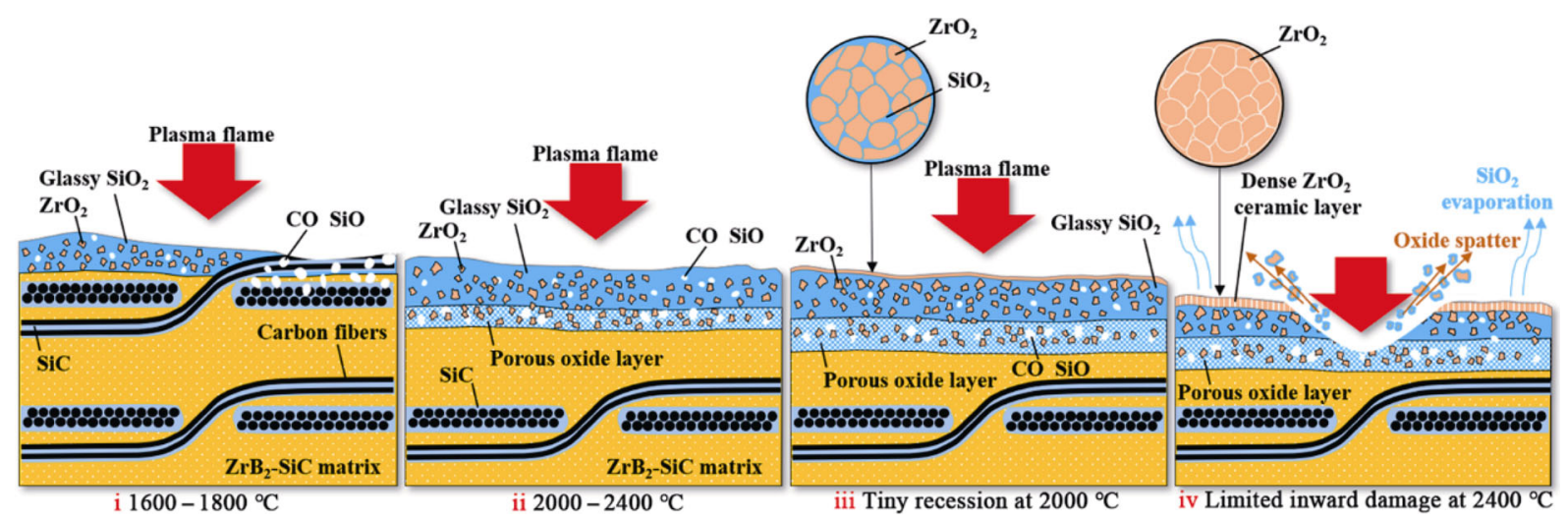

Fig. 27 Schematic diagram of the ablation mechanisms for $2 \mathrm{D}-\mathrm{C}_{\mathrm{f}} / \mathrm{ZrB}_{2}-\mathrm{SiC}$ composites at temperatures from 1600 to $2400{ }^{\circ} \mathrm{C}$. Reproduced with permission from Ref. [198], C Elsevier Ltd. 2020. 


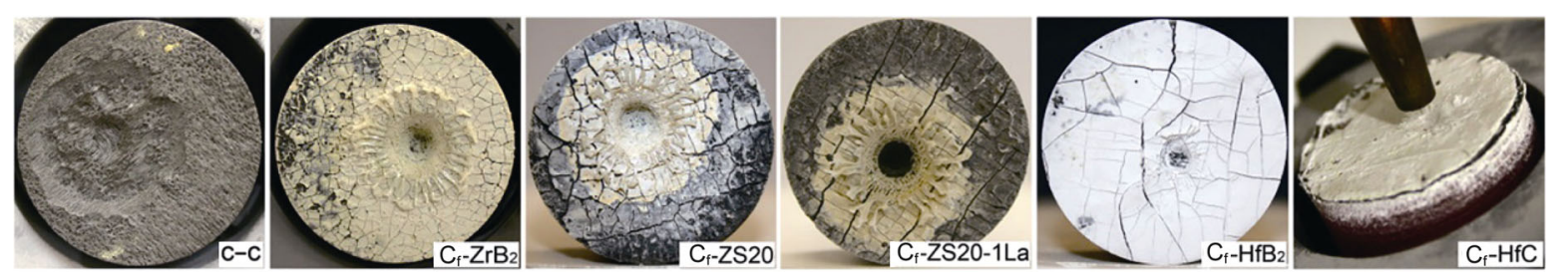

Fig. 28 Optical images of $\mathrm{C} / \mathrm{C}$ and $\mathrm{C}_{\mathrm{f}} / \mathrm{UHTCs}$ composites after 60 -s oxyacetylene torch test. Reproduced with permission from Ref. [288], (C) Elsevier Ltd. 2013.

mechanical denudation at temperatures above $2000{ }^{\circ} \mathrm{C}$ [195,215,287].

In addition to the composition, thermal properties also affect the ablation properties of the composites significantly. Chen et al. [239] compared the ablation behaviors of $\mathrm{RMI}-\mathrm{C}_{\mathrm{f}} / \mathrm{ZrC}-\mathrm{SiC}$ and $\mathrm{PIP}-\mathrm{C}_{\mathrm{f}} / \mathrm{ZrC}-\mathrm{SiC}$ composites with similar compositions. The results revealed that $\mathrm{RMI}-\mathrm{C}_{\mathrm{f}} / \mathrm{ZrC}-\mathrm{SiC}$ composites with higher thermal conductivity are more capable to transmit heat timely and reduce the ablation surface temperature effectively (Fig. 29(a)). As a result, the RMI- $\mathrm{C}_{\mathrm{f}} / \mathrm{ZrC}-\mathrm{SiC}$ composites experience less heat damage and show a better ablation resistance (Figs. 29(b)-29(d)). Generally, heat is conducted mainly by phonon motion of the solid framework (crystal lattice vibration) in the composites. Phonons will be scattered at pores, grain boundaries, and phase boundaries, which result in the low thermal conductivity of the composites. Therefore,
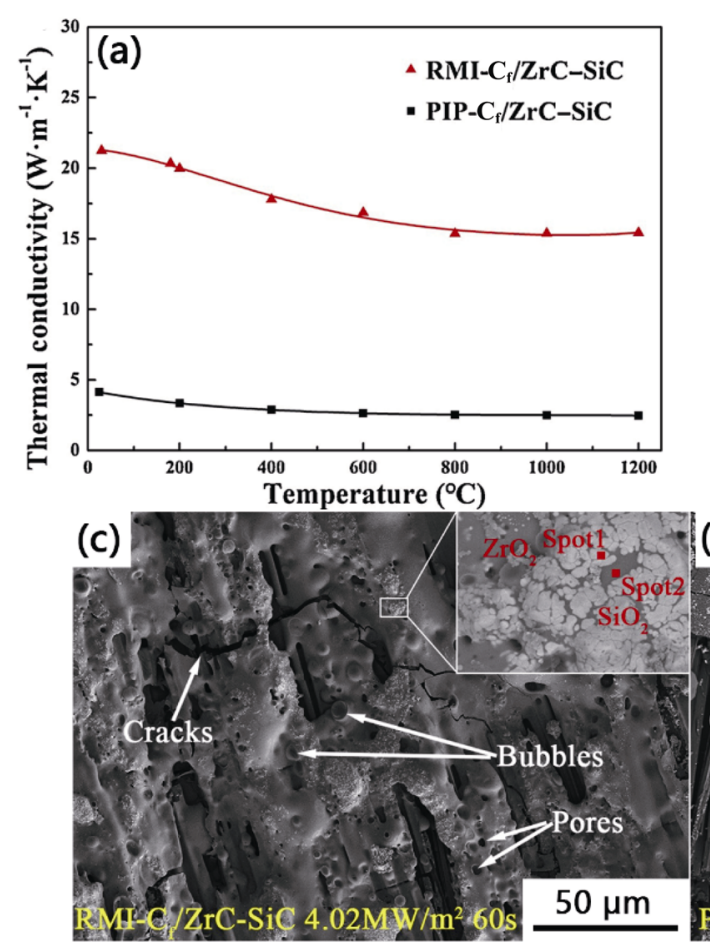

reducing porosity and establishing a dense continuous phase distribution are effective ways to increase the thermal conductivity for a better ablation resistance. Besides, carbon fibers are vulnerable during ablation and prefer to be oxidized to form oxygen diffusion channels [284]. Therefore, ablation resistance can be improved by optimizing the structure of fiber preform [198] or developing UHTC $_{f} /$ UHTC composites [289,290].

\section{UHTC coatings: Processing, microstructure, and performance}

\section{1 Composition and microstructure design of UHTC coatings}

In addition to bulk ceramics and composites, coating is another important application form of UHTCs. The
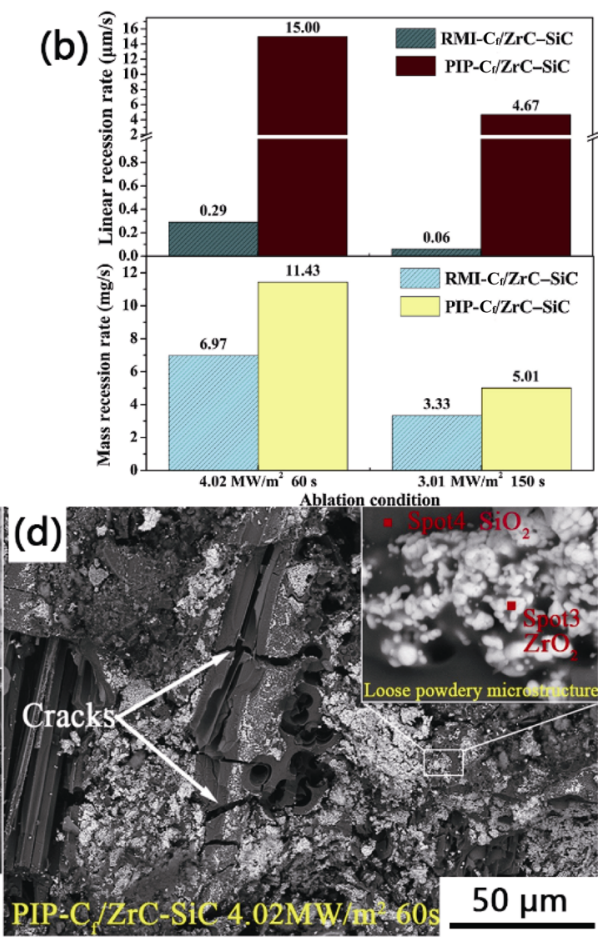

Fig. 29 Thermal conductivity of $\mathrm{RMI}-\mathrm{C}_{\mathrm{f}} / \mathrm{ZrC}-\mathrm{SiC}$ and $\mathrm{PIP}-\mathrm{C}_{\mathrm{f}} / \mathrm{ZrC}-\mathrm{SiC}$ composites (a), ablation recession rates (b), and the ablated surface microstructure of $\mathrm{RMI}-\mathrm{C}_{\mathrm{f}} / \mathrm{ZrC}-\mathrm{SiC}(\mathrm{c})$, and $\mathrm{PIP}-\mathrm{C}_{\mathrm{f}} / \mathrm{ZrC}-\mathrm{SiC}$ composites (d). Reproduced with permission from Ref. [239], (C) Elsevier Ltd. 2019. 
UHTC coatings are designed to protect the substrates from the oxidation/ablation environments at ultra-high temperatures. The composition design rules of UHTC protective coatings are listed as below:

1) Chemical compatibility with the substrate, i.e., any detrimental reaction between the coating and substrate should be prevented.

2) Thermo-physical compatibility, which mainly related to a good match of thermal expansion coefficient (CTE).

3) Low oxygen permeability to prevent the inward diffusion of oxidized species.

4) Low volatility to prevent excessive ablation in high pressure/velocity gas streams.

Figure 30 summarizes possible compositions, processing, microstructures, and applications of the UHTC coatings. Each UHTC has its ideal working temperatures, and usually combines with silicides ( $\mathrm{SiC}$, $\mathrm{MoSi}_{2}$, etc.). The addition of UHTC into silicides can overcome the deficiency of the traditional Si-based ceramic coatings, i.e., SiC easily takes place active oxidation at low oxygen partial pressures or temperatures higher than $1700{ }^{\circ} \mathrm{C}$ [5,291-293]. Various methods including pack cementation (PC) [292,294299], CVD [300-311], plasma spray (PS) [293,312316], slurry-sintering (SS) [317,318], and hot pressing (HP) $[52,319,320]$ have been developed to prepare UHTC coatings. The selection of the UHTC coatings highly depends on the requirements of the target applications (aero-thermo-chemical demands) and the feasibilities of their processing routes (cost and specific shaping availability). With respect to the published reports, the microstructures of the UHTC coatings can be mainly divided into three types, that is, single-phase, multiphase, single-phase multilayer, and multiphase multilayer, as shown in Fig. 30. In addition to the above-mentioned design rules of UHTC coatings, the coating structure design should also consider the interfacial compatibility design, multi-phase synergistic protection, multi-scale toughening, and multi-processing route combination. Due to their high melting point, good oxidation performance, and ablation resistance, UHTC coatings can work under harsh aerospace environments, such as turbines and blades for aero engines, nozzles for rocket engines, and thermal protection systems (TPS) for hypersonic vehicles. The next section will introduce the different fabrication methods of the UHTC coatings and their feasibilities in detail, and then discuss the design purpose of different UHTC coating structures and their performances.

Microstructural designs of gradient and multilayer UHTC coating structure are adopted to realize the good interfacial compatibility. A well compatible coating with the substrate is commonly used as the inner layer to avoid spallation or even stress-induced cracking. Multiphase synergistic protection means UHTC is used
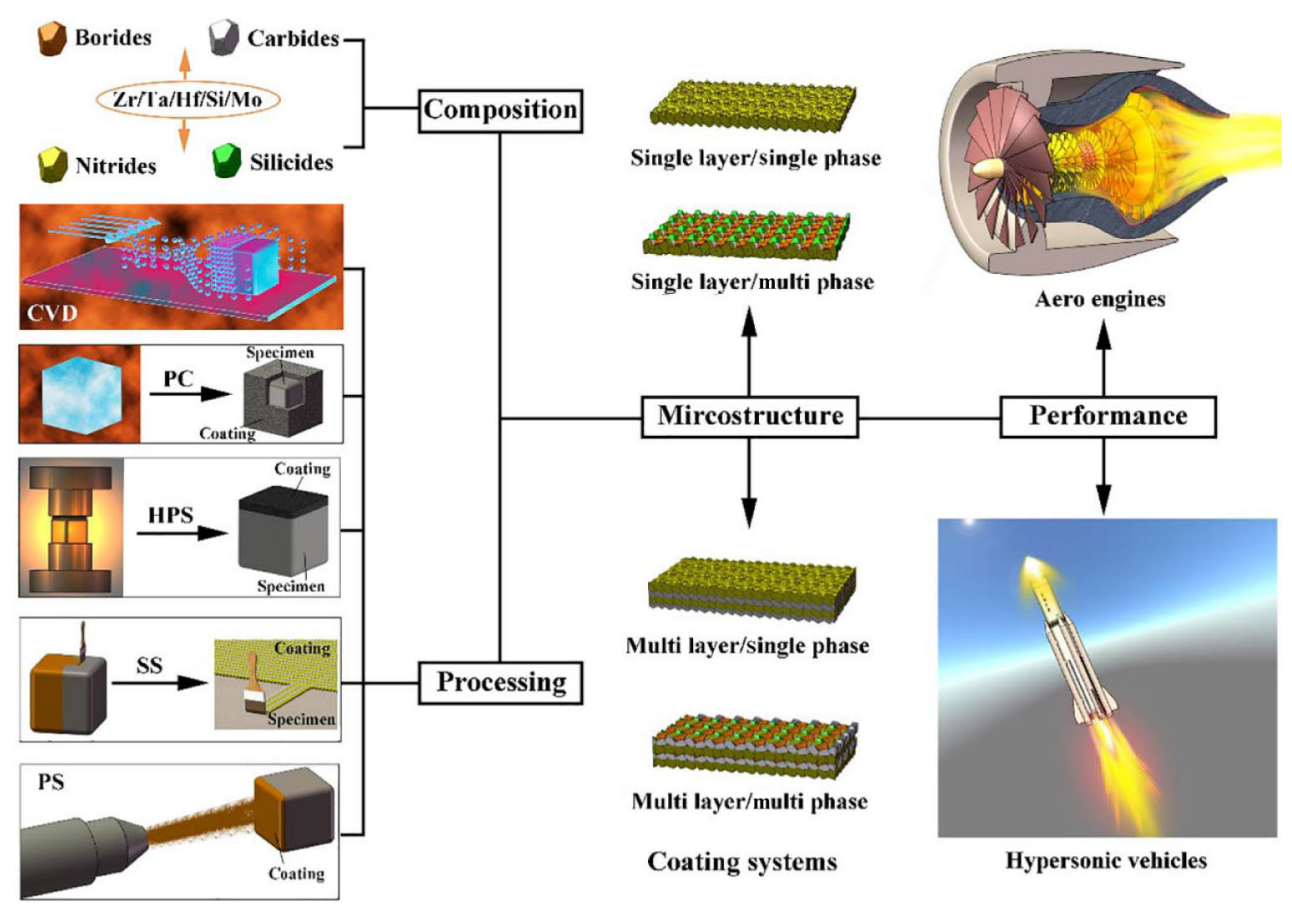

Fig. 30 Schematic diagram of the composition, processing, microstructure, and application of the UHTC coatings. 
together with other materials. Multi-scale synergistic toughening is aimed to solve the intrinsic brittleness and low damage tolerance of the UHTC, where toughened phases are introduced. Multi-processing route is mainly targeted to enhance the coating/ substrate interface bonding and eliminate the coating defects. Flexibly comprehensive use of these design rules is the key to ensure that the UHTC coatings possess desirable properties. Section 4.2 will introduce the different fabrication methods of the UHTC coatings and their feasibilities in detail, and then discuss the design purpose of different UHTC coating structures and their performances.

\section{2 Processing routes of UHTC coatings}

Processing routes determine whether the tailored compositions and structures of the UHTC coatings could be achieved. For each method, its microstructure control, cost, and performance will be discussed as follows with its advantages/disadvantages.

(1) Pack cementation (PC)

$\mathrm{PC}$ is a relatively simple technique that consists of immersing the substrate in a powder mixture of coating materials. During heat-treatment at a high temperature, the molten pack materials will infiltrate into or react with the substrate to form the UHTC coatings. The temperature must be sufficiently high to ensure the diffusion will take place. The desired UHTC coatings are usually obtained by the reactions of the raw coating materials themselves. The main disadvantage of PC is that if the fabrication condition is not strictly controlled, performance degradation of the substrate will inevitably occur due to the high treatment temperature. Additionally, the coating thickness is difficult to control.

(2) Chemical vapor deposition (CVD)

CVD is a deposition method used to produce high-quality, high-performance solid materials. The process mainly consists of the dissociation and/or chemical reactions of gaseous reactants and the deposition of a stable solid product. Its main advantage is the low preparation temperature, at which the substrate can avoid being damaged or forming defects. Microstructures of the UHTC coatings can be tailored by changing temperature, pressure, and precursor injection rate. If the deposition process is controlled well, the deposited solid product can show a dense, fine-grained structure free from impurities. Another advantage is that, by adjusting the injection of precursors, both single phase and multiple composition coatings can be obtained. However, CVD is a slow process, which makes the product expensive. Another shortcoming is that it must be performed under a vacuum or protective atmosphere. CVD UHTC coatings are usually accompanied by the exhaust of unreacted precursor gases and the production of chemical byproducts (e.g., $\mathrm{HCl}$ and HF) [303,304,307,308], and therefore, requirements for equipment are relatively strict.

\section{(3) Plasma spray (PS)}

PS is a simple way to prepare coatings of refractories with high melting points. Diverse materials, such as metal and ceramics, can be applied as spray materials. During coating preparation, UHTC powders are injected into a very high temperature plasma flame, where they are rapidly heated and accelerated to a high velocity. The hot UHTC powders are injected to the substrate and rapidly cooled, forming a coating. However, various drawbacks, such as high porosity, poor bonding strength, high surface roughness, and lamellar stacking characteristics, could also occur. As a result, subsequent processing is usually required to eliminate the above defects [321].

(4) Slurry-sintering (SS)

SS is the most widely exploited coating technique in various fields. The slurry made of particles or organic precursor dispersed in a suitable solvent is brushed onto the substrate, then dried and finally heat-treated in an inert gas atmosphere. The solvent is usually removed in the drying stage. To achieve a high densification level of the UHTC coating, several brushing-dry-heat treatment cycles must be performed. Due to the limitation by the weak bonding of coating/substrate, this method is not used individually but is usually combined with other methods such as liquid and gas infiltration of Si [298,322-327].

(5) Hot pressing (HP)

Like other ceramics, restricted by their covalent bond and intrinsic brittleness, UHTC particles are difficult to be sintered [52,137]. Sinter-additives, which could transform into liquid phases and promote the solid-state reactions, are beneficial for the UHTC coating densification. When coatings are subjected to harsh service environments, since the metallic and intermetallic sinter additives can be easily softened and melt, they are generally not considered as sintering additives for UHTC coatings, whereas the Si-based ceramics such as $\mathrm{SiC}, \mathrm{MoSi}_{2}$, and $\mathrm{TaSi}_{2}$ are frequently used [52,137,319,328-330]. Although sintering aids 
could modify the sintering conditions, UHTC coating with a high densification level is not guaranteed, without the assistance of external pressure. HPS allows for versatile structure design; however, it is not applicative to the fabrication of UHTC coatings on the complex-shaped components.

\section{3 Microstructure and anti-oxidation/ablation properties of the UHTC coatings}

The UHTCs are typically made of the carbide, nitride, and boride of the transition metals, among which Group IVB (Ti, Zr, Hf) carbides and borides together with $\mathrm{TaC}$ are usually used as the coating materials [292,294-297,302-304,311-313,320,325,331-339] due to the in-situ formed oxygen barrier layer, namely UHTC-oxides. The rational selection of the coating materials, the optimal design of the structure, and the accessible processing route are the key steps to obtain the UHTC coatings with good performances. As shown in Fig. 30, UHTC coatings are mainly divided into three types, that is, single-phase, multiphase, and multilayer (single-phase multilayer and multiphase multilayer) coatings. Recent progresses on these three types of coatings are discussed below.

(1) Single-phase UHTC coatings

Figure 31 shows the typical morphologies of the single-phase UHTC coatings. Among the coating fabrication methods, CVD and PS are the two most frequently adopted. UltraMet has prepared a series of CVD UHTC coatings [340], including $\mathrm{HfC}, \mathrm{ZrC}, \mathrm{HfB}_{2}$, and $\mathrm{ZrB}_{2}$ coatings. Domestic studies in this field have also been achieved. Zhang et al. [309] and Wang et al. [307] deposited HfC coatings on $\mathrm{C} / \mathrm{C}$ composites by low-pressure chemical vapor deposition (LPCVD) using the $\mathrm{HfCl}_{4}-\mathrm{CH}_{4}-\mathrm{H}_{2}-\mathrm{Ar}$ system (Fig. 31(a)). It is reported that a moderate HfC coating thickness $(\sim 40 \mu \mathrm{m})$ on $\mathrm{C} / \mathrm{C}$ substrate could effectively release the thermal stress generated during the ablation [309] (Fig. 31(b)), which exhibited excellent ablation resistant performance after ablation for $60 \mathrm{~s}$ under the oxyacetylene flame. The mass and linear ablation rates were only $0.13 \mathrm{mg} \cdot \mathrm{s}^{-1}$ and $0.09 \mu \mathrm{m} \cdot \mathrm{s}^{-1}$, respectively.

Similar to the CVD-HfC coating, Zhu et al. [310] designed a dense cauliflower-shaped $\mathrm{ZrB}_{2}$ coating by LPCVD based on the $\mathrm{ZrCl}_{4}-\mathrm{BCl}_{3}-\mathrm{H}_{2}-\mathrm{Ar}$ system, and the corresponding deposition mechanism was discussed in detail. It was reported that the temperature and $\mathrm{H}_{2}$ and $\mathrm{BCl}_{3}$ fluxes significantly affect surface roughness, growth rate, and phase composition of the $\mathrm{ZrB}_{2}$ coating. In addition to CVD, PS was also used to prepare HfC [316], ZrC [312,337] (Figs. 31(c) and 31(d)) and $\mathrm{ZrB}_{2}$ [315] coatings. The oxidation/ablation properties of the single-phase UHTC coatings mainly depend on the oxidation products formed. The integrity of the formed oxidation scale on the coating surface is crucial for its service reliability. However, each UHTC has its
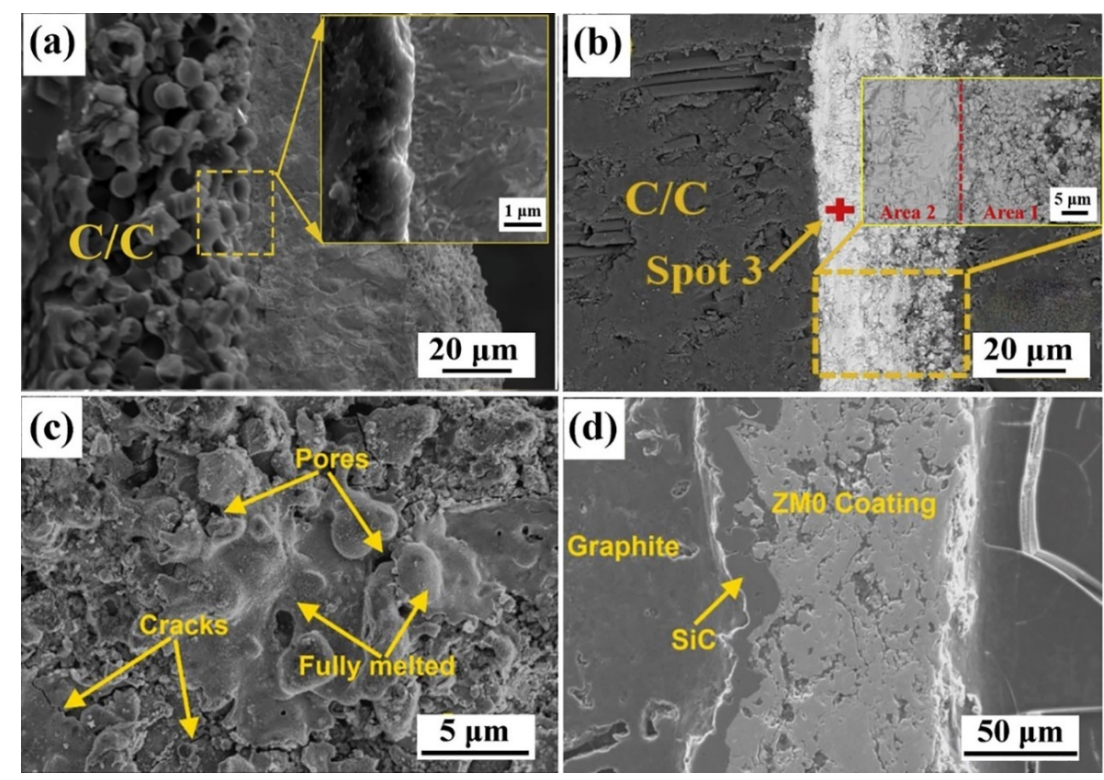

Fig. 31 Typical morphologies of the single UHTC coatings: cross-section of the CVD-HfC coating before ablation (a); cross-section of the CVD-HfC coating after ablation (b). Reproduced with permission from Ref. [309], (C) Elsevier Ltd. 2020. Surface and cross-section of PS-ZrC coating (c, d). Reproduced with permission from Ref. [312], C) Elsevier Ltd and Techna Group S.r.1. 2018. 
working temperature range. Taking carbides for example, the $\mathrm{ZrO}_{2}$ layer on the $\mathrm{ZrC}$ coating after oxidation usually presents loose structure due to the absence of self-sealed phases, and oxygen could easily pass through the channels by gaseous diffusion. Meanwhile, the thermal expansion mismatch between the oxidation layer and un-oxidized coating contributed to the occurrence of cracks during high-low temperature cycles. Compared with carbides, borides with $\mathrm{ZrB}_{2}$ as an example, provide better protection below $1200{ }^{\circ} \mathrm{C}$ due to the formation of $\mathrm{ZrO}_{2}$ containing a molten layer of boron oxide [5,295,296,331,332,341]. The liquid phase $\mathrm{B}_{2} \mathrm{O}_{3}$ could fill the cracks and holes. However, as the temperature further increases, vast volatilization of $\mathrm{B}_{2} \mathrm{O}_{3}$ degrades its performance.

(2) Multiphase UHTC coatings

The flight process of hypersonic vehicles requires a TPS with high resistance to oxidation/ablation. As discussed in the previous Section 3.4, the oxidation/ ablation resistant performances of single-phase UHTC coatings depend highly on the properties of the formed oxidation products that cover the surface, including the composition and the structure of the oxidized surface. According to the design rule of multi-phase synergistic protection, the integration of the different components could mitigate the limits of each single component. As a result, multiphase UHTC coatings were proposed. Table 5 summarizes the reported works of multiphase UHTC coatings, which can be mainly divided into two types, namely UHTC-silicide and multiphase UHTC.
For UHTC-silicide coatings, Richet et al. [317] prepared a $\mathrm{HfB}_{2}-\mathrm{SiC}$ coating and investigated its oxidation resistance. The results showed that the $\mathrm{HfO}_{2}$ phase embedded borosilicate glass led to slower diffusion of oxygen at high temperatures. Lee et al. [311] utilized methyltrichlorosilane (MTS) and $\mathrm{ZrCl}_{4}$ powder respectively as the precursors of $\mathrm{SiC}$ and $\mathrm{ZrC}$ to prepare a $\mathrm{ZrC}-\mathrm{SiC}$ coating by CVD. Zhang et al. [297] successfully coated C/C composites with HfC-SiC, $\mathrm{ZrB}_{2}-\mathrm{SiC}$ coatings by PC [296,299] (Fig. 32(a)). During ablation, the formed $\mathrm{Zr}-\mathrm{O}-\mathrm{Si}$ multiphase glass layer showed good thermal stability at high temperatures, thereby benefiting for withstanding the denudation of the combustion gas [296]. Zhang et al. [320] proposed SPS to prepare the $\mathrm{HfB}_{2}-\mathrm{SiC}-\mathrm{TaSi}_{2}$ coating on graphite (Fig. 32(b)). It was reported that during oxidation at $1700{ }^{\circ} \mathrm{C}$, the $\mathrm{TaSi}_{2}$ could inhibit the active oxidation of $\mathrm{SiC}$, and its oxidation volume expansion could reduce the loosening effect of $\mathrm{HfB}_{2}$. $\mathrm{HfB}_{2}-\mathrm{SiC}-\mathrm{MoSi}_{2}$ coating was fabricated by Wang et al. [342]. After oxidation at $1500{ }^{\circ} \mathrm{C}$ for $408 \mathrm{~h}$, the coating surface was oxidized to form a self-sealing silicate glass layer containing $\mathrm{HfO}_{2}$ and $\mathrm{HfSiO}_{4}$, which could hinder the crack propagation. In general, compared with the single-phase UHTC coatings, the good oxidation/ablation performances of the UHTC-silicide coatings are attributed to the synergistic effects of the different compositions, especially for the formation of the immiscible, multicomponent glass surface layers [292,294-296,303,312,317,320,322,323,325,330,347].

Table 5 Preparation methods and properties of various multiphase UHTC coatings

\begin{tabular}{|c|c|c|c|c|}
\hline Coating & Preparation method & Test & Property & Ref. \\
\hline $\mathrm{ZrB}_{2}-\mathrm{SiC}-\mathrm{ZrC}$ & $\mathrm{PS}+\mathrm{PC}$ & $\begin{array}{c}\text { Oxyacetylene, heat flux: } \\
2.4 \mathrm{MW} \cdot \mathrm{m}^{-2}, \text { ablation } 120 \mathrm{~s}\end{array}$ & $\begin{array}{r}-0.16 \mathrm{mg} \cdot \mathrm{s}^{-1} \\
1.30 \mu \mathrm{m} \cdot \mathrm{s}^{-1}\end{array}$ & {$[321]$} \\
\hline $\mathrm{MoSi}_{2}-\mathrm{TaSi}_{2}$ & $\mathrm{SS}+\mathrm{PC}$ & $1700{ }^{\circ} \mathrm{C}$, oxidation $12 \mathrm{~h}$ & Without failure & {$[343]$} \\
\hline $\mathrm{HfB}_{2}-\mathrm{SiC}-\mathrm{Si}$ & $\mathrm{SS}+$ gas infiltration $\mathrm{Si}$ & $1500{ }^{\circ} \mathrm{C}$, oxidation $538 \mathrm{~h}$ & Mass loss $0.69 \%$ & {$[326]$} \\
\hline $\mathrm{HfB}_{2}-\mathrm{SiC}-\mathrm{TaSi}_{2}$ & SPS & - & - & {$[320]$} \\
\hline $\mathrm{Hf}_{0.5} \mathrm{Ta}_{0.5} \mathrm{~B}_{2}-\mathrm{SiC}-\mathrm{Si}$ & $\mathrm{SS}+$ gas infiltration $\mathrm{Si}$ & $900{ }^{\circ} \mathrm{C}$, oxidation $1320 \mathrm{~h}$ & Mass gain $0.14 \%$ & {$[325]$} \\
\hline $\mathrm{HfC}-\mathrm{TaC}$ & CVD & $\begin{array}{c}\text { Oxyacetylene, heat flux: } \\
2.4 \mathrm{MW} \cdot \mathrm{m}^{-2} \text {, ablation } 120 \mathrm{~s}\end{array}$ & $\begin{array}{l}0.97 \mathrm{mg} \cdot \mathrm{s}^{-1} \\
1.32 \mu \mathrm{m} \cdot \mathrm{s}^{-1}\end{array}$ & {$[303]$} \\
\hline $\mathrm{HfC}-\mathrm{ZrC}$ & CVD & $\begin{array}{c}\text { Oxyacetylene, heat flux: } \\
2.4 \mathrm{MW} \cdot \mathrm{m}^{-2} \text {, ablation } 120 \mathrm{~s}\end{array}$ & $\begin{array}{l}0.63 \mathrm{mg} \cdot \mathrm{s}^{-1} \\
0.21 \mu \mathrm{m} \cdot \mathrm{s}^{-1}\end{array}$ & {$[303]$} \\
\hline $\mathrm{TaB}_{2}-\mathrm{SiC}-\mathrm{Si}$ & $\mathrm{SS}+$ gas infiltration $\mathrm{Si}$ & $1550{ }^{\circ} \mathrm{C}$, oxidation $168 \mathrm{~h}$ & Mass gain $2.06 \%$ & {$[325]$} \\
\hline $\mathrm{ZrB}_{2}-\mathrm{SiC}$ & PS & - & - & {$[344]$} \\
\hline $\mathrm{ZrC}-\mathrm{SiC}$ & Thermal evaporation & $3000{ }^{\circ} \mathrm{C}$, ablation $200 \mathrm{~s}$ & $\begin{array}{c}-0.46 \pm 0.15 \mathrm{mg} \cdot \mathrm{cm}^{-2} \cdot \mathrm{s}^{-1} \\
-1.00 \pm 0.04 \mu \mathrm{m} \cdot \mathrm{s}^{-1}\end{array}$ & {$[345]$} \\
\hline $\mathrm{Ta}-\mathrm{Hf}-\mathrm{C}$ solid solution coating & PS & $\begin{array}{c}\text { Oxyacetylene, heat flux: } \\
4.18 \mathrm{MW} \cdot \mathrm{m}^{-2}, \text { ablation } 30 \mathrm{~s}\end{array}$ & $\begin{array}{l}-0.58 \mathrm{mg} \cdot \mathrm{s}^{-1} \\
-0.94 \mu \mathrm{m} \cdot \mathrm{s}^{-1}\end{array}$ & [346] \\
\hline $\mathrm{ZrC}-\mathrm{SiC}$ & CVD & - & - & {$[311]$} \\
\hline $\mathrm{HfB}_{2}-\mathrm{SiC}-\mathrm{MoSi}_{2}$ & $\mathrm{PC}$ & $1550{ }^{\circ} \mathrm{C}$, oxidation $408 \mathrm{~h}$ & Mass loss $0.76 \%$ & {$[342]$} \\
\hline
\end{tabular}



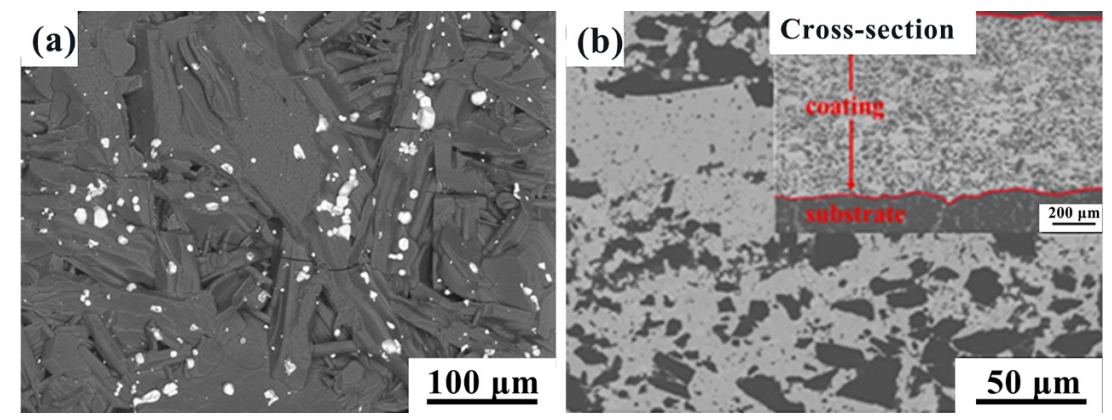

Fig. 32 Typical morphologies of the UHTC-silicide coatings: $\mathrm{PC}-\mathrm{ZrB}_{2}-\mathrm{SiC}$ coating [296] (a) and $\mathrm{SPS}-\mathrm{HfB}_{2}-\mathrm{SiC}_{-}-\mathrm{TaSi}_{2}$ coating [320] (b). Reproduced with permission from Ref. [296], (c) Elsevier Ltd. 2018; Ref. [320], (C) Elsevier Ltd. 2020.

The design of silicates modified UHTC coatings [291,296-298,304,317,320,324,326] is to enhance their long-term oxidation resistances, while multiphase UHTC coatings [303,307,308,327] are mainly to promote the ablation performances. Cui et al. [334] fabricated $\mathrm{ZrB}_{2}-\mathrm{ZrC}$ composite coating on $\mathrm{TC} 4$ titanium alloy by $\mathrm{PS}$. The atomic radii of $\mathrm{Hf}, \mathrm{Zr}$, and $\mathrm{Ta}$ are close, enabling the formation of solid solutions between each other at high temperatures. With these considerations, Li et al. [302,308] prepared a $\mathrm{Hf}(\mathrm{Ta}) \mathrm{C}$ coating by CVD based on the $\mathrm{HfCl}_{4}-\mathrm{TaCl}_{5}-\mathrm{CH}_{4}-\mathrm{H}_{2}-\mathrm{Ar}$ system. Ren et al. [303] have attempted to prepare $\mathrm{HfC}-\mathrm{ZrC}$ coating by CVD using $\mathrm{HfCl}_{4}-\mathrm{ZrCl}_{4}-\mathrm{CH}_{4}-\mathrm{H}_{2}-\mathrm{Ar}$ system. Compared with the HfC coating, the HfC- $\mathrm{ZrC}$ coating exhibited better ablation performance due to the solid solution sintering between the $\mathrm{HfO}_{2}$ and $\mathrm{ZrO}_{2}$, and the formation of the dense protective oxide layer. After ablation for $120 \mathrm{~s}$, the linear and mass ablation rates of the $\mathrm{HfC}-\mathrm{ZrC}$-coated $\mathrm{C} / \mathrm{C}$ sample were only $0.21 \mu \mathrm{m} \cdot \mathrm{s}^{-1}$ and $0.63 \mathrm{mg} \cdot \mathrm{s}^{-1}$, respectively. The linear and mass ablation rates of $\mathrm{HfC}$-coated $\mathrm{C} / \mathrm{C}$ sample under the same condition were $1.48 \mu \mathrm{m} \cdot \mathrm{s}^{-1}$ and $1.21 \mathrm{mg} \cdot \mathrm{s}^{-1}$, respectively. In addition, compared to monolithic UHTC coatings, the addition of rare earth compounds was also reported to improve their oxidation performances [4,291,314,329,331]. For example, Sm dopant was proved to be a beneficial additive to $\mathrm{ZrB}_{2}-\mathrm{SiC}$ coating, which could stabilize the tetragonal $\mathrm{ZrO}_{2}$ phase at high temperatures [314,331].

\section{(3) Multilayer UHTC coatings}

Although the design of multiphase UHTC coatings is beneficial for eliminating the coating defects, it remains difficulty to obtain a UHTC coating with a dense structure. During the preparation, the cooling, or even the thermal shock cycle, the CTE mismatch between the UHTC coating and the substrate $(\mathrm{C} / \mathrm{C}$ [296-298], C/SiC [317,336,348], or graphite [295,325]) will inevitably lead to the formation of pores and cracks, thereby influencing their oxidation/ablation resistances. According to the design rule of interfacial compatibility, multilayer structure could offer the UHTC coatings with multifunctional characteristics: lower residual stress, good adherence to the substrate, and improved hardness/toughness ratio. Different coating concepts can be combined in a multilayer structure and be tailored for specific application demands. Since the UHTC coatings are designed to serve at high temperatures and extreme environment, the multilayer structure design is mainly to alleviate the coating/substrate CTE mismatch, thereby enhancing its service reliability. As a result, a variety of researches are focused on the dense multilayer UHTC coatings accompanied by functionally gradient structures. Table 6 shows part of the reported multilayer UHTC coatings. It is summarized that the multilayer UHTC coatings can mainly be divided into two categories: single-phase UHTC/silicide coatings and multiphase UHTC/silicide coatings. Among the silicides, $\mathrm{SiC}$ is the most adopted bonding or transition layer between the substrates and the UHTC coatings, due to its good physical and chemical compatibility with the substrate. These two types of multilayer UHTC coatings are discussed respectively as follows.

(4) Single-phase UHTC/silicide multilayer coating

Taking advantage of the precise control of the CVD reaction precursor, $\mathrm{HfC} / \mathrm{SiC}$ multilayers coated graphite, fiber, and $\mathrm{C} / \mathrm{C}$ were prepared by Allemand et al [300] and Verdon et al. [305] (Fig. 33(a)) and Wang et al. [306]. The coating consists of 5-10 alternated layers of $\mathrm{SiC}$ and $\mathrm{HfC}$ with a total thickness of 20 or $40 \mu \mathrm{m}$ [300]. C/C composites with $\mathrm{SiC} / \mathrm{TaC}$ multilayer coated carbon fibers were prepared by Chen et al. [301]. In addition to carbide/silicide multilayer coatings, boride/ silicide multilayer coatings have also been developed. 
Table 6 Selected reports of various multilayer UHTC coatings

\begin{tabular}{|c|c|c|c|c|}
\hline Coating & Preparation method & Test & Property & Ref. \\
\hline $\mathrm{SiC} / \mathrm{ZrB}_{2}$ & $\mathrm{PC}+\mathrm{PS}$ & Oxyacetylene, $3000{ }^{\circ} \mathrm{C}$; ablation $120 \mathrm{~s}$ & $4.8 \times 10^{-4} \mathrm{~g} \cdot \mathrm{cm}^{-2} \cdot \mathrm{s}^{-1}$ & {$[313]$} \\
\hline $\mathrm{ZrB}_{2}-\mathrm{SiC} / \mathrm{SiC}$ & $\mathrm{PC}+\mathrm{PS}$ & Arc-heated wind tunnel $2200{ }^{\circ} \mathrm{C}, 1000 \mathrm{~s}$ & $\begin{array}{l}-1.9 \times 10^{-2} \mathrm{mg} \cdot \mathrm{cm}^{-2} \cdot \mathrm{s}^{-1} \\
\quad 2.9 \times 10^{-5} \mathrm{~mm} \cdot \mathrm{s}^{-1}\end{array}$ & {$[349]$} \\
\hline $\begin{array}{c}\mathrm{HfC} / \mathrm{SiC} \\
\mathrm{HfC} / \mathrm{TiC} / \mathrm{SiC}\end{array}$ & PS & - & - & {$[333]$} \\
\hline $\mathrm{SiC} / \mathrm{ZrB}_{2}-\mathrm{SiC} / \mathrm{SiC}$ & $\mathrm{SS}+\mathrm{CVD}$ & $\begin{array}{c}1100{ }^{\circ} \mathrm{C}, 114 \mathrm{~h} ; 1300{ }^{\circ} \mathrm{C}, 114 \mathrm{~h} ; \\
1500{ }^{\circ} \mathrm{C} \text { for } 68 \mathrm{~h}\end{array}$ & $\begin{array}{c}\text { Mass loss of } 0.36,1.65 \text {, and } \\
3.45 \mathrm{mg} \cdot \mathrm{cm}^{-2}\end{array}$ & {$[336]$} \\
\hline $\mathrm{WSi}_{2} / \mathrm{ZrSi}_{2} / \mathrm{Zr}_{x} \mathrm{Hf}_{1-x} \mathrm{C} / \mathrm{SiC}$ & Thermal evaporation & Oxyacetylene, $2600{ }^{\circ} \mathrm{C}, 300 \mathrm{~s}$ & $-0.122 \mathrm{mg} \cdot \mathrm{s}^{-1}$ & {$[339]$} \\
\hline $\mathrm{HfC} / \mathrm{SiC}$ & CVD & - & - & {$[305]$} \\
\hline
\end{tabular}

$\mathrm{SiC} / \mathrm{ZrB}_{2}\left(\mathrm{HfB}_{2}\right)$ multilayer coating was developed by Loehman and Corral [350] to compensate boron loss at high temperatures. $\mathrm{Hu}$ et al. [335] obtained a $\mathrm{ZrB}_{2} / \mathrm{MoSi}_{2}$ multilayer coating on the $\mathrm{SiC}$ coated $\mathrm{C} / \mathrm{C}$ composite by PS (Fig. 33(b)). It was reported that the alternate design resulted in laminated stress distribution and then improved the ablation resistance of the coating. After ablation at a heat flux of $2.4 \mathrm{MW} \cdot \mathrm{m}^{-2}$ for $30 \mathrm{~s}$, its linear growth rate and mass gain rate were $1.67 \mu \mathrm{m} \cdot \mathrm{s}^{-1}$ and $0.44 \mathrm{mg} \cdot \mathrm{s}^{-1}$, respectively.

Strong interfacial adhesion with the substrate and good resistance to the crack caused by the coating/ substrate CTE mismatch are two general requirements for coating structure designs. Based on the design rule of multi-processing routes, two or more processing routes are often used synergistically to satisfy these demands. PC combined with PS or CVD is the most common method. Wang et al. [338] evaluated the ablation properties of $\mathrm{TaC} / \mathrm{SiC}$ coating deposited on $\mathrm{C} / \mathrm{C}$ by PC and PS (Fig. 33(c)). It was reported that at $2100{ }^{\circ} \mathrm{C}$, the oxides formed on the coating surface were easily blown away by the flame; however, as the ablation temperature decreased to 1900 and $1800{ }^{\circ} \mathrm{C}$, the coating exhibited excellent ablation performance.

(5) Multiphase UHTC/silicide multilayer coatings

Boron loss of the borides at high temperatures and the "pesting" oxidation of carbides, to a certain extent, limit the application of the single-phase UHTC/silicide multilayer coatings. The advantage of multiphase UHTC/silicide over single-phase UHTC/silicide coatings is that they can overcome the problems encountered by the single-phase UHTC and better exploit the synergetic oxidation/ablation effects of multiple components. The main processing routes for multiphase UHTC/silicide coatings can be classified into PC [292,295,298], PC+ PS [293,313,327], and SS with liquid/gas infiltrated Si or CVD-SiC [298,322-326,348].

Zhang et al. [293] investigated the ablation performance of $\mathrm{SiC} / \mathrm{ZrB}_{2}-\mathrm{SiC}-\mathrm{ZrC}$ multilayer coating for $\mathrm{C} / \mathrm{C}$ composites prepared by PC+PS (Fig. 34(a)). After ablation for $120 \mathrm{~s}$, the coating exhibited a three-layered structure consisting of a porous $\mathrm{ZrO}_{2}$ layer, a $\mathrm{ZrO}_{2}-\mathrm{SiO}_{2}$ thin layer, and a $\mathrm{SiC}$-depleted layer. The oxidation layers can act as a thermal barrier and inhibit the inward diffusion of oxygen. In addition to PC+PS, Xiang et al. [348] proposed SS combined with $\mathrm{CVD}$ to develop a $\mathrm{ZrC}\left(\mathrm{ZrB}_{2}\right)-\mathrm{SiC} / \mathrm{SiC}$ coating on the $\mathrm{C} / \mathrm{SiC}$ composites. In this process, $\mathrm{ZrC}\left(\mathrm{ZrB}_{2}\right)$ powders with polycarbosilane-xylene were firstly pasted on the surface of $\mathrm{C} / \mathrm{SiC}$ composites, and then CVD $\mathrm{SiC}$ was penetrated in the gaps of $\mathrm{ZrC}\left(\mathrm{ZrB}_{2}\right)$ powders. Similarly, $\mathrm{Hu}$ et al. [336] investigated the oxidation resistance of $\mathrm{SiC} / \mathrm{ZrB}_{2}-\mathrm{SiC} / \mathrm{SiC}$ coated $\mathrm{C} / \mathrm{SiC}$ composites (Fig. 34(b)). Thanks to the synergistic protection effects
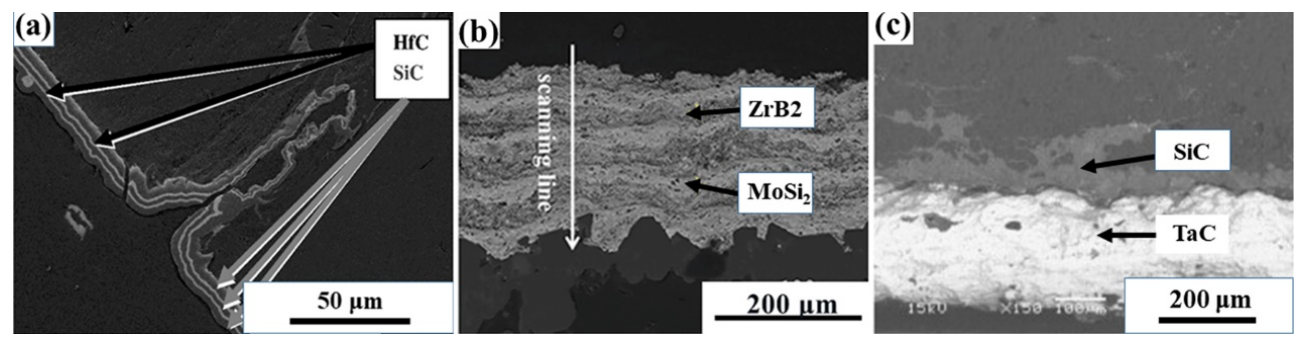

Fig. 33 Typical morphologies of the single UHTC/silicide multilayer coatings: CVD-HfC/SiC coated C/C [305] (a), $\mathrm{PS}-\mathrm{ZrB}_{2} / \mathrm{MoSi}_{2}$ coated C/C [335] (b), and PC+PS TaC/SiC coated C/C [338] (c). Reproduced with permission from Ref. [305], (C) Elsevier B.V. 2013; Ref. [335], (C) Elsevier Ltd. 2020; Ref. [338], (C) Elsevier Ltd and Techna Group S.r.l. 2012. 

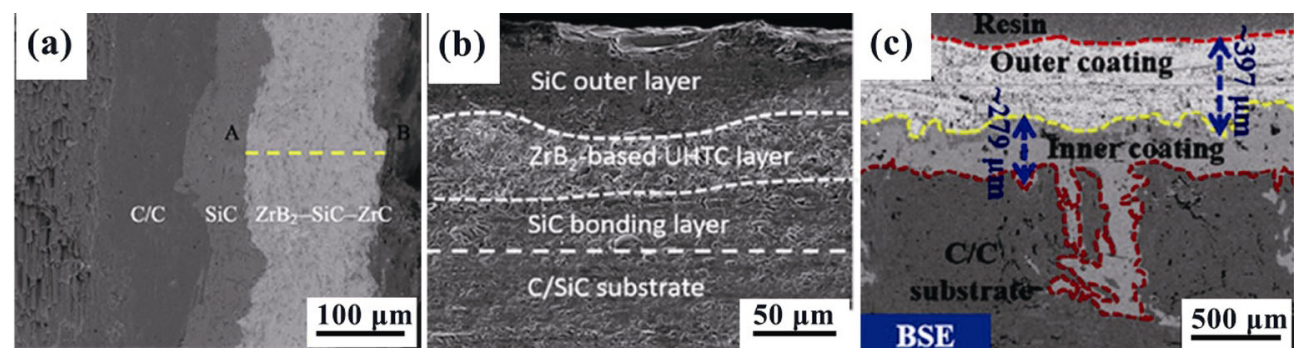

Fig. 34 Typical morphologies of multiphase UHTC/silicide multilayer coatings: $\mathrm{SiC} / \mathrm{ZrB}_{2}-\mathrm{ZrC}-\mathrm{SiC}$ [293] (a), $\mathrm{SiC} / \mathrm{ZrB}{ }_{2}-$ $\mathrm{SiC} / \mathrm{SiC}$ [336] (b), and $\mathrm{HfB}_{2}-\mathrm{MoSi}_{2} / \mathrm{SiC}-\mathrm{Si}$ [324] (c). Reproduced with permission from Ref. [293], C Elsevier B.V. 2016; Ref. [336], (C) Elsevier Ltd. 2018; Ref. [324], (C) Elsevier B.V. 2020.

of the $\mathrm{ZrB}_{2}-\mathrm{SiC}$ and $\mathrm{SiC}$ layers, after exposure to $1100{ }^{\circ} \mathrm{C}$ for $114 \mathrm{~h}, 1300{ }^{\circ} \mathrm{C}$ for $114 \mathrm{~h}$, and $1500{ }^{\circ} \mathrm{C}$ for $68 \mathrm{~h}$ in air, the coated $\mathrm{C} / \mathrm{SiC}$ only had a mass loss of $0.36,1.65$ and $3.45 \mathrm{mg} \cdot \mathrm{cm}^{-2}$, respectively. To further enhance the coating interfacial adhesion, SS combined with gas infiltration of Si were proposed by Zhou et al. [351], Zhou et al. [298], Zhang et al. [324], Jiang et al. [322], and Ren et al. [323]. For example, Zhang et al. [324] utilized this method to prepare $\mathrm{HfB}_{2}-\mathrm{MoSi}_{2} /$ $\mathrm{SiC}-\mathrm{Si}$ coating on the $\mathrm{C} / \mathrm{C}$ composites (Fig. 34(c)). At $1700{ }^{\circ} \mathrm{C}$, the formed $\mathrm{Hf}-\mathrm{Si}-\mathrm{O}$ oxide scale showed good high-temperature stability and self-healing ability, which could protect the $\mathrm{C} / \mathrm{C}$ substrate for $73 \mathrm{~h}$.

As described above, the UHTC coatings play a crucial role in enhancing the oxidation/ablation performances of the underlying substrates. However, due to the intrinsic brittle fracture feature resulted from the strong covalent bonding nature of UHTC itself, when the UHTC coatings subjected to high-low temperature cycles or even harsh aero-thermal environment, they are prone to crack and debond [5,52,137,296,297,315,326,330-332]. To address this problem, according to the design rule of multi-scale synergistic toughening, researchers have proposed to introduce nanostructures (whiskers [352], nanowires [343,353], nanotubes [328], etc.) to toughen the UHTC coatings. The nanostructures mentioned above possess high strength/modulus and are often used in toughening the bulk ceramics [34,318,328,353], as described in Section 2. Among the nanostructures, ceramic whiskers and nanowires are mostly used. Wang and Luo [318] investigated the effect of $\mathrm{SiC}$ whiskers addition on the oxidation behavior of $\mathrm{HfB}_{2}-\mathrm{SiC}-\mathrm{Si} / \mathrm{SiC}$ coating (Fig. 35(a)). The results showed that after oxidation for $468 \mathrm{~h}$ at $1500{ }^{\circ} \mathrm{C}$, the mass loss of the coating was decreased from $4.86 \%$ to $0.88 \%$. Ren et al. [353] proposed $\mathrm{HfC}$ nanowires to toughen the $\mathrm{ZrB}_{2}-\mathrm{SiC} / \mathrm{SiC}$ coating.
Due to the incorporation of HfC nanowires, hardness, elastic modulus, and fracture toughness of the coating were all improved. Cheng et al. [354] discovered that the existence of PyC layer played a positive role in stabilizing the structure and morphology of $\mathrm{SiC}$ nanowires at high temperatures (Figs. 35(b) and 35(c)). They utilized SiC/PyC core-shell nanowires to toughen the $\mathrm{ZrB}_{2}-\mathrm{SiC} / \mathrm{SiC}[327,332]$ and $\mathrm{TaB}_{2}-\mathrm{SiC}$ coating [355] (Fig. 35(d)), which were proved beneficial for alleviating the thermal stress and increasing the coating toughness. In summary, proper processing route and careful microstructure tailor of the nanostructures reinforced UHTC coatings can enhance their crack propagation resistance effectively. The toughening mechanisms of the nanostructures can be mainly ascribed to the three aspects: 1) The nanostructured strengthening phase can induce the deflection of cracks at the crack tips, which can reduce the stress intensity factor and hinder the crack propagation. 2) The pulling out of the strengthening phase can produce new surfaces and consume more energy. 3) The strengthening phase can bridge the crack and resist the crack propagation.

\section{4 Oxidation/ablation mechanisms of the UHTC coatings}

A substantial number of studies have described the oxidation and ablation mechanisms of the UHTC coatings [292-299,303,304,309,312-315,317,318,320, 322-326,330,332,333,335-339]. Oxidation/ablation performance manifests its resistance to the aggressive chemical environment that the UHTC coatings will encounter. However, the boron loss of the borides at high temperatures and the "pesting" oxidation of the carbides harm the service reliability of the single-phase UHTC coatings. According to the design rule of multiphase synergistic protection, silicides are commonly 

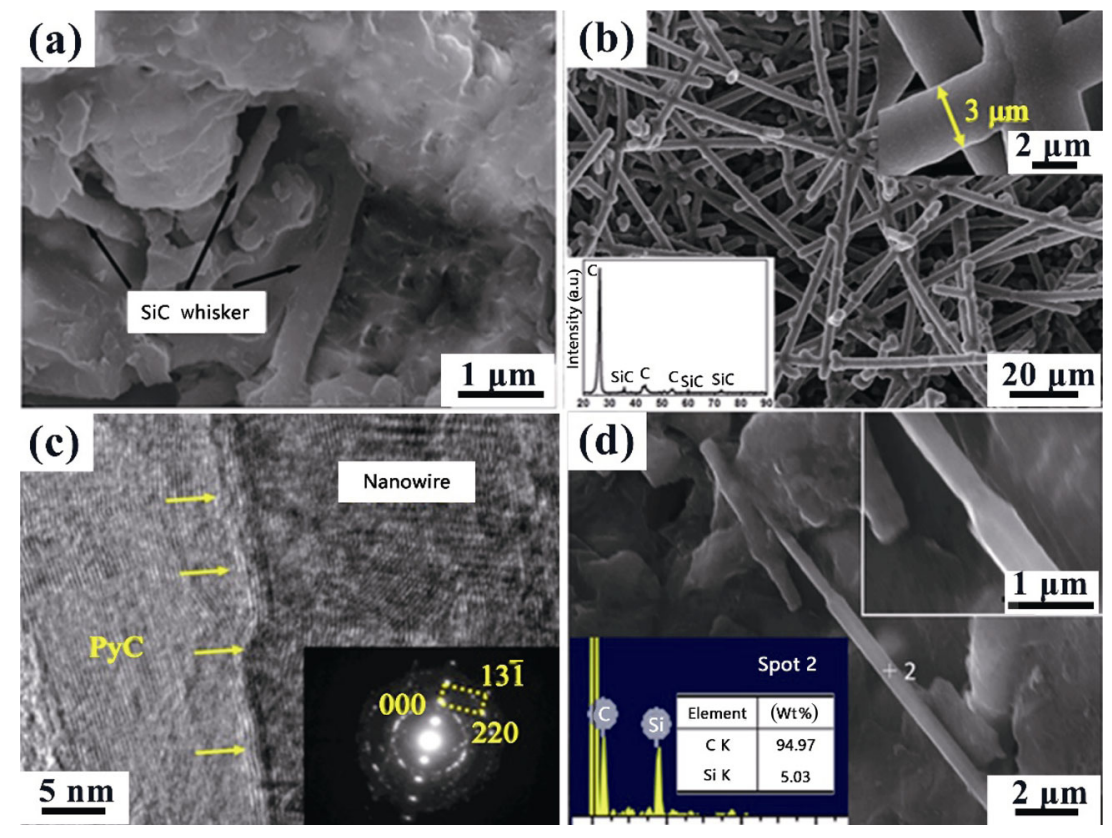

Fig. 35 Typical nanostructures used for UHTC coating toughening: $\mathrm{SiC}$ whiskers in the $\mathrm{HfB}_{2}-\mathrm{SiC}-\mathrm{Si} / \mathrm{SiC}$ coating [318] (a), $\mathrm{SiC} / \mathrm{PyC}$ core-shell nanowires [354] (b, c), and $\mathrm{SiC} / \mathrm{PyC}$ core-shell nanowires in the $\mathrm{TaB}_{2}-\mathrm{SiC}$ coating [355] (d). Reproduced with permission from Ref. [318], (C) Elsevier Ltd and Techna Group S.r.1. 2018; Ref. [354], (C) The American Ceramic Society 2018; Ref. [355], (C) Elsevier Ltd. 2018.

used to improve the oxidation resistance of the UHTC coatings in which $\mathrm{SiC}$ and $\mathrm{MoSi}_{2}$ stand out [5,292, 293,295-297,299,305,306,314,315,317-320,322-324, 331,332,334,336,338,342,348,353]. The $\mathrm{SiC}$ and $\mathrm{MoSi}_{2}$ improve the oxidation resistance of UHTC coatings via the formed silica-rich scales. The silica-rich scales show high fluidities and thus self-sealing behaviors that can reduce oxidation defects, making them ideal barriers for oxygen diffusion [291-293,295-297,299, $305,306,314,315,317,318,320,322-324,331,335,336,342]$. The oxide layers could limit the oxygen inward diffusion and lower oxygen partial pressures for the inner coatings, so UHTC-silicide multiphase coatings could form different grades of oxide layer. Taking $\mathrm{ZrB}_{2}-\mathrm{SiC}-\mathrm{ZrC}$ coating as an example, $\mathrm{ZrO}_{2}-\mathrm{SiO}_{2}$ thin layer and a $\mathrm{SiC}$-depleted layer are observed from the cross-section image of the $\mathrm{ZrB}_{2}-\mathrm{SiC}-\mathrm{ZrC}$ coating [293], as shown in Fig. 36. The external $\mathrm{ZrO}_{2}-\mathrm{SiO}_{2}$ glassy layer is effective in limiting the diffusion of oxygen into the inner coating. Beneath the $\mathrm{ZrO}_{2}-\mathrm{SiO}_{2}$ layer, the SiC-depleted layer is formed, due to the active oxidation of $\mathrm{SiC}$ under low oxygen partial pressure.

It is noted that borate and silicate glasses containing transition or rare earth metal oxides present strong tendency for phase separation due to immiscibility. The immiscibility could raise the liquidus temperature and increase the viscosity of the glass [356]. In this sense, $\mathrm{Zr}$ could be incorporated in the glasses network, which in turn helps to stabilize the $\mathrm{O}$ atoms in $\mathrm{Si}-\mathrm{O}$ network (Fig. 37(a)). Based on the Stoke-Einstein relation, the high viscosity glass could also decrease the oxygen diffusion rate, which explains the good thermal stability of the $\mathrm{Zr}-\mathrm{Si}-\mathrm{O}$ glass layer [357]. Meanwhile, $\mathrm{ZrO}_{2}$ can also be embedded in $\mathrm{SiO}_{2}$ glass, and part $\mathrm{ZrO}_{2}$ can react with $\mathrm{SiO}_{2}$ to form $\mathrm{ZrSiO}_{4}$. The pinning effect of $\mathrm{ZrSiO}_{4}$ and $\mathrm{ZrO}_{2}$ will resist the crack propagation of the $\mathrm{Zr}-\mathrm{Si}-\mathrm{O}$ glass layer during thermal shock and further improve the stability. The integrity of $\mathrm{Zr}-\mathrm{Si}-\mathrm{O}$ glass layer could in turn suppress the borate evaporation and the escape of gas by-products derived from the active oxidation of the inner coating. These are the main origins for the good oxidation resistance of $\mathrm{ZrC}-\mathrm{SiC}, \mathrm{ZrB}_{2}-\mathrm{SiC}$, or $\mathrm{ZrB}_{2}-\mathrm{ZrC}-\mathrm{SiC}$ coatings, which can also be observed in other UHTCsilicide multiphase coating systems such as $\mathrm{Ta}-\mathrm{Si}-\mathrm{O}$ glass layer for $\mathrm{TaB}_{2}-\mathrm{SiC}$ coating [294] (Fig. 37(b)), synergistic effects of $\mathrm{Hf}-\mathrm{Si}-\mathrm{O}$ glass layer, $\mathrm{HfSiO}_{4}$, and $\mathrm{HfO}_{2}$ for $\mathrm{HfC}-\mathrm{SiC}$ coating [304] (Fig. 37(c)), and synergistic effects of $\mathrm{Hf}-\mathrm{Ta}-\mathrm{B}-\mathrm{Si}-\mathrm{O}$ glass layer, $\mathrm{HfSiO}_{4}$, and $\mathrm{HfO}_{2}$ for $\mathrm{HfB}_{2}-\mathrm{SiC}-\mathrm{TaSi}_{2}$ coating [320] (Fig. 37(d)). 

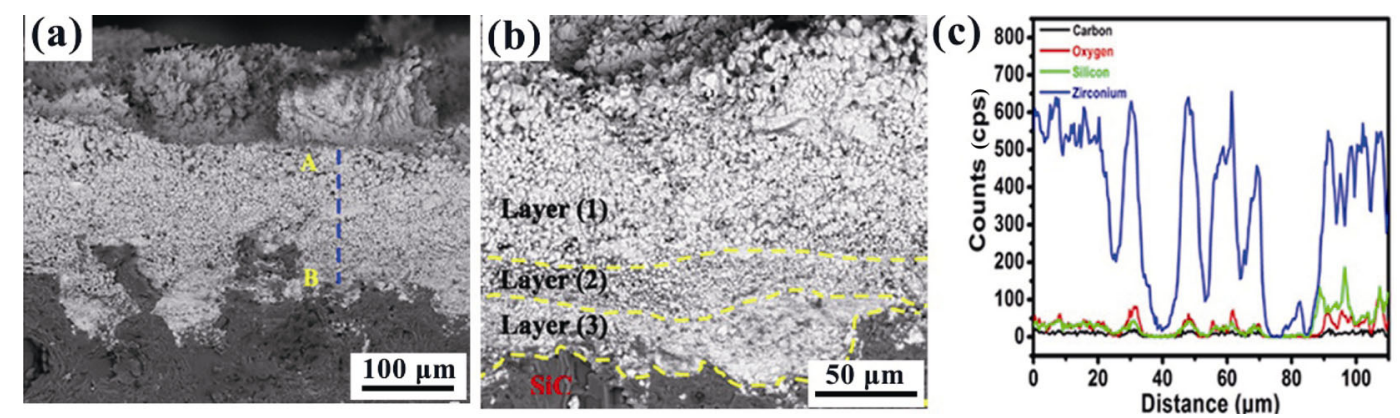

Fig. 36 Cross-section micrograph and element line analysis of the $\mathrm{ZrB}_{2}-\mathrm{SiC}-\mathrm{ZrC}$ coating after ablation. Reproduced with permission from Ref. [293], (c) Elsevier B.V. 2016.

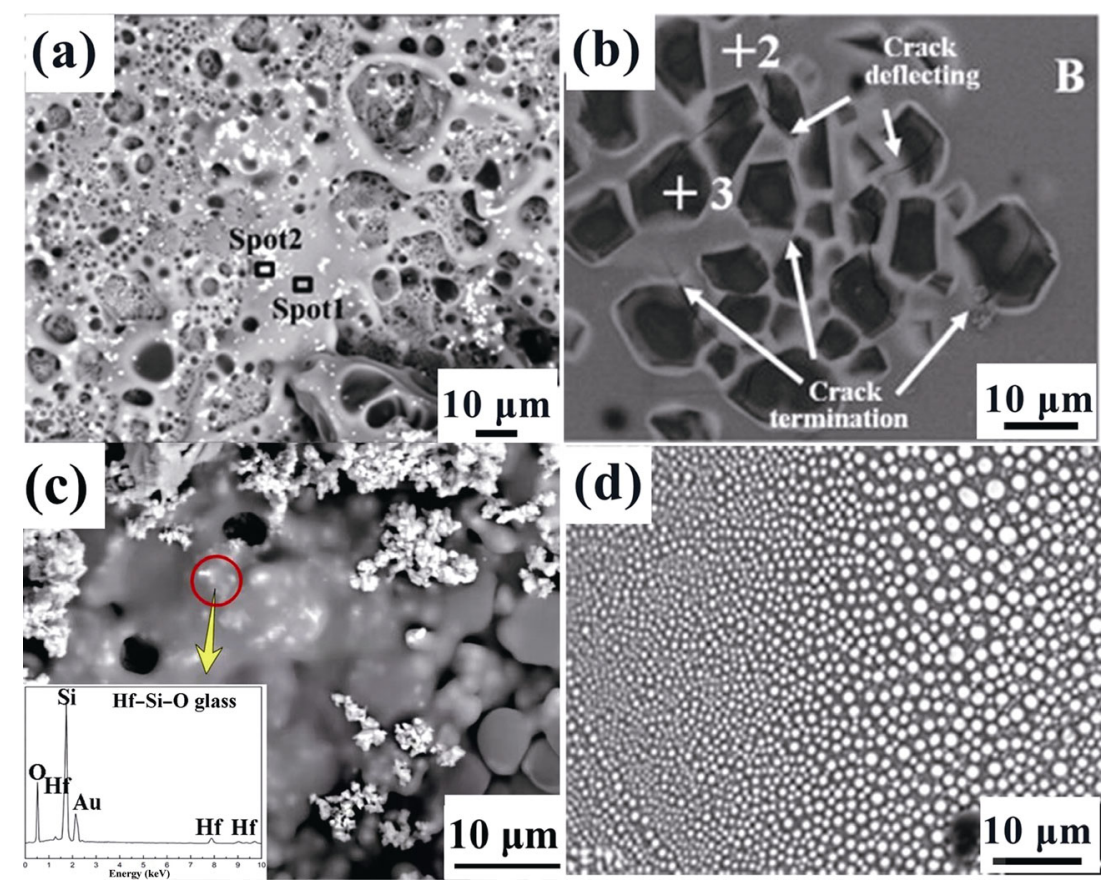

Fig. 37 Microstructures of glassy protective layers formed on the UHTC-silicide coatings: morphology and element analysis of $\mathrm{Zr}-\mathrm{Si}-\mathrm{O}$ glass [296] (a), Ta-Si-O glass [294] (b), Hf-Si-O glass [304] (c), and Hf-Ta-B-Si-O glass [320] (d). Reproduced with permission from Ref. [296], (C) Elsevier Ltd. 2018; Ref. [294], C Elsevier Ltd. 2014; Ref. [304], (C Elsevier Ltd. 2018; Ref. [320], C) Elsevier Ltd. 2020.

Introducing silicides could improve the oxidation resistance of the UHTC coatings; however, the formed silica scales show limited applicable temperature ranges (usually below $1700{ }^{\circ} \mathrm{C}$ ). In addition to the oxidation test, the UHTC coatings will be subjected to harsher aerodynamic loads and higher temperatures during ablation test. In such extreme environments, more gas byproducts will be generated through the active oxidation of $\mathrm{SiC}$ which are likely to break through the top glassy layer due to the increased vapor pressure, resulting in the formation of "island" structures on the surface of UHTC-silicide coatings which destroy the continuality of the glass protective layer [292,295]. As a result, when the ablation temperature is higher than $2000{ }^{\circ} \mathrm{C}$, the ablation performance of the coating mainly relies on the transition metal (TM) oxides (for example $\mathrm{ZrO}_{2}$ and $\mathrm{HfO}_{2}$ ). In other words, the stability of the TM oxides determines the ablation performances of the UHTC coatings. However, it is not only the consumption of glass phase caused by the evaporation and the denudation of high-velocity steam, but also the volume change resulted from the phase transformation of TM oxides (tetragonal to monoclinic $\mathrm{HfO}_{2}$ or $\mathrm{ZrO}_{2}$ ) that lead to the integrity degradation and even peeling off of the TM oxides layer. The addition of rare earth (RE) compounds can react with TM oxides and promote the formation of RETM oxides such as $\mathrm{La}_{2} \mathrm{Zr}_{2} \mathrm{O}_{7}$ [337] to 
stabilize their tetragonal phases, thereby contributing to the improvement of ablation performances. In addition, the solid solution sintering between the $\mathrm{Hf} / \mathrm{Zr} / \mathrm{Ta}$ oxides can also lead to the formation of dense oxide protective layer [302,303,308]. These are the main reasons for the ablation resistance improvements of RE modified UHTC-silicide coatings and UHTC-UHTC coatings.

The aerospace development is putting higher requirements for UHTC coatings, that is they can service longer time and have better resistance to higher temperature/stronger scouring. To meet these demands, research efforts should direct to further improving the coating cohesion, alleviating the UHTC/substrate CTE mismatch, optimizing the type and quantity of glass-forming elements, and enhancing the thermal stability of TM oxides (stabilize the phase and promote the sintering).

\section{High-entropy UHTCs: An emerging direction for the development of ultra-high temperature materials}

\section{1 Introduction of high-entropy UHTCs}

The concept of high-entropy alloys inspires the development of high-entropy ceramics. High-entropy alloys consisted of five or more metal elements in equimolar or near-equimolar, which make the material have high configurational entropy $(>1.5 R, R$ is the gas constant) and favor to form single-phase solid solution with simple crystal structures such as BCC, FCC, and HCP [358]. Some high-entropy alloys exhibited excellent properties, including high strength, high plasticity, high corrosion resistance, etc. As a result, the concept of high-entropy materials attracts more and more attention from researchers all over the world. A number of rules for the formation of high-entropy phase are proposed based on the atomic size difference, valence electron concentration, and the related thermal dynamic parameters such as enthalpy of mixing and entropy of mixing. These rules play an effective role in the design of high-entropy alloys and help researchers to understand the relationship between the chemical composition and phase structure of high-entropy alloys. However, there are many exceptions beyond these rules.

Recently, the concept of high-entropy alloys was expanded to the field of ceramics, leading to the fast development of high-entropy ceramics [359]. Many kinds of high-entropy ceramics were reported, such as high-entropy oxides [360,361], high-entropy borides [362-368], high-entropy carbides [369-372], highentropy silicides $[373,374]$, and high-entropy fluorides [375]. Among them, the high-entropy diborides and carbides whose related individual components are UHTCs such as $\mathrm{ZrB}_{2}, \mathrm{HfB}_{2}, \mathrm{ZrC}$, HfC, and $\mathrm{TaC}$ are also called high-entropy UHTCs.

According to the published references, single-phase ceramics with equimolar or near-equimolar compositions (5-35 at\%) of five or more principal cations/anions which often have $>1.5 R$ per mol. of cations/anions ideal configuration entropy can be called high-entropy ceramics. Wright et al. [361] expanded the concept from high-entropy ceramics to compositionally-complex ceramics. The compositionally-complex ceramics contain high-entropy ceramics, entropy-stabilized ceramics, medium-entropy ceramics and/or single-phase ceramics with non-equimolar 3-4 principal (5-35 at\%) cations or $1-1.5 R$ per mol of cations ideal configuration entropy. Some high-entropy ceramics are also entropystabilized. For example, Rost et al. [360] prepared the first high-entropy ceramic- $(\mathrm{Mg}, \mathrm{Co}, \mathrm{Ni}, \mathrm{Cu}, \mathrm{Zn}) \mathrm{O}$ in 2015. This high-entropy $(\mathrm{Mg}, \mathrm{Co}, \mathrm{Ni}, \mathrm{Cu}, \mathrm{Zn}) \mathrm{O}$ ceramic is also entropy-stabilized because it shows an entropydominated reversible phase transition during heating and cooling cycles.

Gild et al. [362] reported the first high-entropy boride in 2016. And then, Sarker et al. [369], Castle et al. [370], and Yan et al. [376] prepared high-entropy carbides in 2018. Till now, a serious of high-entropy UHTCs have been prepared successfully, such as $\left(\mathrm{Ti}_{0.2} \mathrm{Zr}_{0.2} \mathrm{Hf}_{0.2} \mathrm{Nb}_{0.2} \mathrm{Ta}_{0.2}\right) \mathrm{B}_{2}, \quad\left(\mathrm{Ti}_{0.2} \mathrm{Zr}_{0.2} \mathrm{Hf}_{0.2} \mathrm{Nb}_{0.2} \mathrm{Mo}_{0.2}\right) \mathrm{B}_{2}$, $\left(\mathrm{Ti}_{0.2} \mathrm{Zr}_{0.2} \mathrm{Hf}_{0.2} \mathrm{Nb}_{0.2} \mathrm{Ta}_{0.2}\right) \mathrm{C}$, and $\left(\mathrm{Ti}_{0.2} \mathrm{Zr}_{0.2} \mathrm{Hf}_{0.2} \mathrm{Ta}_{0.2} \mathrm{~W}_{0.2}\right) \mathrm{C}$ [362-372,376-389]. All the synthesized high-entropy diborides show hexagonal crystal structure, while the developed high-entropy carbides have FCC crystal structure. Up to now, the main works are focused on the crystal structure, phase formation ability and the related theoretical model, powder synthesis, densification, mechanical properties, thermal conductivity, and oxidation resistance of high-entropy UHTCs. Besides, up to now there is no report to point out that the developed high-entropy UHTCs show any entropystabilized reversible phase transformation phenomenon.

\section{2 Preparation of high-entropy UHTCs}

(1) Synthesis of high-entropy UHTC powders

Ceramic powders with high purity, fine particle size, 
specialized particle size distribution, as well as good shaping behavior and sinterability are critical issues for producing ceramic products. Accordingly, it is believed that the synthesis of pure and fine high-entropy UHTC powders is essential for the preparation of highperformance high-entropy UHTCs.

Table 7 summarized the typical methods for high-entropy UHTC powder synthesis. Combination reaction between the transition metal mixture and boron element and boro/carbothermal of the mixture of transition metal oxides are the main routes for the synthesis of high-entropy diboride powders. The synthesis of $\left(\mathrm{Ti}_{0.2} \mathrm{Hf}_{0.2} \mathrm{Nb}_{0.2} \mathrm{Ta}_{0.2} \mathrm{Mo}_{0.2}\right) \mathrm{B}_{2}$ powders via combination reaction route by self-propagating high-temperature synthesis (SHS) technique presents high efficiency, but the resulted powder often contains other boride phases [377]. Borothermal and boro/ carbothermal reduction of the mixture of transition metal oxides are effective ways for the synthesis of pure high-entropy diboride powders. To completely remove the oxides by boro/carbothermal reduction, excessive boron sources are often needed, and $1550-1650{ }^{\circ} \mathrm{C}$ is usually required for the synthesis temperature, leading to particle sizes of $0.2-1.5 \mu \mathrm{m}$ [363-365].

The synthesis methods of high-entropy carbide powder mainly include mechanical alloying, SHS, liquid precursor method, direct solid soluting from monocarbide, and carbothermal reduction of the mixture of the related oxides. Among these methods, SHS is the most time-saving technique. Mechanical alloying and liquid precursor methods are favorable to prepare high-entropy carbide powder with particle size less than $500 \mathrm{~nm}$. Direct solid solution from monocarbides and the carbothermal reduction of the mixture of transition metal oxides are suitable for the synthesis of sub-micron/micron-sized high-entropy carbides powder in batch production at temperatures higher than $1600{ }^{\circ} \mathrm{C}$.

As mentioned above, many ways have been developed successfully for the synthesis of highentropy UHTC powders. However, investigations on adjusting the characteristics of high-entropy UHTC powders and understanding the relationship between their characteristics and the compactibility and sinterability are still very needed.

(2) Preparation of bulk high-entropy UHTCs

As a new family member of UHTCs, the sintering techniques, such as PLS, HP, SPS, and reactive spark plasma sintering (RSPS) used to prepare UHTCs can also be applied to high-entropy UHTCs. HP is widely applied for the preparation of high-entropy UHTCs, such as $\left(\mathrm{Ti}_{0.2} \mathrm{Zr}_{0.2} \mathrm{Hf}_{0.2} \mathrm{Nb}_{0.2} \mathrm{Ta}_{0.2}\right) \mathrm{C}$ [385], $\left(\mathrm{Ti}_{0.2} \mathrm{Zr}_{0.2}\right.$ $\left.\mathrm{Hf}_{0.2} \mathrm{Nb}_{0.2} \mathrm{Ta}_{0.2}\right) \mathrm{B}_{2}[368,386]$, and $\left(\mathrm{Ti}_{0.2} \mathrm{Zr}_{0.2} \mathrm{Hf}_{0.2} \mathrm{Nb}_{0.2}\right.$ $\left.\mathrm{Ta}_{0.2}\right) \mathrm{B}_{2}-\mathrm{SiC}$ ceramics [368]. The sintering temperature for $\mathrm{HP}$ is often higher than $1800{ }^{\circ} \mathrm{C}$, resulting in dense high-entropy UHTCs. Feng et al. [385] fabricated $\left(\mathrm{Ti}_{0.2} \mathrm{Zr}_{0.2} \mathrm{Hf}_{0.2} \mathrm{Nb}_{0.2} \mathrm{Ta}_{0.2}\right) \mathrm{C}$ ceramic with a relative density of $99.3 \%$ by $\mathrm{HP}$ at $1900{ }^{\circ} \mathrm{C}$ under a uniaxial pressure of $32 \mathrm{MPa}$.

Compared to PLS and HP, SPS is the most commonly sintering technique used for dense high-entropy UHTCs due to its advantage of time-saving. The first highentropy boride ceramic was fabricated by SPS at $2000{ }^{\circ} \mathrm{C}$ for 5 min using high-energy ball-milled transition metal diboride powders as starting material [362]. Lu et al. [372] prepared dense $\left(\mathrm{Ti}_{0.2} \mathrm{Zr}_{0.2} \mathrm{Hf}_{0.2} \mathrm{Nb}_{0.2} \mathrm{Ta}_{0.2}\right) \mathrm{C}$ and $\left(\mathrm{Ti}_{0.2} \mathrm{Zr}_{0.2} \mathrm{Hf}_{0.2} \mathrm{Nb}_{0.2} \mathrm{Ta}_{0.2}\right) \mathrm{C}-\mathrm{SiC}$ ceramics with high relative densities by SPS at $1800{ }^{\circ} \mathrm{C}$ using a dualphase high-entropy carbide powder synthesized via

Table 7 Methods for the synthesis of high-entropy UHTC powders

\begin{tabular}{|c|c|c|c|c|}
\hline \multirow{3}{*}{$\begin{array}{c}\text { High-entropy UHTC powders } \\
\left(\mathrm{Ti}_{0.2} \mathrm{Hf}_{0.2} \mathrm{Nb}_{0.2} \mathrm{Ta}_{0.2} \mathrm{Mo}_{0.2}\right) \mathrm{B}_{2} \\
\left(\mathrm{Ti}_{0.2} \mathrm{Zr}_{0.2} \mathrm{Hf}_{0.2} \mathrm{Nb}_{0.2} \mathrm{Mo}_{0.2}\right) \mathrm{B}_{2}\end{array}$} & \multicolumn{2}{|c|}{ Synthesis method } & \multirow{2}{*}{$\begin{array}{c}\text { Particle size }(\mu \mathrm{m}) \\
1.94\end{array}$} & \multirow{2}{*}{$\begin{array}{l}\text { Ref. } \\
{[377]}\end{array}$} \\
\hline & $\mathrm{M}+\mathrm{B}$ & SHS+ball milling & & \\
\hline & $\mathrm{MO}_{x}+\mathrm{B}$ & Borothermal reduction & 0.36 & [363] \\
\hline$\left(\mathrm{Ti}_{0.2} \mathrm{Zr}_{0.2} \mathrm{Hf}_{0.2} \mathrm{Nb}_{0.2} \mathrm{Ta}_{0.2}\right) \mathrm{B}_{2}$ & $\begin{array}{c}\mathrm{MO}_{x}+\mathrm{B}_{4} \mathrm{C} \\
\mathrm{MO}_{x}+\mathrm{B}_{4} \mathrm{C}+\mathrm{C}\end{array}$ & Boro/carbothermal reduction & $0.2-1.5$ & {$[364,368,379,380]$} \\
\hline$\left(\mathrm{Ti}_{0.2} \mathrm{Zr}_{0.2} \mathrm{Hf}_{0.2} \mathrm{~V}_{0.2} \mathrm{Nb}_{0.2}\right) \mathrm{C}$ & $\mathrm{M}+\mathrm{C}$ & Mechanical alloying & $0.1-0.3$ & [381] \\
\hline$\left(\mathrm{Ti}_{0.2} \mathrm{Hf}_{0.2} \mathrm{Nb}_{0.2} \mathrm{Ta}_{0.2} \mathrm{Mo}_{0.2}\right) \mathrm{C}$ & $\mathrm{M}+\mathrm{C}$ & SHS & - & [382] \\
\hline \multirow{3}{*}{$\left(\mathrm{Ti}_{0.2} \mathrm{Zr}_{0.2} \mathrm{Hf}_{0.2} \mathrm{Nb}_{0.2} \mathrm{Ta}_{0.2}\right) \mathrm{C}$} & $\mathrm{MCl}_{x}$ & Liquid precursor method & 0.132 & [383] \\
\hline & $\mathrm{MC}$ & Direct solid soluting & 2 & [378] \\
\hline & $\mathrm{MO}_{x}+\mathrm{C}$ & Carbothermal reduction & $0.5-1.5$ & [384] \\
\hline
\end{tabular}

${ }^{*} \mathrm{M}, \mathrm{MO}_{x}$, and $\mathrm{MCl}_{x}$ are the mixture of five transition metal elements, five transition metal oxides, and the mixture of five transition metal chlorides, respectively. 
carbothermal reduction route. Wei et al. [371] prepared dense $\left(\mathrm{Ti}_{0.2} \mathrm{Zr}_{0.2} \mathrm{Hf}_{0.2} \mathrm{Nb}_{0.2} \mathrm{Ta}_{0.2}\right) \mathrm{C}$ ceramics by RSPS via three different routes: the mixture of metal elements and carbon, the mixture of five individual carbides and the mixture of oxides and carbon, respectively. The obtained ceramics through the different routes showed different microstructure features. Gild et al. [387] developed a new method based on RSPS and flash sintering technique, which is called reactive flash SPS (ReaFSPS) for the fast densification of high-entropy UHTCs. Dense $\left(\mathrm{Ti}_{0.2} \mathrm{Zr}_{0.2} \mathrm{Hf}_{0.2} \mathrm{Nb}_{0.2} \mathrm{Ta}_{0.2}\right) \mathrm{B}_{2}$ and $\left(\mathrm{Ti}_{0.2} \mathrm{Zr}_{0.2} \mathrm{Hf}_{0.2} \mathrm{Nb}_{0.2} \mathrm{Ta}_{0.2}\right) \mathrm{C}$ ceramics with $3 \mathrm{wt} \%$ graphite addition can be achieved in $120 \mathrm{~s}$ by ReaFSPS.

Although dense high-entropy UHTCs can be successfully prepared by advanced sintering techniques, the sintering temperature is often higher than $1800{ }^{\circ} \mathrm{C}$. Such high temperature not only causes high energy consumption but also results in a coarse microstructure. Chen et al. [367] prepared porous high-entropy $\left(\mathrm{Ti}_{0.2} \mathrm{Zr}_{0.2} \mathrm{Hf}_{0.2} \mathrm{Nb}_{0.2} \mathrm{Ta}_{0.2}\right) \mathrm{B}_{2}$ ceramics by an in-situ boro/carbothermal reduction combined with a partial PLS process. The thermal conductivity of this material is as low as $0.51 \mathrm{~W} \cdot \mathrm{m}^{-1} \cdot \mathrm{K}^{-1}$, which making it a proper UHTCs thermal insulating candidate.

How to decrease the sintering temperature is still challenge in the field of high-entropy UHTCs. Moreover, the microstructure tailoring by the design of composition and processing remains needing systematically studies.

\section{3 Properties of high-entropy UHTCs}

Like other ceramic materials, the mechanical properties of high-entropy UHTCs are also susceptible to the microstructure of the ceramics. For example, the four-point bending strength of hot-pressed $\left(\mathrm{Ti}_{0.2} \mathrm{Zr}_{0.2} \mathrm{Hf}_{0.2} \mathrm{Nb}_{0.2} \mathrm{Ta}_{0.2}\right) \mathrm{B}_{2}$ ceramic with a relative density of $99.8 \%$ and average grain size of $4.06 \mu \mathrm{m}$ is about $339 \mathrm{MPa}$. With the addition of $20 \mathrm{vol} \% \mathrm{SiC}$, the average grain size of $\left(\mathrm{Ti}_{0.2} \mathrm{Zr}_{0.2} \mathrm{Hf}_{0.2} \mathrm{Nb}_{0.2} \mathrm{Ta}_{0.2}\right) \mathrm{B}_{2}$ matrix phase decreases to $2.70 \mu \mathrm{m}$, which makes bending strength of $\left(\mathrm{Ti}_{0.2} \mathrm{Zr}_{0.2} \mathrm{Hf}_{0.2} \mathrm{Nb}_{0.2} \mathrm{Ta}_{0.2}\right) \mathrm{B}_{2}-$ $20 \mathrm{vol} \% \mathrm{SiC}$ increased to about $447 \mathrm{MPa}$. Besides, the fracture toughness of $\left(\mathrm{Ti}_{0.2} \mathrm{Zr}_{0.2} \mathrm{Hf}_{0.2} \mathrm{Nb}_{0.2} \mathrm{Ta}_{0.2}\right) \mathrm{B}_{2}-$ $20 \mathrm{vol} \% \mathrm{SiC}$ ceramic measured by SENB (single-edge notched beam) method is also higher than that of the single-phase $\left(\mathrm{Ti}_{0.2} \mathrm{Zr}_{0.2} \mathrm{Hf}_{0.2} \mathrm{Nb}_{0.2} \mathrm{Ta}_{0.2}\right) \mathrm{B}_{2}$ [368]. Dense high-entropy UHTCs often show Vickers hardness $\mathrm{HV}_{0.2}$ of about $20-35 \mathrm{GPa}$, which is higher than that of the average performances of the individual metal diborides or carbides [362-372,388-390]. The hardness of high-entropy UHTCs is not only controlled by their average grain size but also strongly affected by their composition. Qin et al. [391] found that high-entropy borides containing $\mathrm{W}$ and Mo elements have higher hardness than $\left(\mathrm{Ti}_{0.2} \mathrm{Zr}_{0.2} \mathrm{Hf}_{0.2} \mathrm{Nb}_{0.2} \mathrm{Ta}_{0.2}\right) \mathrm{B}_{2}$ ceramic.

As the strong phonon scattering by the serious lattice distortion, the thermal conductivity of dense high-entropy UHTC is lower than their related individual metal diborides and carbides. The thermal conductivities of $\left(\mathrm{Ti}_{0.2} \mathrm{Zr}_{0.2} \mathrm{Hf}_{0.2} \mathrm{Nb}_{0.2} \mathrm{Ta}_{0.2}\right) \mathrm{B}_{2}$, $\left(\mathrm{Ti}_{0.2} \mathrm{Zr}_{0.2} \mathrm{Hf}_{0.2} \mathrm{Ta}_{0.2} \mathrm{Mo}_{0.2}\right) \mathrm{B}_{2}$, and $\left(\mathrm{Ti}_{0.2} \mathrm{Zr}_{0.2} \mathrm{Hf}_{0.2} \mathrm{Ta}_{0.2} \mathrm{Cr}_{0.2}\right) \mathrm{B}_{2}$ ceramics are about $24.8,15.2$, and $12.6 \mathrm{~W} \cdot \mathrm{m}^{-1} \cdot \mathrm{K}^{-1}$, respectively, which are much lower than those $\left(\sim 100 \mathrm{~W} \cdot \mathrm{m}^{-1} \cdot \mathrm{K}^{-1}\right)$ of $\mathrm{ZrB}_{2}$ and $\mathrm{HfB}_{2}$ ceramics [392-394]. The thermal conductivity of high-entropy UHTC can be affected by its oxygen impurity content. The addition of graphite can effectively remove the oxygen impurity in $\left(\mathrm{Ti}_{0.2} \mathrm{Zr}_{0.2} \mathrm{Hf}_{0.2} \mathrm{Nb}_{0.2} \mathrm{Ta}_{0.2}\right) \mathrm{C}$ ceramics and improve their thermal conductivity [395].

Oxidation resistance is another important property of high-entropy UHTCs [362,396-398]. The oxidation resistance of high-entropy diboride is better than that of the average performances of the individual metal diborides [362]. Backman et al. [396] pointed out that the composition diversity of high-entropy ceramics provides an opportunity to improve the oxidation resistance of the material based on the oxidation resistance order of its individual metal diborides and carbides. Moreover, the addition of $\mathrm{SiC}$ in $\left(\mathrm{Ti}_{0.2} \mathrm{Zr}_{0.2} \mathrm{Hf}_{0.2} \mathrm{Nb}_{0.2} \mathrm{Ta}_{0.2}\right) \mathrm{C}$ ceramic can enhance its oxidation resistance through the formation of $\mathrm{Hf}(\mathrm{Zr}) \mathrm{SiO}_{4}$ and $\mathrm{Hf}(\mathrm{Zr}) \mathrm{TiO}_{4}$ protective oxide layer [396].

Previous works mainly focus on the mechanical properties at room temperature, thermal conductivity, and oxidation resistance of high-entropy UHTCs. However, as one candidate for ultra-high temperature applications, the high-temperature strength, ablation resistance, thermal shock resistance, as well as melting points are critical, which need intensive studies in the future.

\section{4 Applications of high-entropy UHTCs}

Like conventional UHTCs, high-entropy UHTCs also have several application forms, such as bulk ceramics, ceramic matrix for fiber-reinforced ceramic composite, and ceramic coatings. Compared to the bulk high-entropy UHTCs, fiber-reinforced high-entropy UHTCs are expected to have higher mechanical reliability and the 
high-entropy UHTC coatings can take full advantage of the high oxidation resistance of high-entropy UHTCs. Investigations on fiber-reinforced high-entropy UHTC composites and high-entropy UHTC coatings are very important. Just recently, Cai et al. [399] reported $\mathrm{C}_{\mathrm{f}} /\left(\mathrm{Ti}_{0.2} \mathrm{Zr}_{0.2} \mathrm{Hf}_{0.2} \mathrm{Nb}_{0.2} \mathrm{Ta}_{0.2}\right) \mathrm{C}-\mathrm{SiC}$ high-entropy UHTC composite for the first time, which shows outstanding bending strength $(322 \mathrm{MPa})$, fracture toughness $\left(8.24 \mathrm{MPa} \cdot \mathrm{m}^{1 / 2}\right)$, and linear recession rate of $2.89 \mu \mathrm{m} \cdot \mathrm{s}^{-1}$ at a heat flux density of $5 \mathrm{MW} \cdot \mathrm{m}^{-2}$. However, studies on high-entropy UHTC composites and high-entropy UHTC coatings are very scarce till now.

In a summary, high-entropy UHTC is a new kind of UHTCs. It shows a series of good properties and is a potential candidate for ultra-high temperature applications. However, systematical investigations on the relationship among the composition, processing, microstructure, and property of high-entropy UHTCs are urgently needed. For the powder synthesis, adjusting the characteristics of high-entropy UHTC powders and understanding the relationship between their characteristics and the formability and sinterability are key issues in further work. For the preparation of high-entropy UHTCs, new sintering technologies and microstructure controlling approaches are important research interests. Fiber-reinforced high-entropy UHTC composites and high-entropy UHTC coatings will be hot topics in the future. For the properties, high-temperature strength, ablation resistance, thermal shock resistance, and even the melting points of high-entropy UHTCs and their composites are very worth to be studied.

\section{Summary and outlook}

UHTCs are generally referred to the carbides, nitrides, and borides of the transition metals, with the Group IVB compounds ( $\mathrm{Zr} \& \mathrm{Hf}$ ) and $\mathrm{TaC}$ as the main focus. Carbide and nitride UHTCs commonly have a face-centered cubic structure, while boride UHTCs have the $\mathrm{AlB}_{2}$ structure $(P 6 / \mathrm{mmm})$ composed of alternating planes of hexagonally close-packed metal atoms and graphite-like B atoms. The strong covalent structure endows the UHTCs with ultra-high melting points, excellent mechanical properties, and ablation resistance at elevated temperatures. These unique combinations of properties make UHTCs leading candidates for extremely environmental structural applications in rocket and hypersonic vehicles. Generally, bulk UTHCs are severely limited by their low fracture toughness and poor thermal shock resistance, hindering their direct use as external thermal protection systems on leading edges and propulsion systems. Although various toughening methods, such as particles, whiskers, carbon nanotubes, and graphene, have been developed, the reliability of bulk UHTCs still cannot meet the requirements of engineering applications. To solve the intrinsic brittleness of bulk ceramics fundamentally, coatings and fibers reinforced ceramic matrix composites are developed as the main application forms for UHTCs. This review presents the advances of processing approaches, composition and microstructure design, properties and mechanisms of UHTCs including from bulk materials to composites and coatings. In particular, the relationships among composition-processingstructure-properties of UHTCs are discussed. In the past few years, high-entropy UHTCs are developed rapidly as an emerging direction for ultra-high temperature materials, which has also been discussed in this review.

For the further development of UHTCs, there are still quite a few challenges should be considered. Technically and economically successful fabrication of the UHTCs and their high-performance retentions in extremely environmental conditions remain challenging.

1) Carbon fibers are the most commonly used reinforcements for UHTCMCs. However, the poor anti-oxidation properties of carbon fibers intrinsically restrict the performance of UHTCMCs under more extreme conditions. Development of UHTC fibers and $\mathrm{UHTC}_{\mathrm{f}} / \mathrm{UHTCs}$ can improve the performance of UHTCMCs fundamentally. Currently, only the US Matech GSM has reported the development of UHTC fibers, such as HfC fibers, TaC fibers, and $\mathrm{UHTC}_{\mathrm{f}} /$ UHTC composites. There is still a long way to go before the commercialization and application of the UHTC fibers and $\mathrm{UHTC}_{\mathrm{f}} / \mathrm{UHTC}$ composites.

2) Generally, property requirements of UHTC thermal structures at different areas are quite different. Therefore, composition and microstructure generally need to be designed to satisfy the specific requirements at different regions of the thermal structure. Joining the different parts as an integrity and its reliability under extreme service conditions are another big challenge for 
UHTCs. More efforts need to be taken toward technology breakthroughs such as cost-effective preparation, improved interphase quality, especially good thermal expansion compatibility between different parts, and enhanced ultra-high temperature stability in aggressive aero-thermo-chemical environments.

3) Characterizations of the UHTCs at real or near-real extreme service conditions are critical to reveal their actual failure mechanisms during service. This can provide a more accurate direction for material design to achieve high performance and long service life. Although various techniques have been developed, new and ever-more realistic testing is still required. In particular, tests that can be done rapidly and at low cost and which provide excellent guidance on the performance of the UHTCs and components under real or near real environmental conditions are needed.

4) Multiscale modelling, from Density Functional Theory (DFT) to Finite Element Analysis (FEA) and Computational Fluid Dynamics (CFD) will become essential. Integrated computational models which link across among composition, microstructure, processing, and properties are strongly required to be created and validated based on extensive experimental work and characterization. Although it is not easy, it will significantly reduce the costs for developing new UHTCs that offer the required properties.

\section{Acknowledgements}

The financial support from the National Natural Science Foundation of China (52032001, 52022072, 52032003, 51972243, 92060202, 51872239, 51872059, 51772061, 52061135102, 52002321, 50632070, 51272266, and 52102093), bilateral project of NSFC-JSPS (51111140017 and 51611140121), China Postdoctoral Science Foundation (2021M690817), Fundamental Research Funds for the Central Universities (G2020KY05125), Key Research Program of Frontier Sciences, CAS (QYZDY-SSWJSC031), the projects supported by the State Key Laboratory of Advanced Technology for Materials Synthesis and Processing, Wuhan University of Technology (2021-KF-5), and the State Key Laboratory for Modification of Chemical Fibers and Polymer Materials, Donghua University (KF2116) are greatly acknowledged. The authors also would like to thank Prof. Shi C. Zhang (Missouri University of Science and Technology, Rolla, Missouri, USA) for language proofreading and helpful suggestions.

\section{References}

[1] Telle R, Sigl LS, Takagi K. Boride-based hard materials. In Handbook of Ceramic Hard Materials. Weinheim, Germany: Wiley-VCH Verlag GmbH, 2000: 802-945.

[2] Fahrenholtz WG, Hilmas GE. Oxidation of ultra-high temperature transition metal diboride ceramics. Int Mater Rev 2012, 57: 61-72.

[3] Eakins E, Jayaseelan DD, Lee WE. Toward oxidationresistant $\mathrm{ZrB}_{2}-\mathrm{SiC}$ ultra high temperature ceramics. Metall Mater Trans A 2011, 42: 878-887.

[4] Guo SQ. Densification of $\mathrm{ZrB}_{2}$-based composites and their mechanical and physical properties: A review. J Eur Ceram Soc 2009, 29: 995-1011.

[5] Binner J, Porter M, Baker B, et al. Selection, processing, properties and applications of ultra-high temperature ceramic matrix composites, UHTCMCs-A review. Int Mater Rev 2020, 65: 389-444.

[6] Liu PC, Zhang PC, Pang XX, et al. A study on fabrication technique of $\mathrm{ZrB}_{2}$ target. Procedia Eng 2012, 27: 1305-1312.

[7] Nasseri MM. Comparison of $\mathrm{HfB}_{2}$ and $\mathrm{ZrB}_{2}$ behaviors for using in nuclear industry. Ann Nucl Energy 2018, 114: 603-606.

[8] Middleburgh SC, Parfitt DC, Blair PR, et al. Atomic scale modeling of point defects in zirconium diboride. $\mathrm{J} \mathrm{Am}$ Ceram Soc 2011, 94: 2225-2229.

[9] Glaser FW, Post B. System zirconium-boron. JOM 1953, 5: 1117-1118.

[10] Rogl P, Potter PE. A critical review and thermodynamic calculation of the binary system: Zirconium-boron. Calphad 1988, 12: 191-204.

[11] Mchale AE. Phase Diagrams for Ceramists Volume X: Borides, Carbides, and Nitrides. Westerville, OH, USA: The American Ceramic Society, 1994.

[12] Opeka MM, Talmy IG, Wuchina EJ, et al. Mechanical, thermal, and oxidation properties of refractory hafnium and zirconium compounds. J Eur Ceram Soc 1999, 19: 2405-2414.

[13] Kaplan FS, Kalyada TL, Gaenko NS, et al. Porous structure of the periclase plates of steel-teeming ladle slide gates. Refractories 1982, 23: 625-630.

[14] Opila E, Levine S, Lorincz J. Oxidation of $\mathrm{ZrB}_{2^{-}}$and $\mathrm{HfB}_{2}$-based ultra-high temperature ceramics: Effect of Ta additions. J Mater Sci 2004, 39: 5969-5977.

[15] Venkateswaran T, Basu B, Raju GB, et al. Densification and properties of transition metal borides-based cermets via spark plasma sintering. J Eur Ceram Soc 2006, 26: 2431-2440.

[16] Chamberlain AL, Fahrenholtz WG, Hilmas GE, et al. High-strength zirconium diboride-based ceramics. $J \mathrm{Am}$ Ceram Soc 2004, 87: 1170-1172.

[17] Cotton J. Ultra-high-temperature ceramics. Adv Mater Process 2010, 168: 26-28.

[18] Fahrenholtz WG, Hilmas GE, Talmy IG, et al. Refractory 
diborides of zirconium and hafnium. J Am Ceram Soc 2007, 90: 1347-1364.

[19] Hwang SS, Vasiliev AL, Padture NP. Improved processing an oxidation-resistance of $\mathrm{ZrB}_{2}$ ultra-high temperature ceramics containing $\mathrm{SiC}$ nanodispersoids. Mater Sci Eng A 2007, 464: 216-224.

[20] Rueschhoff LM, Carney CM, Apostolov ZD, et al. Processing of fiber-reinforced ultra-high temperature ceramic composites: A review. Int J Ceram Eng Sci 2020, 2: 22-37.

[21] Rubio V, Ramanujam P, Cousinet S, et al. Thermal properties and performance of carbon fiber-based ultra-high temperature ceramic matrix composites ( $\mathrm{C}_{\mathrm{f}}$-UHTCMCs). J Am Ceram Soc 2020, 103: 3788-3796.

[22] Ding Q, Ni DW, Wang Z, et al. 3D C $\mathrm{C}_{\mathrm{f}} / \mathrm{SiBCN}$ composites prepared by an improved polymer infiltration and pyrolysis. $J$ Adv Ceram 2018, 7: 266-275.

[23] Chen BW, Ding Q, Ni DW, et al. Microstructure and mechanical properties of $3 \mathrm{D} \mathrm{C}_{\mathrm{f}} / \mathrm{SiBCN}$ composites fabricated by polymer infiltration and pyrolysis. $J A d v$ Ceram 2021, 10: 28-38.

[24] Tang SF, Deng JY, Wang SJ, et al. Fabrication and characterization of an ultra-high-temperature carbon fiber-reinforced $\mathrm{ZrB}_{2}-\mathrm{SiC}$ matrix composite. J Am Ceram Soc 2007, 90: 3320-3322.

[25] Sayir A. Carbon fiber reinforced hafnium carbide composite. J Mater Sci 2004, 39: 5995-6003.

[26] Cecere A, Savino R, Allouis C, et al. Heat transfer in ultra-high temperature advanced ceramics under high enthalpy arc-jet conditions. Int J Heat Mass Transf 2015, 91: 747-755.

[27] Murthy TSRC, Reeman L, Zou J, et al. Role of rare earth oxide particles on the oxidation behaviour of silicon carbide coated 2.5D carbon fibre preforms. Open Ceram 2020, 2: 100018.

[28] Zou J, Zhang GJ, Kan YM. Formation of tough interlocking microstructure in $\mathrm{ZrB}_{2}-\mathrm{SiC}$-based ultrahightemperature ceramics by pressureless sintering. J Mater Res 2009, 24: 2428-2434.

[29] Zou J, Ma HB, Liu JJ, et al. Nanoceramic composites with duplex microstructure break the strength-toughness tradeoff. J Mater Sci Technol 2020, 58: 1-9.

[30] Pazhouhanfar Y, Sabahi Namini A, Shaddel S, et al. Combined role of $\mathrm{SiC}$ particles and $\mathrm{SiC}$ whiskers on the characteristics of spark plasma sintered $\mathrm{ZrB}_{2}$ ceramics. Ceram Int 2020, 46: 5773-5778.

[31] Jin H, Meng SH, Xie WH, et al. $\mathrm{HfB}_{2}-\mathrm{CNTs}$ composites with enhanced mechanical properties prepared by spark plasma sintering. Ceram Int 2017, 43: 2170-2173.

[32] Zhou $\mathrm{P}, \mathrm{Hu} \mathrm{P}$, Zhang XH, et al. R-curve behavior of laminated $\mathrm{ZrB}_{2}-\mathrm{SiC}$ ceramic with strong interfaces. Int $\mathrm{J}$ Refract Met Hard Mater 2015, 52: 12-16.

[33] Sciti D, Pienti L, Fabbriche DD, et al. Combined effect of $\mathrm{SiC}$ chopped fibers and $\mathrm{SiC}$ whiskers on the toughening of $\mathrm{ZrB}_{2}$. Ceram Int 2014, 40: 4819-4826.
[34] Silvestroni L, Sciti D, Melandri C, et al. Toughened $\mathrm{ZrB}_{2}$-based ceramics through $\mathrm{SiC}$ whisker or $\mathrm{SiC}$ chopped fiber additions. J Eur Ceram Soc 2010, 30: 2155-2164.

[35] Silvestroni L, Dalle Fabbriche D, Melandri C, et al. Relationships between carbon fiber type and interfacial domain in $\mathrm{ZrB}_{2}$-based ceramics. J Eur Ceram Soc 2016, 36: 17-24.

[36] Pulci G, Tului M, Tirillò J, et al. High temperature mechanical behavior of UHTC coatings for thermal protection of Re-entry vehicles. $J$ Therm Spray Technol 2011, 20: 139-144.

[37] Corral EL, Walker LS. Improved ablation resistance of $\mathrm{C}-\mathrm{C}$ composites using zirconium diboride and boron carbide. J Eur Ceram Soc 2010, 30: 2357-2364.

[38] Li SP, Li KZ, Li HJ, et al. Effect of HfC on the ablative and mechanical properties of $\mathrm{C} / \mathrm{C}$ composites. Mater Sci Eng: A 2009, 517: 61-67.

[39] Pavese M, Fino $\mathrm{P}$, Badini $\mathrm{C}$, et al. $\mathrm{HfB}_{2} / \mathrm{SiC}$ as a protective coating for $2 \mathrm{D} \mathrm{Cf} / \mathrm{SiC}$ composites: Effect of high temperature oxidation on mechanical properties. Surf Coat Technol 2008, 202: 2059-2067.

[40] Corral EL, Loehman RE. Ultra-high-temperature ceramic coatings for oxidation protection of carbon-carbon composites. J Am Ceram Soc 2008, 91: 1495-1502.

[41] Blum YD, Marschall J, Hui D, et al. Thick protective UHTC coatings for SiC-based structures: Process establishment. J Am Ceram Soc 2008, 91: 1453-1460.

[42] Cheng LF, Xu YD, Zhang LT, et al. Oxidation behavior from room temperature to $1500{ }^{\circ} \mathrm{C}$ of $3 \mathrm{D}-\mathrm{C} / \mathrm{SiC}$ composites with different coatings. J Am Ceram Soc 2004, 85: 989-991.

[43] Ushakov SV, Navrotsky A, Hong QJ, et al. Carbides and nitrides of zirconium and hafnium. Materials 2019, 12: 2728.

[44] Mei ZG, Bhattacharya S, Yacout AM. First-principles study of fracture toughness enhancement in transition metal nitrides. Surf Coat Technol 2019, 357: 903-909.

[45] Kuo CC, Lin YT, Chan A, et al. High temperature wear behavior of titanium nitride coating deposited using high power impulse magnetron sputtering. Coatings 2019, 9: 555.

[46] Demirskyi D, Solodkyi I, Nishimura T, et al. Fracture and property relationships in the double diboride ceramic composites by spark plasma sintering of $\mathrm{TiB}_{2}$ and $\mathrm{NbB}_{2} . J$ Am Ceram Soc 2019, 102: 4259-4271.

[47] Jin XC, Fan XL, Lu CS, et al. Advances in oxidation and ablation resistance of high and ultra-high temperature ceramics modified or coated carbon/carbon composites. $J$ Eur Ceram Soc 2018, 38: 1-28.

[48] Harrison RW, Lee WE. Processing and properties of $\mathrm{ZrC}$, $\mathrm{ZrN}$ and ZrCN ceramics: A review. Adv Appl Ceram 2016, 115: 294-307.

[49] Harrison RW, Lee WE. Mechanism and kinetics of oxidation of $\mathrm{ZrN}$ ceramics. J Am Ceram Soc 2015, 98: 2205-2213. 
[50] Li D, Tian FB, Duan DF, et al. Mechanical and metallic properties of tantalum nitrides from first-principles calculations. RSC Adv 2014, 4: 10133.

[51] Tallon C, Franks GV. Near-net-shaping of ultra-high temperature ceramics. In Ultra-High Temperature Ceramics. Hoboken, NJ, USA: John Wiley \& Sons, Inc, 2014: 83-111.

[52] Zapata-Solvas E, Jayaseelan DD, Lin HT, et al. Mechanical properties of $\mathrm{ZrB}_{2}$ - and $\mathrm{HfB}_{2}$-based ultra-high temperature ceramics fabricated by spark plasma sintering. J Eur Ceram Soc 2013, 33: 1373-1386.

[53] Information on https://hal.archives-ouvertes.fr/hal-01183657/ document.

[54] Wuchina E, Opila E, Opeka M, et al. UHTCs: Ultra-high temperature ceramic materials for extreme environment applications. Electrochem Soc Interface 2007, 16: 30-36.

[55] Matsushita J, Hwang GC, Shim KB. Oxidation behavior of tantalum boride ceramics. Solid State Phenom 2007, 124-126: 819-822.

[56] Basu B, Raju GB, Suri AK. Processing and properties of monolithic $\mathrm{TiB}_{2}$ based materials. Int Mater Rev 2006, 51: 352-374.

[57] Koh YH, Lee SY, Kim HE. Oxidation behavior of titanium boride at elevated temperatures. $\mathrm{J} \mathrm{Am} \mathrm{Ceram} \mathrm{Soc}$ 2001, 84: 239-241.

[58] Lévy F, Hones P, Schmid PE, et al. Electronic states and mechanical properties in transition metal nitrides. Surf Coat Technol 1999, 120-121: 284-290.

[59] Yu RM, Sun EM, Jiao LG, et al. Crystal structures of transition metal pernitrides predicted from first principles. RSC Adv 2018, 8: 36412-36421.

[60] Barraud E, Bégin-Colin S, Le Caër G, et al. Mechanically activated solid-state synthesis of hafnium carbide and hafnium nitride nanoparticles. J Alloys Compd 2008, 456: 224-233.

[61] Ibidunni AO, Masaitis RL, Opila RL, et al. Characterization of the oxidation of tantalum nitride. Surf Interface Anal 1993, 20: 559-564.

[62] Voitovich RF, Pugach ÉA. High-temperature oxidation characteristics of the carbides of the Group VI transition metals. Sov Powder Metall Met Ceram 1973, 12: 314-318.

[63] Karwal S, Verheijen MA, Arts K, et al. Plasma-assisted ALD of highly conductive $\mathrm{HfN}_{x}$ : On the effect of energetic ions on film microstructure. Plasma Chem Plasma Process 2020, 40: 697-712.

[64] Lu HP, Ran YJ, Zhao SJ, et al. Effects of assisting ions on the structural and plasmonic properties of $\mathrm{ZrN}_{x}$ thin films. J Phys D: Appl Phys 2019, 52: 245102.

[65] Wu YY, Kohn A, Eizenberg M. Structures of ultra-thin atomic-layer-deposited $\mathrm{TaN}_{x}$ films. J Appl Phys 2004, 95: 6167-6174.

[66] Fleurence A, Friedlein R, Ozaki T, et al. Experimental evidence for epitaxial silicene on diboride thin films. Phys Rev Lett 2012, 108: 245501.
[67] Sciti D, Silvestroni L, Bellosi A. Fabrication and properties of $\mathrm{HfB}_{2}-\mathrm{MoSi}_{2}$ composites produced by hot pressing and spark plasma sintering. J Mater Res 2006, 21: 1460-1466.

[68] Monteverde F, Bellosi A. Beneficial effects of AlN as sintering aid on microstructure and mechanical properties of hot-pressed $\mathrm{ZrB}_{2}$. Adv Eng Mater 2003, 5: 508-512.

[69] Wang MF, Wang CG, Zhang XH. Effects of SiC platelet and $\mathrm{ZrSi}_{2}$ additive on sintering and mechanical properties of $\mathrm{ZrB}_{2}$-based ceramics by hot-pressing. Mater Des 2012, 34: 293-297.

[70] Sciti D, Silvestroni L, Celotti G, et al. Sintering and mechanical properties of $\mathrm{ZrB}_{2}-\mathrm{TaSi}_{2}$ and $\mathrm{HfB}_{2}-\mathrm{TaSi}_{2}$ ceramic composites. J Am Ceram Soc 2008, 91: 32853291.

[71] Wang XG, Liu JX, Kan YM, et al. Effect of solid solution formation on densification of hot-pressed $\mathrm{ZrC}$ ceramics with $\mathrm{MC}(\mathrm{M}=\mathrm{V}, \mathrm{Nb}$, and Ta) additions. J Eur Ceram Soc 2012, 32: 1795-1802.

[72] Wang XG, Guo WM, Kan YM, et al. Densification behavior and properties of hot-pressed $\mathrm{ZrC}$ ceramics with $\mathrm{Zr}$ and graphite additives. J Eur Ceram Soc 2011, 31: 1103-1111.

[73] Medri V, Monteverde F, Balbo A, et al. Comparison of $\mathrm{ZrB}_{2}-\mathrm{ZrC}-\mathrm{SiC}$ composites fabricated by spark plasma sintering and hot-pressing. Adv Eng Mater 2005, 7: 159-163.

[74] Vafa NP, Shahedi Asl M, Jaberi Zamharir M, et al. Reactive hot pressing of $\mathrm{ZrB}_{2}$-based composites with changes in $\mathrm{ZrO}_{2} / \mathrm{SiC}$ ratio and sintering conditions. Part I: Densification behavior. Ceram Int 2015, 41: 8388-8396.

[75] Wang XG, Zhang GJ, Xue JX, et al. Reactive hot pressing of $\mathrm{ZrC}-\mathrm{SiC}$ ceramics at low temperature. J Am Ceram Soc 2013, 96: 32-36.

[76] Guo WM, Yang ZG, Zhang GJ. Comparison of $\mathrm{ZrB}_{2}-\mathrm{SiC}$ ceramics with $\mathrm{Yb}_{2} \mathrm{O}_{3}$ additive prepared by hot pressing and spark plasma sintering. Int J Refract Met Hard Mater 2011, 29: 452-455.

[77] Qu Q, Zhang XH, Meng SH, et al. Reactive hot pressing and sintering characterization of $\mathrm{ZrB}_{2}-\mathrm{SiC}-\mathrm{ZrC}$ composites. Mater Sci Eng: A 2008, 491: 117-123.

[78] Wu WW, Zhang GJ, Kan YM, et al. Synthesis and microstructural features of $\mathrm{ZrB}_{2}-\mathrm{SiC}$-based composites by reactive spark plasma sintering and reactive hot pressing. Scripta Mater 2007, 57: 317-320.

[79] Monteverde F. Ultra-high temperature $\mathrm{HfB}_{2}-\mathrm{SiC}$ ceramics consolidated by hot-pressing and spark plasma sintering. J Alloys Compd 2007, 428: 197-205.

[80] Yan YJ, Huang ZR, Dong SM, et al. Pressureless sintering of high-density $\mathrm{ZrB}_{2}-\mathrm{SiC}$ ceramic composites. $\mathrm{J} \mathrm{Am}$ Ceram Soc 2006, 89: 3589-3592.

[81] Chamberlain AL, Fahrenholtz WG, Hilmas GE. Pressureless sintering of zirconium diboride. J Am Ceram Soc 2006, 89: 450-456. 
[82] Fahrenholtz WG, Hilmas GE, Zhang SC, et al. Pressureless sintering of zirconium diboride: Particle size and additive effects. $J$ Am Ceram Soc 2008, 91: 1398-1404.

[83] Liu JX, Kan YM, Zhang GJ. Pressureless sintering of tantalum carbide ceramics without additives. J Am Ceram Soc 2010, 93: 370-373.

[84] Liu JX, Kan YM, Zhang GJ. Synthesis of ultra-fine hafnium carbide powder and its pressureless sintering. $J$ Am Ceram Soc 2010, 93: 980-986.

[85] Wang XG, Guo WM, Zhang GJ. Pressureless sintering mechanism and microstructure of $\mathrm{ZrB}_{2}-\mathrm{SiC}$ ceramics doped with boron. Scripta Mater 2009, 61: 177-180.

[86] Zhang SC, Hilmas GE, Fahrenholtz WG. Pressureless densification of zirconium diboride with boron carbide additions. J Am Ceram Soc 2006, 89: 1544-1550.

[87] Dole SL, Prochazka S, Doremus RH. Microstructural coarsening during sintering of boron carbide. J Am Ceram Soc 1989, 72: 958-966.

[88] Liu JX, Zhang GJ, Xu FF, et al. Densification, microstructure evolution and mechanical properties of WC doped $\mathrm{HfB}_{2}-\mathrm{SiC}$ ceramics. J Eur Ceram Soc 2015, 35: 2707-2714.

[89] Zou J, Zhang GJ, Kan YM, et al. Hot-pressed $\mathrm{ZrB}_{2}-\mathrm{SiC}$ ceramics with VC addition: Chemical reactions, microstructures, and mechanical properties. J Am Ceram Soc 2009, 92: 2838-2846.

[90] Monteverde F, Grohsmeyer RJ, Stanfield AD, et al. Densification behavior of $\mathrm{ZrB}_{2}-\mathrm{MoSi}_{2}$ ceramics: The formation and evolution of core-shell solid solution structures. J Alloys Compd 2019, 779: 950-961.

[91] Sun X, Han WB, Liu Q, et al. ZrB $\mathrm{rr}_{2}$-ceramic toughened by refractory metal $\mathrm{Nb}$ prepared by hot-pressing. Mater Des 2010, 31: 4427-4431.

[92] Wang HL, Chen DL, Wang CA, et al. Preparation and characterization of high-toughness $\mathrm{ZrB}_{2} /$ Mo composites by hot-pressing process. Int $J$ Refract Met Hard Mater 2009, 27: 1024-1026.

[93] Liu Q, Han WB, Hu P. Microstructure and mechanical properties of $\mathrm{ZrB}_{2}-\mathrm{SiC}$ nanocomposite ceramic. Scripta Mater 2009, 61: 690-692.

[94] Li WJ, Zhang XH, Hong CQ, et al. Microstructure and mechanical properties of zirconia-toughened $\mathrm{ZrB}_{2}-\mathrm{MoSi}_{2}$ composites prepared by hot-pressing. Scripta Mater 2009, 60: $100-103$.

[95] Han WB, Li G, Zhang XH, et al. Effect of AlN as sintering aid on hot-pressed $\mathrm{ZrB}_{2}-\mathrm{SiC}$ ceramic composite. $J$ Alloys Compd 2009, 471: 488-491.

[96] Guo SQ, Kagawa Y, Nishimura T. Mechanical behavior of two-step hot-pressed $\mathrm{ZrB}_{2}$-based composites with $\mathrm{ZrSi}_{2} . J$ Eur Ceram Soc 2009, 29: 787-794.

[97] Zhang XH, Xu L, Du SY, et al. Thermal shock behavior of SiC-whisker-reinforced diboride ultrahigh-temperature ceramics. Scripta Mater 2008, 59: 55-58.

[98] Monteverde F, Guicciardi S, Bellosi A. Advances in microstructure and mechanical properties of zirconium diboride based ceramics. Mater Sci Eng: A 2003, 346: 310-319.

[99] Meléndez-Martínez JJ, Domínguez-Rodríguez A, Monteverde F, et al. Characterisation and high temperature mechanical properties of zirconium boride-based materials. J Eur Ceram Soc 2002, 22: 2543-2549.

[100] Andrievskii RA, Korolev LA, Klimenko VV, et al. Effect of zirconium carbide and carbon additions on some physicomechanical properties of zirconium diboride. Sov Powder Metall Met Ceram 1980, 19: 93-94.

[101] Čech B, Oliverius P, Sejbal J. Sintering of zirconium boride with activating additions. Powder Metall 1965, 8: 142-151.

[102] Kislyi PS, Kuzenkova MA. Regularities of sintering of zirconium-diboride-molybenum alloys. Sov Powder Metall Met Ceram 1966, 5: 360-365.

[103] Einarsrud MA, Hagen E, Pettersen G, et al. Pressureless sintering of titanium diboride with nickel, nickel boride, and iron additives. J Am Ceram Soc 1997, 80: 3013-3020.

[104] Sciti D, Brach M, Bellosi A. Oxidation behavior of a pressureless sintered $\mathrm{ZrB}_{2}-\mathrm{MoSi}_{2}$ ceramic composite. $J$ Mater Res 2005, 20: 922-930.

[105] Rodríguez-Sánchez J, Sánchez-González E, Guiberteau F, et al. Contact-mechanical properties at intermediate temperatures of $\mathrm{ZrB}_{2}$ ultra-high-temperature ceramics pressureless sintered with Mo, Ta, or Zr disilicides. J Eur Ceram Soc 2015, 35: 3179-3185.

[106] Zhu SM, Fahrenholtz WG, Hilmas GE, et al. Pressureless sintering of zirconium diboride using boron carbide and carbon additions. J Am Ceram Soc 2007, 90: 3660-3663.

[107] Ma HB, Zou J, Lu P, et al. Oxygen contamination on the surface of $\mathrm{ZrB}_{2}$ powders and its removal. Scripta Mater 2017, 127: 160-164.

[108] Zou J, Zhang GJ, Sun SK, et al. $\mathrm{ZrO}_{2}$ removing reactions of Groups IV-VI transition metal carbides in $\mathrm{ZrB}_{2}$ based composites. J Eur Ceram Soc 2011, 31: 421-427.

[109] Ni DW, Liu JX, Zhang GJ. Pressureless sintering of $\mathrm{HfB}_{2}-\mathrm{SiC}$ ceramics doped with WC. J Eur Ceram Soc 2012, 32: 3627-3635.

[110] Zou J, Sun SK, Zhang GJ, et al. Chemical reactions, anisotropic grain growth and sintering mechanisms of self-reinforced $\mathrm{ZrB}_{2}-\mathrm{SiC}$ doped with WC. J Am Ceram Soc 2011, 94: 1575-1583.

[111] Zou J, Zhang GJ, Kan YM. Formation of tough interlocking microstructure in $\mathrm{ZrB}_{2}-\mathrm{SiC}$-based ultrahightemperature ceramics by pressureless sintering. $J$ Mater Res 2009, 24: 2428-2434.

[112] Krishnarao RV, Sankarasubramanian R. Thermite assisted synthesis of $\mathrm{ZrB}_{2}$ and $\mathrm{ZrB}_{2}-\mathrm{SiC}$ through $\mathrm{B}_{4} \mathrm{C}$ reduction of $\mathrm{ZrO}_{2}$ and $\mathrm{ZrSiO}_{4}$ in air. $J$ Adv Ceram 2017, 6: 139-148.

[113] Jafari S, Bavand-Vandchali M, Mashhadi M, et al. Effects of $\mathrm{HfB}_{2}$ addition on pressureless sintering behavior and microstructure of $\mathrm{ZrB}_{2}-\mathrm{SiC}$ composites. Int J Refract Met Hard Mater 2021, 94: 105371. 
[114] Zhang GJ, Deng ZY, Kondo N, et al. Reactive hot pressing of $\mathrm{ZrB}_{2}-\mathrm{SiC}$ composites. J Am Ceram Soc 2004, 83: $2330-2332$.

[115] Wu WW, Zhang GJ, Kan YM, et al. Reactive hot pressing of $\mathrm{ZrB}_{2}-\mathrm{SiC}-\mathrm{ZrC}$ ultra high-temperature ceramics at $1800{ }^{\circ} \mathrm{C}$. J Am Ceram Soc 2006, 89: 2967-2969.

[116] Zhao Y, Wang LJ, Zhang GJ, et al. Preparation and microstructure of a $\mathrm{ZrB}_{2}-\mathrm{SiC}$ composite fabricated by the spark plasma sintering-reactive synthesis (SPS-RS) method. J Am Ceram Soc 2007, 90: 4040-4042.

[117] Zhao H, He Y, Jin ZZ. Preparation of zirconium boride powder. J Am Ceram Soc 1995, 78: 2534-2536.

[118] Kannan R, Rangaraj L. Densification, mechanical, and tribological properties of $\mathrm{ZrB}_{2}-\mathrm{ZrC}_{x}$ composites produced by reactive hot pressing. $J$ Am Ceram Soc 2020, 103: 6120-6135.

[119] Zhang XH, Hu P, Du SY, et al. Research progress on ultra-high temperature ceramic composites. Chin Sci Bull 2015, 60: 257-266.

[120] Kim S, Chae JM, Lee SM, et al. Change in microstructures and physical properties of $\mathrm{ZrB}_{2}-\mathrm{SiC}$ ceramics hot-pressed with a variety of $\mathrm{SiC}$ sources. Ceram Int 2014, 40: 3477-3483.

[121] Zhang SC, Hilmas GE, Fahrenholtz WG. Mechanical properties of sintered $\mathrm{ZrB}_{2}-\mathrm{SiC}$ ceramics. J Eur Ceram Soc 2011, 31: 893-901.

[122] Zhang XH, Qu Q, Han JC, et al. Microstructural features and mechanical properties of $\mathrm{ZrB}_{2}-\mathrm{SiC}-\mathrm{ZrC}$ composites fabricated by hot pressing and reactive hot pressing. Scripta Mater 2008, 59: 753-756.

[123] Zhang XH, Xu L, Du SY, et al. Spark plasma sintering and hot pressing of $\mathrm{ZrB}_{2}-\mathrm{SiCW}$ ultra-high temperature ceramics. J Alloys Compd 2008, 466: 241-245.

[124] Wang Z, Hong CQ, Zhang XH, et al. Microstructure and thermal shock behavior of $\mathrm{ZrB}_{2}-\mathrm{SiC}$-graphite composite. Mater Chem Phys 2009, 113: 338-341.

[125] Chen DJ, Li WJ, Zhang XH, et al. Microstructural feature and thermal shock behavior of hot-pressed $\mathrm{ZrB}_{2}-\mathrm{SiC}-$ $\mathrm{ZrO}_{2}$ composite. Mater Chem Phys 2009, 116: 348-352.

[126] Guo QL, Li JG, Shen Q, et al. Toughening of $\mathrm{ZrB}_{2}-\mathrm{SiC}$ ceramics with the microstructure $\mathrm{ZrB}_{2} / \mathrm{Zr}-\mathrm{Al}-\mathrm{C}$ fibrous monolith. Scripta Mater 2012, 66: 296-299.

[127] Zhou $\mathrm{P}, \mathrm{Hu} \mathrm{P}$, Zhang $\mathrm{XH}$, et al. Laminated $\mathrm{ZrB}_{2}-\mathrm{SiC}$ ceramic with improved strength and toughness. Scripta Mater 2011, 64: 276-279.

[128] Fahrenholtz WG, Hilmas GE, Chamberlain AL, et al. Processing and characterization of $\mathrm{ZrB}_{2}$-based ultra-high temperature monolithic and fibrous monolithic ceramics. J Mater Sci 2004, 39: 5951-5957.

[129] Hu P, Wang Z. Flexural strength and fracture behavior of $\mathrm{ZrB}_{2}-\mathrm{SiC}$ ultra-high temperature ceramic composites at $1800{ }^{\circ} \mathrm{C}$. J Eur Ceram Soc 2010, 30: 1021-1026.

[130] Zou J, Zhang GJ, Vleugels J, et al. High temperature strength of hot pressed $\mathrm{ZrB}_{2}-20$ vol\% $\%$ SiC ceramics based on $\mathrm{ZrB}_{2}$ starting powders prepared by different carbo/boro-thermal reduction routes. J Eur Ceram Soc 2013, 33: 1609-1614.

[131] Zou J, Zhang GJ, Hu CF, et al. Strong $\mathrm{ZrB}_{2}-\mathrm{SiC}-\mathrm{WC}$ ceramics At $1600{ }^{\circ} \mathrm{C}$. J Am Ceram Soc 2012, 95: 874-878.

[132] Zou J, Ma HB, D'Angio A, et al. Tungsten carbide: A versatile additive to get trace alkaline-earth oxide impurities out of $\mathrm{ZrB}_{2}$ based ceramics. Scripta Mater 2018, 147: 40-44.

[133] Ma HB, Zou J, Zhu JT, et al. Segregation of tungsten atoms at $\mathrm{ZrB}_{2}$ grain boundaries in strong $\mathrm{ZrB}_{2}-\mathrm{SiC}-\mathrm{WC}$ ceramics. Scripta Mater 2018, 157: 76-80.

[134] $\mathrm{Hu} \mathrm{DL}, \mathrm{Gu} \mathrm{H}$, Zou J, et al. Core-rim structure, bi-solubility and a hierarchical phase relationship in hot-pressed $\mathrm{ZrB}_{2}-\mathrm{SiC}-\mathrm{MC}$ ceramics $(\mathrm{M}=\mathrm{Nb}, \mathrm{Hf}, \mathrm{Ta}, \mathrm{W})$. J Materiomics 2021, 7: 69-79.

[135] Dai FZ, Zhou YC, Sun W. Segregation of solute atoms (Y, $\mathrm{Nb}, \mathrm{Ta}, \mathrm{Mo}$ and $\mathrm{W}$ ) in $\mathrm{ZrB}_{2}$ grain boundaries and their effects on grain boundary strengths: A first-principles investigation. Acta Mater 2017, 127: 312-318.

[136] Dai FZ, Wen B, Xiang HM, et al. Grain boundary strengthening in $\mathrm{ZrB}_{2}$ by segregation of $\mathrm{W}$ : Atomistic simulations with deep learning potential. J Eur Ceram Soc 2020, 40: 5029-5036.

[137] Bellosi A, Monteverde F, Sciti D. Fast densification of ultra-high-temperature ceramics by spark plasma sintering. Int J Appl Ceram Technol 2006, 3: 32-40.

[138] Li WG, Yang F, Fang DN. The temperature-dependent fracture strength model for ultra-high temperature ceramics. Acta Mech Sin 2010, 26: 235-239.

[139] Wang RZ, Li WG, Ji BH, et al. Fracture strength of the particulate-reinforced ultra-high temperature ceramics based on a temperature dependent fracture toughness model. J Mech Phys Solids 2017, 107: 365-378.

[140] Wang RZ, Li WG, Li DY, et al. A new temperature dependent fracture strength model for the $\mathrm{ZrB}_{2}-\mathrm{SiC}$ composites. J Eur Ceram Soc 2015, 35: 2957-2962.

[141] Wang Y, Liang J, Han WB, et al. Mechanical properties and thermal shock behavior of hot-pressed $\mathrm{ZrB}_{2}-\mathrm{SiC}-$ AlN composites. J Alloys Compd 2009, 475: 762-765.

[142] Hasselman DPH. Strength behavior of polycrystalline alumina subjected to thermal shock. J Am Ceram Soc 1970, 53: 490-495.

[143] Hasselman DP. Thermal stress resistance parameters for brittle refractory ceramics: A compendium. Am Ceram Soc Bull 1970, 49: 1033-1037.

[144] Zimmermann JW, Hilmas GE, Fahrenholtz WG. Thermal shock resistance and fracture behavior of $\mathrm{ZrB}_{2}$-based fibrous monolith ceramics. J Am Ceram Soc 2009, 92: 161-166.

[145] Ritchie RO. The conflicts between strength and toughness. Nat Mater 2011, 10: 817-822.

[146] Zhao J, Xue JX, Liu HT, et al. ZrC ceramics incorporated with different-sized SiC particles. Adv Appl Ceram 2018, 117: 383-388. 
[147] Asl MS, Kakroudi MG, Noori S. Hardness and toughness of hot pressed $\mathrm{ZrB}_{2}-\mathrm{SiC}$ composites consolidated under relatively low pressure. J Alloys Compd 2015, 619: 481-487.

[148] Rezaie A, Fahrenholtz WG, Hilmas GE. Effect of hot pressing time and temperature on the microstructure and mechanical properties of $\mathrm{ZrB}_{2}-\mathrm{SiC}$. J Mater Sci 2007, 42: 2735-2744.

[149] Yuan LJ, Zhang PJ, Zuo F, et al. Comparison of sintering behavior and reinforcing mechanisms between $3 \mathrm{Y}-\mathrm{TZP} / \mathrm{Al}_{2} \mathrm{O}_{3(\mathrm{w})}$ and $12 \mathrm{Ce}-\mathrm{TZP} / \mathrm{Al}_{2} \mathrm{O}_{3(\mathrm{w})}$ composites: Combined effects of lanthanide stabilizer and $\mathrm{Al}_{2} \mathrm{O}_{3}$ whisker length. J Eur Ceram Soc 2021, 41: 706-718.

[150] Li JP, Meng SH, Wang ZB, et al. Study on ZrC-20 vol. $\% \mathrm{SiC}_{\mathrm{w}}$ ultrahigh temperature ceramics by hot pressing. Adv Mater Res 2012, 557-559: 772-775.

[151] Zhang XH, Xu L, Du SY, et al. Fabrication and mechanical properties of $\mathrm{ZrB}_{2}-\mathrm{SiCw}$ ceramic matrix composite. Mater Lett 2008, 62: 1058-1060.

[152] Iijima S. Helical microtubules of graphitic carbon. Nat 1991, 354: 56-58.

[153] Tian WB, Kan YM, Zhang GJ, et al. Effect of carbon nanotubes on the properties of $\mathrm{ZrB}_{2}-\mathrm{SiC}$ ceramics. Mater Sci Eng: A 2008, 487: 568-573.

[154] Lin J, Huang Y, Zhang H, et al. Microstructure and mechanical properties of multiwalled carbon nanotube toughened spark plasma sintered $\mathrm{ZrB}_{2}$ composites. $A d v$ Appl Ceram 2016, 115: 308-312.

[155] Li L, Zhang D, Deng JP, et al. Review-Progress of research on the preparation of graphene oxide via electrochemical approaches. J Electrochem Soc 2020, 167: 155519.

[156] Ocak BC, Yavas B, Akin I, et al. Spark plasma sintered ZrC-TiC-GNP composites: Solid solution formation and mechanical properties. Ceram Int 2018, 44: 2336-2344.

[157] Cheng YH, Hu P, Zhou SB, et al. Using macroporous graphene networks to toughen $\mathrm{ZrC}-\mathrm{SiC}$ ceramic. J Eur Ceram Soc 2018, 38: 3752-3758.

[158] Rama Rao GA, Venugopal V. Kinetics and mechanism of the oxidation of ZrC. J Alloys Compd 1994, 206: 237-242.

[159] Voitovich RF, Pugach ÉA. High-temperature oxidation of ZrC and HfC. Sov Powder Metall Met Ceram 1973, 12: 916-921.

[160] Florez R, Crespillo ML, He XQ, et al. Early stage oxidation of $\mathrm{ZrC}$ under $10 \mathrm{MeV} \mathrm{Au}{ }^{3+}$ ion-irradiation at $800{ }^{\circ} \mathrm{C}$. Corros Sci 2020, 169: 108609.

[161] Zhang XH, Hu P, Meng SH, et al. Microstructure and mechanical properties of $\mathrm{ZrB}_{2}$-based ceramics. Key Eng Mater 2006, 312: 287-292.

[162] Hu P, Gui K, Yang Y, et al. Effect of SiC content on the ablation and oxidation behavior of $\mathrm{ZrB}_{2}$-based ultra high temperature ceramic composites. Materials: Basel 2013, 6: $1730-1744$.

[163] Zhang DY, Hu P, Dong S, et al. Microstructures and mechanical properties of $\mathrm{C}_{\mathrm{f}} / \mathrm{ZrB}_{2}-\mathrm{SiC}$ composite fabricated by nano slurry brushing combined with low-temperature hot pressing. J Alloys Compd 2019, 789: 755-761.

[164] Fahrenholtz WG. Thermodynamic analysis of $\mathrm{ZrB}_{2}-\mathrm{SiC}$ oxidation: Formation of a SiC-depleted region. $\mathrm{J} \mathrm{Am}$ Ceram Soc 2007, 90: 143-148.

[165] Darihaki F, Balak Z, Eatemadi R. Effect of nano and micro $\mathrm{SiC}$ particles on the microstructure and fracture toughness of $\mathrm{ZrB}_{2}-\mathrm{SiC}$ nanocomposite produced by SPS method. Mater Res Express 2019, 6: 095608.

[166] Zhao LY. Effect of $\mathrm{SiC}$ and $\mathrm{LaB}_{6}$ on mechanical properties and oxidation resistance of $\mathrm{ZrC}$ ceramic. Ph.D. Thesis. Harbin (China): Harbin Institute of Technology, 2012. (in Chinese)

[167] He RJ, Zhang XH, Hu P, et al. Aqueous gelcasting of $\mathrm{ZrB}_{2}-\mathrm{SiC}$ ultra high temperature ceramics. Ceram Int 2012, 38: 5411-5418.

[168] Parthasarathy TA, Rapp RA, Opeka M, et al. A model for the oxidation of $\mathrm{ZrB}_{2}, \mathrm{HfB}_{2}$ and $\mathrm{TiB}_{2}$. Acta Mater 2007, 55: 5999-6010.

[169] Ping H, Wang GL, Zhi W. Oxidation mechanism and resistance of $\mathrm{ZrB}_{2}-\mathrm{SiC}$ composites. Corros Sci 2009, 51: 2724-2732.

[170] Zhang XH, Hu P, Han JC. Structure evolution of $\mathrm{ZrB}_{2}-\mathrm{SiC}$ during the oxidation in air. J Mater Res 2008, 23: 1961-1972.

[171] Han WB, Hu P, Zhang $\mathrm{XH}$, et al. High-temperature oxidation at $1900{ }^{\circ} \mathrm{C}$ of $\mathrm{ZrB}_{2-x} \mathrm{SiC}$ ultrahigh-temperature ceramic composites. J Am Ceram Soc 2008, 91: 3328-3334.

[172] Li Y, Yang X, Wang W, et al. Reaction behavior, microstructure, and radiative properties of in situ $\mathrm{ZrB}_{2}-\mathrm{SiC}$ ceramic composites from a $\mathrm{Si}-\mathrm{Zr}-\mathrm{B}_{4} \mathrm{C}$ system. J Mater Eng Perform 2020, 29: 4822-4829.

[173] Ni DW, Zhang GJ, Xu FF, et al. Initial stage of oxidation process and microstructure analysis of $\mathrm{HfB}_{2}-20$ vol.\% $\mathrm{SiC}$ composite at $1500{ }^{\circ} \mathrm{C}$. Scripta Mater 2011, 64: 617-620.

[174] $\mathrm{Lu} \mathrm{Y,} \mathrm{Zou} \mathrm{J,} \mathrm{Xu} \mathrm{FF,} \mathrm{et} \mathrm{al.} \mathrm{Volatility} \mathrm{diagram} \mathrm{of}$ $\mathrm{ZrB}_{2}-\mathrm{SiC}-\mathrm{ZrC}$ system and experimental validation. $J \mathrm{Am}$ Ceram Soc 2018, 101: 3627-3635.

[175] Han JC, Hu P, Zhang XH, et al. Oxidation-resistant $\mathrm{ZrB}_{2}-\mathrm{SiC}$ composites at $2200{ }^{\circ} \mathrm{C}$. Compos Sci Technol 2008, 68: 799-806.

[176] Hu P, Zhang DY, Dong S, et al. A novel vibration-assisted slurry impregnation to fabricate $\mathrm{C}_{\mathrm{f}} / \mathrm{ZrB}_{2}-\mathrm{SiC}$ composite with enhanced mechanical properties. J Eur Ceram Soc 2019, 39: 798-805.

[177] Gui KX, Liu FY, Wang G, et al. Microstructural evolution and performance of carbon fiber-toughened $\mathrm{ZrB}_{2}$ ceramics with $\mathrm{SiC}$ or $\mathrm{ZrSi}_{2}$ additive. J Adv Ceram 2018, 7: 343-351.

[178] Shojaie-Bahaabad M, Hasani-Arefi A. Ablation properties of $\mathrm{ZrC}-\mathrm{SiC}-\mathrm{HfB}_{2}$ ceramic with different 
amount of carbon fiber under an oxyacetylene flame. Mater Res Express 2020, 7: 025604.

[179] Baharvandi HR, Mashayekh S. Effects of SiC content on the densification, microstructure, and mechanical properties of $\mathrm{HfB}_{2}-\mathrm{SiC}$ composites. Int J Appl Ceram Technol 2020, 17: 449-458.

[180] Simonenko EP, Simonenko NP, Gordeev AN, et al. The effects of subsonic and supersonic dissociated air flow on the surface of ultra-high-temperature $\mathrm{HfB}_{2}-30$ vol\% $\mathrm{SiC}$ ceramics obtained using the Sol-gel method. J Eur Ceram Soc 2020, 40: 1093-1102.

[181] Weng L, Zhang XH, Han WB, et al. Fabrication and evaluation on thermal stability of hafnium diboride matrix composite at severe oxidation condition. Int J Refract Met Hard Mater 2009, 27: 711-717.

[182] Monteverde F, Bellosi A. Microstructure and properties of an $\mathrm{HfB}_{2}-\mathrm{SiC}$ composite for ultra high temperature applications. Adv Eng Mater 2004, 6: 331-336.

[183] Zhang SC, Hilmas GE, Fahrenholtz WG. Oxidation of zirconium diboride with tungsten carbide additions. $\mathrm{J} \mathrm{Am}$ Ceram Soc 2011, 94: 1198-1205.

[184] Ni DW, Zhang GJ, Kan YM, et al. Textured $\mathrm{HfB}_{2}$-based ultrahigh-temperature ceramics with anisotropic oxidation behavior. Scripta Mater 2009, 60: 913-916.

[185] Ni DW, Zhang GJ, Kan YM, et al. Highly textured $\mathrm{ZrB}_{2}$-based ultrahigh temperature ceramics via strong magnetic field alignment. Scripta Mater 2009, 60: 615-618.

[186] Zhang GJ, Ni DW, Zou J, et al. Inherent anisotropy in transition metal diborides and microstructure/property tailoring in ultra-high temperature ceramics-A review. $J$ Eur Ceram Soc 2018, 38: 371-389.

[187] Liu HT, Zou J, Ni DW, et al. Anisotropy oxidation of textured $\mathrm{ZrB}_{2}-\mathrm{MoSi}_{2}$ ceramics. J Eur Ceram Soc 2012, 32: 3469-3476.

[188] Li F, Kang Z, Huang X, et al. Fabrication of zirconium carbide nanofibers by electrospinning. Ceram Int 2014, 40: 10137-10141.

[189] She J, Zhan YZ, Pang MJ, et al. In situ synthesized $\left(\mathrm{ZrB}_{2}+\mathrm{ZrC}\right)$ hybrid short fibers reinforced $\mathrm{Zr}$ matrix composites for nuclear applications. Int $J$ Refract Met Hard Mater 2011, 29: 401-404.

[190] Ren JC, Zhang YL, Hu H, et al. Oxidation resistance and mechanical properties of HfC nanowire-toughened ultra-high temperature ceramic coating for SiC-coated C/C composites. Appl Surf Sci 2016, 360: 970-978.

[191] Sciti D, Pienti L, Natali Murri A, et al. From random chopped to oriented continuous $\mathrm{SiC}$ fibers $-\mathrm{ZrB}_{2}$ composites. Mater Des 2014, 63: 464-470.

[192] Pienti L, Sciti D, Silvestroni L, et al. Effect of milling on the mechanical properties of chopped SiC fiber-reinforced $\mathrm{ZrB}_{2}$. Materials 2013, 6: 1980-1993.

[193] Sciti D, Guicciardi S, Silvestroni L. SiC chopped fibers reinforced $\mathrm{ZrB}_{2}$ : Effect of the sintering aid. Scripta Mater 2011, 64: 769-772.
[194] Failla S, Galizia P, Zoli L, et al. Toughening effect of non-periodic fiber distribution on crack propagation energy of UHTC composites. J Alloys Compd 2019, 777: 612-618.

[195] Chen SA, Hu HF, Zhang YD, et al. Effects of TaC amount on the properties of $2 \mathrm{D} \mathrm{C} / \mathrm{SiC}-\mathrm{TaC}$ composites prepared via precursor infiltration and pyrolysis. Mater Des 2013, 51: 19-24.

[196] Rubio V, Binner J, Cousinet S, et al. Materials characterisation and mechanical properties of $\mathrm{C}_{\mathrm{f}}$-UHTC powder composites. J Eur Ceram Soc 2019, 39: 813-824.

[197] Rueschhoff LM, Carney CM, Apostolov ZD, et al. Processing of fiber-reinforced ultra-high temperature ceramic composites: A review. Int J Ceram Eng Sci 2020, 2: 22-37.

[198] Chen BW, Ni DW, Liao CJ, et al. Long-term ablation behavior and mechanisms of $2 \mathrm{D}-\mathrm{C}_{\mathrm{f}} / \mathrm{ZrB}_{2}-\mathrm{SiC}$ composites at temperatures up to $2400{ }^{\circ} \mathrm{C}$. Corros Sci 2020, 177: 108967.

[199] Zhou HJ, Yang JS, Le G, et al. Effect of ZrC amount and distribution on the thermomechanical properties of $\mathrm{C}_{\mathrm{f}} / \mathrm{SiC}-\mathrm{ZrC}$ composites. Int J Appl Ceram Technol 2019, 16: 1321-1328.

[200] Ding Q, Chen BW, Ni DW, et al. Improved ablation resistance of $3 \mathrm{D}-\mathrm{C}_{\mathrm{f}} / \mathrm{SiBCN}$ composites with $(\mathrm{PyC} / \mathrm{SiC})_{3}$ multi-layers as interphase. J Eur Ceram Soc 2021, 41: 1114-1120.

[201] Xie J, Li KZ, Sun GD, et al. Effects of surface structure unit of $2 \mathrm{D}$ needled carbon fiber preform on the microstructure and ablation properties of $\mathrm{C} / \mathrm{C}-\mathrm{ZrC}-\mathrm{SiC}$ composites. Ceram Int 2019, 45: 11912-11919.

[202] Li QG, Dong SM, Wang Z, et al. Microstructures and mechanical properties of 3D 4-directional, $\mathrm{C}_{\mathrm{f}} / \mathrm{ZrC}-\mathrm{SiC}$ composites using $\mathrm{ZrC}$ precursor and polycarbosilane. Mater Sci Eng: B 2013, 178: 1186-1190.

[203] Ogasawara T, Aoki T, Hassan MSA, et al. Ablation behavior of $\mathrm{SiC}$ fiber/carbon matrix composites under simulated atmospheric reentry conditions. Compos $A$ : Appl Sci Manuf 2011, 42: 221-228.

[204] Zhu GX, Dong SM, Ni DW, et al. Microstructure, mechanical properties and oxidation resistance of $\mathrm{SiC}_{\mathrm{f}} / \mathrm{SiC}$ composites incorporated with boron nitride nanotubes. RSC Adv 2016, 6: 83482-83492.

[205] Zhu GX, Dong SM, Hu JB, et al. In situ growth behavior of boron nitride nanotubes on the surface of silicon carbide fibers as hierarchical reinforcements. RSC Adv 2016, 6: 14112-14119.

[206] Boitier G, Darzens S, Chermant JL, et al. Microstructural investigation of interfaces in CMCs. Compos A: Appl Sci Manuf 2002, 33: 1467-1470.

[207] Kerans RJ, Hay RS, Parthasarathy TA, et al. Interface design for oxidation-resistant ceramic composites. $J \mathrm{Am}$ Ceram Soc 2002, 85: 2599-2632.

[208] Yun HM, Dicarlo JA. Comparison of the tensile, creep, and rupture strength properties of stoichiometric $\mathrm{SiC}$ 
fibers. Ustundag E, Fischman G, eds. In 23rd Annual Conference on Composites, Advanced Ceramics, Materials, and StructuresCeramic Engineering and Science Proceedings, Volume 20. Westerville, OH, USA: 1999, 259-272.

[209] Ni DW, Wang JX, Dong SM, et al. Fabrication and properties of $\mathrm{C}_{\mathrm{f}} / \mathrm{ZrC}-\mathrm{SiC}$-based composites by an improved reactive melt infiltration. J Am Ceram Soc 2018, 101: 3253-3258.

[210] Zeng Y, Wang DN, Xiong X, et al. Ablation-resistant carbide $\mathrm{Zr}_{0.8} \mathrm{Ti}_{0.2} \mathrm{C}_{0.74} \mathrm{~B}_{0.26}$ for oxidizing environments up to $3,000{ }^{\circ} \mathrm{C}$. Nat Commun 2017, 8: 15836.

[211] Zhang JP, Fu QG, Tong MD, et al. Microstructure, ablation behavior and thermal retardant ability of $\mathrm{C} / \mathrm{C}-\mathrm{HfB}_{2}$ composites prepared by precursor infiltration pyrolysis combined with chemical vapor infiltration. $J$ Alloys Compd 2018, 742: 123-129.

[212] Yan CL, Liu RJ, Zhang CR, et al. Effects of SiC/HfC ratios on the ablation and mechanical properties of $3 \mathrm{D}$ $\mathrm{C}_{\mathrm{f}} / \mathrm{HfC}-\mathrm{SiC}$ composites. J Eur Ceram Soc 2017, 37: 2343-2351.

[213] Paul A, Binner J, Vaidhyanathan B. UHTC composites for hypersonic applications. In Ultra-high Temperature Ceramics. Hoboken, New Jersey, USA: John Wiley \& Sons, 2014, 144-166.

[214] Chen ZK, Xiong X. Microstructure, mechanical properties and oxidation behavior of carbon fiber reinforced $\mathrm{PyC} / \mathrm{C}-\mathrm{TaC} / \mathrm{PyC}$ layered-structure ceramic matrix composites prepared by chemical vapor infiltration. Mater Chem Phys 2013, 141: 613-619.

[215] Pienti L, Sciti D, Silvestroni L, et al. Ablation tests on HfC- and TaC-based ceramics for aeropropulsive applications. J Eur Ceram Soc 2015, 35: 1401-1411.

[216] Vinci A, Zoli L, Sciti D. Influence of SiC content on the oxidation of carbon fibre reinforced $\mathrm{ZrB}_{2} / \mathrm{SiC}$ composites at 1500 and $1650{ }^{\circ} \mathrm{C}$ in air. J Eur Ceram Soc 2018, 38: 3767-3776.

[217] Patra N, Al Nasiri N, Jayaseelan DD, et al. Thermal properties of $\mathrm{C}_{\mathrm{f}} / \mathrm{HfC}$ and $\mathrm{C}_{\mathrm{f}} / \mathrm{HfC}-\mathrm{SiC}$ composites prepared by precursor infiltration and pyrolysis. $J$ Eur Ceram Soc 2018, 38: 2297-2303.

[218] Luo L, Liu JP, Duan LY, et al. Multiple ablation resistance of $\mathrm{La}_{2} \mathrm{O}_{3} / \mathrm{Y}_{2} \mathrm{O}_{3}$-doped $\mathrm{C} / \mathrm{SiC}-\mathrm{ZrC}$ composites. Ceram Int 2015, 41: 12878-12886.

[219] Zeng Y, Wang DN, Xiong X, et al. Ultra-high-temperature ablation behavior of $\mathrm{SiC}-\mathrm{ZrC}-\mathrm{TiC}$ modified carbon/carbon composites fabricated via reactive melt infiltration. J Eur Ceram Soc 2020, 40: 651-659.

[220] Pan XH, Niu YR, Xu XT, et al. Long time ablation behaviors of designed $\mathrm{ZrC}-\mathrm{SiC}-\mathrm{TiC}$ ternary coatings for environments above $2000{ }^{\circ} \mathrm{C}$. Corros Sci 2020, 170: 108645.

[221] Ding Q, Ni DW, Ni N, et al. Thermal damage and microstructure evolution mechanisms of $\mathrm{C}_{\mathrm{f}} / \mathrm{SiBCN}$ composites during plasma ablation. Corros Sci 2020, 169: 108621.
[222] Liang B, Yang ZH, Li YT, et al. Ablation behavior and mechanism of $\mathrm{SiC}_{\mathrm{f}} / \mathrm{C}_{\mathrm{f}} / \mathrm{SiBCN}$ ceramic composites with improved thermal shock resistance under oxyacetylene combustion flow. Ceram Int 2015, 41: 8868-8877.

[223] Li DX, Yang ZH, Jia DC, et al. Ablation behavior of graphene reinforced $\mathrm{SiBCN}$ ceramics in an oxyacetylene combustion flame. Corros Sci 2015, 100: 85-100.

[224] Wang JY, Duan XM, Yang ZH, et al. Ablation mechanism and properties of $\mathrm{SiC}_{\mathrm{f}} / \mathrm{SiBCN}$ ceramic composites under an oxyacetylene torch environment. Corros Sci 2014, 82: 101-107.

[225] Rubio V, Ramanujam P, Binner J. Ultra-high temperature ceramic composite. Adv Appl Ceram 2018, 117: s56-s61.

[226] Tang SF, Hu CL. Design, preparation and properties of carbon fiber reinforced ultra-high temperature ceramic composites for aerospace applications: A review. J Mater Sci Technol 2017, 33: 117-130.

[227] Wang HD, Feng Q, Wang Z, et al. Microstructure evolution and high-temperature mechanical properties of $\mathrm{SiC}_{\mathrm{f}} / \mathrm{SiC}$ composites in liquid fluoride salt environment. Corros Sci 2017, 124: 131-137.

[228] Baker B, Rubio V, Ramanujam P, et al. Development of a slurry injection technique for continuous fibre ultra-high temperature ceramic matrix composites. J Eur Ceram Soc 2019, 39: 3927-3937.

[229] Servadei F, Zoli L, Galizia P, et al. Development of UHTCMCs via water based $\mathrm{ZrB}_{2}$ powder slurry infiltration and polymer infiltration and pyrolysis. $J$ Eur Ceram Soc 2020, 40: 5076-5084.

[230] Yan CL, Liu RJ, Cao YB, et al. Fabrication and properties of PIP 3D C $\mathrm{f} / \mathrm{ZrC}-\mathrm{SiC}$ composites. Mater Sci Eng: A 2014, 591: 105-110.

[231] Yan CL, Liu RJ, Cao YB, et al. Preparation and properties of 3D needle-punched $\mathrm{C} / \mathrm{ZrC}-\mathrm{SiC}$ composites by polymer infiltration and pyrolysis process. Ceram Int 2014, 40: 10961-10970.

[232] Duan LY, Luo L, Liu LP, et al. Ablation of C/SiC-HfC composite prepared by precursor infiltration and pyrolysis in plasma wind tunnel. $J A d v$ Ceram 2020, 9: 393-402.

[233] Wang Z, Dong SM, Zhang XY, et al. Fabrication and properties of $\mathrm{C}_{\mathrm{f}} / \mathrm{SiC}-\mathrm{ZrC}$ composites. J Am Ceram Soc 2008, 91: 3434-3436.

[234] Chen SA, Zhang YD, Zhang CR, et al. Effects of SiC interphase by chemical vapor deposition on the properties of $\mathrm{C} / \mathrm{ZrC}$ composite prepared via precursor infiltration and pyrolysis route. Mater Des 2013, 46: 497-502.

[235] Li QG, Dong SM, Wang Z, et al. Fabrication and properties of 3-D $\mathrm{C}_{\mathrm{f}} / \mathrm{ZrB}_{2}-\mathrm{ZrC}-\mathrm{SiC}$ composites via polymer infiltration and pyrolysis. Ceram Int 2013, 39: 5937-5941.

[236] Zhang MY, Li KZ, Shi XH, et al. Effects of SiC interphase on the mechanical and ablation properties of $\mathrm{C} / \mathrm{C}-\mathrm{ZrC}-\mathrm{ZrB}_{2}-\mathrm{SiC}$ composites prepared by precursor infiltration and pyrolysis. Mater Des 2017, 122: 322-329.

[237] Hu P, Cheng Y, Zhang DY, et al. From ferroconcrete to 
$\mathrm{C}_{\mathrm{f}} / \mathrm{UHTC}-\mathrm{SiC}$ : A totally novel densification method and mechanism at $1300{ }^{\circ} \mathrm{C}$ without pressure. Compos B: Eng 2019, 174: 107023.

[238] Zou LH, Wali N, Yang JM, et al. Microstructural development of a $\mathrm{C}_{\mathrm{f}} / \mathrm{ZrC}$ composite manufactured by reactive melt infiltration. J Eur Ceram Soc 2010, 30: $1527-1535$.

[239] Chen BW, Ni DW, Wang JX, et al. Ablation behavior of $\mathrm{C}_{\mathrm{f}} / \mathrm{ZrC}-\mathrm{SiC}$-based composites fabricated by an improved reactive melt infiltration. J Eur Ceram Soc 2019, 39: 4617-4624.

[240] Zhao ZG, Li KZ, Li W, et al. Ablation behavior of $\mathrm{C} / \mathrm{C}-\mathrm{ZrC}-\mathrm{SiC}$ composites prepared by reactive melt infiltration under oxyacetylene torch at two heat fluxes. Ceram Int 2018, 44: 17345-17358.

[241] Wing BL, Halloran JW. Microstress in the matrix of a melt-infiltrated $\mathrm{SiC} / \mathrm{SiC}$ ceramic matrix composite. $J \mathrm{Am}$ Ceram Soc 2017, 100: 5286-5294.

[242] Tong YG, Bai SX, Chen K. C/C-ZrC composite prepared by chemical vapor infiltration combined with alloyed reactive melt infiltration. Ceram Int 2012, 38: 5723-5730.

[243] Chen XW, Feng Q, Gao L, et al. Interphase degradation of three-dimensional $\quad \mathrm{C}_{\mathrm{f}} / \mathrm{SiC}-\mathrm{ZrC}-\mathrm{ZrB}_{2} \quad$ composites fabricated via reactive melt infiltration. $\mathrm{J} \mathrm{Am} \mathrm{Ceram} \mathrm{Soc}$ 2017, 100: 4816-4826.

[244] Vinci A, Zoli L, Galizia P, et al. Reactive melt infiltration of carbon fibre reinforced $\mathrm{ZrB}_{2} / \mathrm{B}$ composites with $\mathrm{Zr}_{2} \mathrm{Cu}$. Compos A: Appl Sci Manuf 2020, 137: 105973.

[245] Levenspiel O. Ingeniería de las Reacciones Químicas. 2nd edn. Barcelona: Wiley, 1990. (in Spanish)

[246] Chen XW, Feng Q, Kan YM, et al. Effects of preform pore structure on infiltration kinetics and microstructure evolution of RMI-derived $\mathrm{C}_{\mathrm{f}} / \mathrm{ZrC}-\mathrm{ZrB}_{2}-\mathrm{SiC}$ composite. $J$ Eur Ceram Soc 2020, 40: 2683-2690.

[247] Li L, Qiao HW, Li QG, et al. In situ fabrication and characterization of laminated $\mathrm{C} / \mathrm{ZrC}$ ceramic via filter papers and zirconia powders. Ceram Int 2017, 43: 5607-5615.

[248] Zoli L, Vinci A, Silvestroni L, et al. Rapid spark plasma sintering to produce dense UHTCs reinforced with undamaged carbon fibres. Mater Des 2017, 130: 1-7.

[249] Zoli L, Sciti D. Efficacy of a $\mathrm{ZrB}_{2}-\mathrm{SiC}$ matrix in protecting $\mathrm{C}$ fibres from oxidation in novel UHTCMC materials. Mater Des 2017, 113: 207-213.

[250] Zoli L, Vinci A, Galizia P, et al. Is spark plasma sintering suitable for the densification of continuous carbon fibre-UHTCMCs? J Eur Ceram Soc 2020, 40: 25972603.

[251] Yao JJ, Pang SY, Hu CL, et al. Mechanical, oxidation and ablation properties of $\mathrm{C} /(\mathrm{C}-\mathrm{SiC}) \mathrm{CVI}-(\mathrm{ZrC}-\mathrm{SiC}) \mathrm{PIP}$ composites. Corros Sci 2020, 162: 108200.

[252] Zhang DY, Hu P, Feng JX, et al. Characterization and mechanical properties of $\mathrm{C}_{\mathrm{f}} / \mathrm{ZrB}_{2}-\mathrm{SiC}$ composites fabricated by a hybrid technique based on slurry impregnation, polymer infiltration and pyrolysis and low-temperature hot pressing. Ceram Int 2019, 45: 5467-5474.

[253] Zhang DY, Hu P, Dong S, et al. Oxidation behavior and ablation mechanism of $\mathrm{C}_{\mathrm{f}} / \mathrm{ZrB}_{2}-\mathrm{SiC}$ composite fabricated by vibration-assisted slurry impregnation combined with low-temperature hot pressing. Corros Sci 2019, 161: 108181.

[254] Wang YG, Liu W, Cheng LF, et al. Preparation and properties of $2 \mathrm{D} \mathrm{C} / \mathrm{ZrB}_{2}-\mathrm{SiC}$ ultra high temperature ceramic composites. Mater Sci Eng: A 2009, 524: 129-133.

[255] Ouyang HB, Zhang YL, Li CY, et al. Effects of ZrC/SiC ratios on mechanical and ablation behavior of $\mathrm{C} / \mathrm{C}-\mathrm{ZrC}-\mathrm{SiC}$ composites prepared by carbothermal reaction of hydrothermal co-deposited oxides. Corros Sci 2020, 163: 108239.

[256] Yan CL, Liu RJ, Zhang CR, et al. Effect of PyC interphase thickness on mechanical and ablation properties of $3 \mathrm{D}$ $\mathrm{C}_{\mathrm{f}} / \mathrm{ZrC}-\mathrm{SiC}$ composite. Ceram Int 2016, 42: 1275612762.

[257] Li QG, Dong SM, Wang Z, et al. Fabrication and properties of 3-D $\mathrm{C}_{\mathrm{f}} / \mathrm{SiC}-\mathrm{ZrC}$ composites, using $\mathrm{ZrC}$ precursor and polycarbosilane. J Am Ceram Soc 2012, 95: 1216-1219.

[258] Li HJ, He QC, Wang CC, et al. Effects of precursor feeding rate on the microstructure and ablation resistance of gradient $\mathrm{C} / \mathrm{C}-\mathrm{ZrC}-\mathrm{SiC}$ composites prepared by chemical liquid-vapor deposition. Vacuum 2019, 164: 265-277.

[259] Chen BW, Ni DW, Lu J, et al. Multi-cycle and long-term ablation behavior of $\mathrm{C}_{\mathrm{f}} / \mathrm{ZrB}_{2}-\mathrm{SiC}$ composites at $2500{ }^{\circ} \mathrm{C}$. Corros Sci 2021, 184: 109385.

[260] Wu XW, Su ZA, Huang QZ, et al. Effect of $\mathrm{ZrC}$ particle distribution on the ablation resistance of $\mathrm{C} / \mathrm{C}-\mathrm{SiC}-\mathrm{ZrC}$ composites fabricated using precursor infiltration pyrolysis. Ceram Int 2020, 46: 16062-16067.

[261] Wang Z, Dong SM, Ding YS, et al. Mechanical properties and microstructures of $\mathrm{C}_{\mathrm{f}} / \mathrm{SiC}-\mathrm{ZrC}$ composites using T700SC carbon fibers as reinforcements. Ceram Int 2011, 37: 695-700.

[262] Kannan R, Rangaraj L. Properties of $\mathrm{C}_{\mathrm{f}} / \mathrm{SiC}-\mathrm{ZrB}_{2}-\mathrm{Ta}_{x} \mathrm{Cy}$ composite produced by reactive hot pressing and polymer impregnation pyrolysis (RHP/PIP). J Eur Ceram Soc 2019, 39: 2257-2265.

[263] Jia Y, Chen SA, Li Y, et al. High-temperature mechanical properties and microstructure of $\mathrm{C} / \mathrm{C}-\mathrm{ZrC}-\mathrm{SiC}-\mathrm{ZrB}_{2}$ composites prepared by a joint process of precursor infiltration and pyrolysis and slurry infiltration. $J$ Alloys Compd 2019, 811: 151953.

[264] Sciti D, Zoli L, Vinci A, et al. Effect of PAN-based and pitch-based carbon fibres on microstructure and properties of continuous $\mathrm{C}_{\mathrm{f}} / \mathrm{ZrB}_{2}-\mathrm{SiC}$ UHTCMCs. J Eur Ceram Soc 2021, 41: 3045-3050.

[265] Vinci A, Zoli L, Sciti D, et al. Mechanical behaviour of carbon fibre reinforced $\mathrm{TaC} / \mathrm{SiC}$ and $\mathrm{ZrC} / \mathrm{SiC}$ composites 
up to $2100{ }^{\circ} \mathrm{C}$. J Eur Ceram Soc 2019, 39: 780-787.

[266] Silvestroni L, Pienti L, Guicciardi S, et al. Strength and toughness: The challenging case of TaC-based composites. Compos B: Eng 2015, 72: 10-20.

[267] Gui KX, Hu P, Hong WH, et al. Microstructure, mechanical properties and thermal shock resistance of $\mathrm{ZrB}_{2}-\mathrm{SiC}-\mathrm{C}_{\mathrm{f}}$ composite with inhibited degradation of carbon fibers. J Alloys Compd 2017, 706: 16-23.

[268] Hu P, Cheng Y, Xie MS, et al. Damage mechanism analysis to the carbon fiber and fiber-ceramic interface tailoring of $\mathrm{C}_{\mathrm{f}} / \mathrm{ZrC}-\mathrm{SiC}$ using $\mathrm{PyC}$ coating. Ceram Int 2018, 44: 19038-19043.

[269] Hu CL, Pang SY, Tang SF, et al. An integrated composite with a porous $\mathrm{C}_{\mathrm{f}} / \mathrm{C}-\mathrm{ZrB}_{2}-\mathrm{SiC}$ core between two compact outer layers of $\mathrm{C}_{\mathrm{f}} / \mathrm{C}-\mathrm{ZrB}_{2}-\mathrm{SiC}$ and $\mathrm{C}_{\mathrm{f}} / \mathrm{C}-\mathrm{SiC}$. J Eur Ceram Soc 2015, 35: 1113-1117.

[270] Hu CL, Pang SY, Tang SF, et al. Ablation and mechanical behavior of a sandwich-structured composite with an inner layer of $\mathrm{C}_{\mathrm{f}} / \mathrm{SiC}$ between two outer layers of $\mathrm{C}_{\mathrm{f}} / \mathrm{SiC}-\mathrm{ZrB}_{2}-\mathrm{ZrC}$. Corros Sci 2014, 80: 154-163.

[271] Chen XW, Dong SM, Kan YM, et al. Microstructure and mechanical properties of three dimensional $\mathrm{C}_{\mathrm{f}} / \mathrm{SiC}-\mathrm{ZrC}-$ $\mathrm{ZrB}_{2}$ composites prepared by reactive melt infiltration method. J Eur Ceram Soc 2016, 36: 3969-3976.

[272] Chen SA, Ji HL, Li Y, et al. Effects of high-temperature annealing on the microstructure and properties of $\mathrm{C} / \mathrm{ZrC}$ composites prepared by reactive melt infiltration. Mater Sci Eng: A 2017, 686: 41-45.

[273] Chen SA, Zhang CR, Zhang YD, et al. Effects of polymer derived $\mathrm{SiC}$ interphase on the properties of $\mathrm{C} / \mathrm{ZrC}$ composites. Mater Des 2014, 58: 102-107.

[274] Das J, Kesava BC, Reddy JJ, et al. Microstructure, mechanical properties and oxidation behavior of short carbon fiber reinforced $\mathrm{ZrB}_{2}-20 \mathrm{v} / \mathrm{oSiC}-2 \mathrm{v} / \mathrm{oB}_{4} \mathrm{C}$ composite. Mater Sci Eng: A 2018, 719: 206-226.

[275] Vinci A, Zoli L, Landi E, et al. Oxidation behaviour of a continuous carbon fibre reinforced $\mathrm{ZrB}_{2}-\mathrm{SiC}$ composite. Corros Sci 2017, 123: 129-138.

[276] Vinci A, Zoli L, Galizia $\mathrm{P}$, et al. Influence of $\mathrm{Y}_{2} \mathrm{O}_{3}$ addition on the mechanical and oxidation behaviour of carbon fibre reinforced $\mathrm{ZrB}_{2} / \mathrm{SiC}$ composites. $J$ Eur Ceram Soc 2020, 40: 5067-5075.

[277] Guo SQ. Oxidation and strength retention of $\mathrm{HfB}_{2}-\mathrm{SiC}$ composite with $\mathrm{La}_{2} \mathrm{O}_{3}$ additives. Adv Appl Ceram 2020, 119: $218-223$.

[278] Chen $\mathrm{ZK}$, Wu $\mathrm{Y}$, Chen $\mathrm{YH}$, et al. Preparation and oxidation behavior of $\mathrm{C}_{\mathrm{f}} / \mathrm{C}-\mathrm{TaC}$ composites. Mater Chem Phys 2020, 254: 123428.

[279] Mungiguerra S, di Martino GD, Cecere A, et al. Arc-jet wind tunnel characterization of ultra-high-temperature ceramic matrix composites. Corros Sci 2019, 149: 18-28.

[280] Ni C, Li KZ, Liu L, et al. Ablation mechanism of SiC coated $\mathrm{C} / \mathrm{C}$ composites at $0^{\circ}$ angle in two flame conditions under an oxyacetylene flame. Corros Sci 2014, 84: 1-10.

[281] Ma Y, Li QG, Dong SM, et al. Microstructures and ablation properties of $3 \mathrm{D}$ 4-directional $\mathrm{Cf} / \mathrm{ZrC}-\mathrm{SiC}$ composite in a plasma wind tunnel environment. Ceram Int 2014, 40: 11387-11392.

[282] Tang SF, Deng JY, Wang SJ, et al. Comparison of thermal and ablation behaviors of $\mathrm{C} / \mathrm{SiC}$ composites and C/ZrB $2-S i C$ composites. Corros Sci 2009, 51: 54-61.

[283] Tong YG, $\mathrm{Hu}$ YL, Liang XB, et al. Carbon fiber reinforced $\mathrm{ZrC}$ based ultra-high temperature ceramic matrix composite subjected to laser ablation: Ablation resistance, microstructure and damage mechanism. Ceram Int 2020, 46: 14408-14415.

[284] Zhou HJ, Ni DW, He P, et al. Ablation behavior of $\mathrm{C} / \mathrm{C}-\mathrm{ZrC}$ and $\mathrm{C} / \mathrm{SiC}-\mathrm{ZrC}$ composites fabricated by a joint process of slurry impregnation and chemical vapor infiltration. Ceram Int 2018, 44: 4777-4782.

[285] Li QG, Dong SM, Wang Z, et al. Ablation behavior and mechanism of $3 \mathrm{D} \mathrm{C}_{\mathrm{f}} / \mathrm{ZrC}-\mathrm{SiC}$ composites in a plasma wind tunnel environment. J Asian Ceram Soc 2015, 3: 377-382.

[286] Yan CL, Liu RJ, Zhang CR, et al. Ablation and mechanical properties of $3 \mathrm{D}$ braided $\mathrm{C} / \mathrm{ZrC}-\mathrm{SiC}$ composites with various $\mathrm{SiC} / \mathrm{ZrC}$ ratios. Ceram Int 2016, 42: 19019-19026.

[287] Tang SF, Deng JY, Wang SJ, et al. Ablation behaviors of ultra-high temperature ceramic composites. Mater Sci Eng: A 2007, 465: 1-7.

[288] Paul A, Venugopal S, Binner JGP, et al. UHTC-carbon fibre composites: Preparation, oxyacetylene torch testing and characterisation. J Eur Ceram Soc 2013, 33: 423-432.

[289] Zhou YC, Xiang HM, Feng ZH, et al. Electronic structure and mechanical properties of $\mathrm{NiB}$ : A promising interphase material for future $\mathrm{UHTC}_{\mathrm{f}} / \mathrm{UHTC}$ composites. $\mathrm{J} \mathrm{Am}$ Ceram Soc 2016, 99: 2110-2119.

[290] Zhou YC, Wang XF, Xiang HM, et al. Theoretical prediction, preparation, and mechanical properties of $\mathrm{YbB}_{6}$, a candidate interphase material for future UHTC $_{\mathrm{f}} /$ UHTC composites. J Eur Ceram Soc 2016, 36: 3571-3579.

[291] Jayaseelan DD, Zapata-Solvas E, Brown P, et al. In situ formation of oxidation resistant refractory coatings on SiC-reinforced $\mathrm{ZrB}_{2}$ ultra high temperature ceramics. $J$ Am Ceram Soc 2012, 95: 1247-1254.

[292] Wang P, Zhou CL, Zhang XH, et al. Oxidation protective $\mathrm{ZrB}_{2}-\mathrm{SiC}$ coatings with ferrocene addition on $\mathrm{SiC}$ coated graphite. Ceram Int 2016, 42: 2654-2661.

[293] Zhang YL, Hu H, Zhang PF, et al. $\mathrm{SiC} / \mathrm{ZrB}_{2}-\mathrm{SiC}-\mathrm{ZrC}$ multilayer coating for carbon/carbon composites against ablation. Surf Coat Technol 2016, 300: 1-9.

[294] Ren XR, Li HJ, Fu QG, et al. Oxidation protective $\mathrm{TaB}_{2}-\mathrm{SiC}$ gradient coating to protect $\mathrm{SiC}-\mathrm{Si}$ coated carbon/carbon composites against oxidation. Compos B: Eng 2014, 66: 174-179.

[295] Wang P, Zhou SB, Hu P, et al. Ablation resistance of $\mathrm{ZrB}_{2}-\mathrm{SiC} / \mathrm{SiC}$ coating prepared by pack cementation for graphite. J Alloys Compd 2016, 682: 203-207. 
[296] Zhang JP, Fu QG. The effects of carbon/carbon composites blasting treatment and modifying $\mathrm{SiC}$ coatings with $\mathrm{SiC} / \mathrm{ZrB}_{2}$ on their oxidation and cyclic ablation performances. Corros Sci 2018, 140: 134-142.

[297] Zhang JP, Fu QG, Wang YJ. Interface design and HfC additive to enhance the cyclic ablation performance of $\mathrm{SiC}$ coating for carbon/carbon composites from $1750{ }^{\circ} \mathrm{C}$ to room temperature under vertical oxyacetylene torch. Corros Sci 2017, 123: 139-146.

[298] Zhou L, Fu QG, Hu D, et al. Oxidation protective SiC-Si coating for carbon/carbon composites by gaseous silicon infiltration and pack cementation: A comparative investigation. J Eur Ceram Soc 2021, 41: 194-203.

[299] Zou X, Fu QG, Liu L, et al. $\mathrm{ZrB}_{2}-\mathrm{SiC}$ coating to protect carbon/carbon composites against ablation. Surf Coat Technol 2013, 226: 17-21.

[300] Allemand A, Szwedek O, Epherre J F, et al. Procédé pour revêtir une pièce d'un revêtement de protection contre l'oxydation par une technique de dépôt chimique en phase vapeur, et revêtement et pièce. EP patent 2782886, Oct. 2014.

[301] Chen ZK, Xiong X, Li GD, et al. Ablation behaviors of carbon/carbon composites with $\mathrm{C}-\mathrm{SiC}-\mathrm{TaC}$ multiinterlayers. Appl Surf Sci 2009, 255: 9217-9223.

[302] Li ZH, Wang YL, Xiong X, et al. Microstructure and growth behavior of $\mathrm{Hf}(\mathrm{Ta}) \mathrm{C}$ ceramic coating synthesized by low pressure chemical vapor deposition. J Alloys Compd 2017, 705: 79-88.

[303] Ren JC, Feng ER, Zhang YL, et al. Microstructure and anti-ablation performance of $\mathrm{HfC}-\mathrm{TaC}$ and $\mathrm{HfC}-\mathrm{ZrC}$ coatings synthesized by $\mathrm{CVD}$ on $\mathrm{C} / \mathrm{C}$ composites. Ceram Int 2020, 46: 10147-10158.

[304] Tong MD, Fu QG, Zhou L, et al. Ablation behavior of a novel HfC-SiC gradient coating fabricated by a facile one-step chemical vapor co-deposition. J Eur Ceram Soc 2018, 38: 4346-4355.

[305] Verdon C, Szwedek O, Jacques S, et al. Hafnium and silicon carbide multilayer coatings for the protection of carbon composites. Surf Coat Technol 2013, 230: 124-129.

[306] Wang YJ, Li HJ, Fu QG, et al. SiC/HfC/SiC ablation resistant coating for carbon/carbon composites. Surf Coat Technol 2012, 206: 3883-3887.

[307] Wang YL, Li ZH, Xiong X, et al. Action mechanism of hydrogen gas on deposition of $\mathrm{HfC}$ coating using $\mathrm{HfCl}_{4}-\mathrm{CH}_{4}-\mathrm{H}_{2}-\mathrm{Ar}$ system. Appl Surf Sci 2016, 390: 903-908.

[308] Wang YL, Xiong X, Li GD, et al. Preparation and ablation properties of $\mathrm{Hf}(\mathrm{Ta}) \mathrm{C}$ co-deposition coating for carbon/carbon composites. Corros Sci 2013, 66: 177-182.

[309] Zhang J, Zhang YL, Fu YQ, et al. Ablation behavior of HfC coating with different thickness for carbon/carbon composites at ultra-high temperature. J Eur Ceram Soc 2021, 41: 1769-1778.

[310] Zhu Y, Cheng LF, Li MX, et al. The synthesis and characterization of CVD $\mathrm{ZrB}_{2}$ coating from $\mathrm{ZrCl}_{4}-\mathrm{BCl}_{3}-$
$\mathrm{H}_{2}-\mathrm{Ar}$ system. Ceram Int 2018, 44: 2002-2010.

[311] Lee HG, Kim D, Park JY, et al. Microstructure of SiC-ZrC composite coatings on TRISO particles via fluidized bed chemical vapor deposition. Ceram Int 2019, 45: 24001-24006.

[312] Liu T, Niu YR, Li C, et al. Effect of $\mathrm{MoSi}_{2}$ addition on ablation behavior of $\mathrm{ZrC}$ coating fabricated by vacuum plasma spray. Ceram Int 2018, 44: 8946-8954.

[313] Torabi S, Valefi Z, Ehsani N. Ablation behavior of $\mathrm{SiC} / \mathrm{ZrB}_{2}$ ultra-high temperature ceramic coatings by solid shielding shrouded plasma spray for hightemperature applications (temperature above $2000{ }^{\circ} \mathrm{C}$ ). Surf Coat Technol 2020, 403: 126271.

[314] Tan W, Adducci M, Trice R. Evaluation of rare-earth modified $\mathrm{ZrB}_{2}-\mathrm{SiC}$ ablation resistance using an oxyacetylene torch. $J$ Am Ceram Soc 2014, 97: 2639-2645.

[315] Xu XT, Pan XH, Niu YR, et al. Difference evaluation on ablation behaviors of $\mathrm{ZrC}$-based and $\mathrm{ZrB}_{2}$-based UHTCs coatings. Corros Sci 2021, 180: 109181.

[316] Yoo HI, Kim HS, Hong BG, et al. Hafnium carbide protective layer coatings on carbon/carbon composites deposited with a vacuum plasma spray coating method. $J$ Eur Ceram Soc 2016, 36: 1581-1587.

[317] Richet N, Lespade P, Goursat P, et al. Oxidation resistance of $\mathrm{HfB}_{2}-\mathrm{SiC}$ coatings for protection of carbon fiber based composites. Key Eng Mater 2004, 264-268: 1047-1050.

[318] Wang TY, Luo RY. Oxidation protection and mechanism of the $\mathrm{HfB}_{2}-\mathrm{SiC}-\mathrm{Si} / \mathrm{SiC}$ coatings modified by in situ strengthening of $\mathrm{SiC}$ whiskers for $\mathrm{C} / \mathrm{C}$ composites. Ceram Int 2018, 44: 12370-12380.

[319] Zapata-Solvas E, Gómez-García D, DomínguezRodríguez A, et al. High temperature creep of $20 \mathrm{vol} \%$. $\mathrm{SiC}-\mathrm{HfB}_{2}$ UHTCs up to $2000{ }^{\circ} \mathrm{C}$ and the effect of $\mathrm{La}_{2} \mathrm{O}_{3}$ addition. $J$ Eur Ceram Soc 2018, 38: 47-56.

[320] Zhang ML, Ren XR, Chu H, et al. Oxidation inhibition behaviors of the $\mathrm{HfB}_{2}-\mathrm{SiC}-\mathrm{TaSi}_{2}$ coating for carbon structural materials at $1700{ }^{\circ} \mathrm{C}$. Corros Sci 2020, 177: 108982.

[321] Zhang YL, Wang HH, Li T, et al. Ultra-high temperature ceramic coating for carbon/carbon composites against ablation above $2000 \mathrm{~K}$. Ceram Int 2018, 44: 3056-3063.

[322] Jiang Y, Liu WL, Wang N, et al. Multiphase composite $\mathrm{Hf}_{0.8} \mathrm{Ti}_{0.2} \mathrm{~B}_{2}-\mathrm{SiC}-\mathrm{Si}$ coating providing oxidation and ablation protection for graphite under different high temperature oxygen-containing environments. Ceram Int 2021, 47: 1903-1916.

[323] Ren Y, Qian $\mathrm{YH}, \mathrm{Xu} \mathrm{JJ}$, et al. Oxidation and cracking/spallation resistance of $\mathrm{ZrB}_{2}-\mathrm{SiC}-\mathrm{TaSi}_{2}-\mathrm{Si}$ coating on siliconized graphite at $1500{ }^{\circ} \mathrm{C}$ in air. Ceram Int 2020, 46: 6254-6261.

[324] Zhang P, Fu QG, Cheng CY, et al. Comparing oxidation behaviors at $1773 \mathrm{~K}$ and $1973 \mathrm{~K}$ of $\mathrm{HfB}_{2}-\mathrm{MoSi}_{2} / \mathrm{SiC}-\mathrm{Si}$ coating prepared by a combination method of pack cementation, slurry painting and in situ synthesis. Surf 
Coat Technol 2020, 403: 126418.

[325] Jiang Y, Liu T, Ru HQ, et al. Oxidation and ablation protection of multiphase $\mathrm{Hf}_{0.5} \mathrm{Ta}_{0.5} \mathrm{~B}_{2}-\mathrm{SiC}-\mathrm{Si}$ coating for graphite prepared by dipping-pyrolysis and reactive infiltration of gaseous silicon. Appl Surf Sci 2018, 459: 527-536.

[326] Zhang $\mathrm{P}, \mathrm{Fu} \mathrm{QG}, \mathrm{Hu} \mathrm{D}$, et al. Oxidation behavior of $\mathrm{SiC}-\mathrm{HfB}_{2}-\mathrm{Si}$ coating on $\mathrm{C} / \mathrm{C}$ composites prepared by slurry dipping combined with gaseous Si infiltration. Surf Coat Technol 2020, 385: 125335.

[327] Zhuang L, Fu QG, Li HJ. SiCnw/PyC core-shell networks to improve the bonding strength and oxyacetylene ablation resistance of $\mathrm{ZrB}_{2}-\mathrm{ZrC}$ coating for $\mathrm{C} / \mathrm{C}-\mathrm{ZrB}_{2}-$ ZrC-SiC composites. Carbon 2017, 124: 675-684.

[328] Nisar A, Ariharan S, Venkateswaran T, et al. Effect of carbon nanotube on processing, microstructural, mechanical and ablation behavior of $\mathrm{ZrB}_{2}-20 \mathrm{SiC}$ based ultra-high temperature ceramic composites. Carbon 2017, 111: 269-282.

[329] Zapata-Solvas E, Jayaseelan DD, Brown PM, et al. Thermal properties of $\mathrm{La}_{2} \mathrm{O}_{3}$-doped $\mathrm{ZrB}_{2}$ - and $\mathrm{HfB}_{2}$-based ultra-high temperature ceramics. J Eur Ceram Soc 2013, 33: 3467-3472.

[330] Zhang XH, Hu P, Han JC, et al. Ablation behavior of $\mathrm{ZrB}_{2}-\mathrm{SiC}$ ultra high temperature ceramics under simulated atmospheric re-entry conditions. Compos Sci Technol 2008, 68: 1718-1726.

[331] Brenner AE, Peña AA, Phuah XL, et al. Cyclic ablation of high-emissivity $\mathrm{Sm}$-doped $\mathrm{ZrB}_{2} / \mathrm{SiC}$ coatings on alumina substrates. J Eur Ceram Soc 2018, 38: 1136-1142.

[332] Cheng CY, Li HJ, Fu QG, et al. A SiCnw/PyC-toughened $\mathrm{ZrB}_{2}-\mathrm{SiC}$ coating for protecting $\mathrm{Si}-\mathrm{SiC}$ coated $\mathrm{C} / \mathrm{C}$ composites against oxidation. Appl Surf Sci 2018, 457: 360-366.

[333] Chinnaraj RK, Hong SM, Kim HS, et al. Ablation experiments of ultra-high-temperature ceramic coating on carbon-carbon composite using ICP plasma wind tunnel. Int J Aeronaut Space Sci 2020, 21: 889-905.

[334] Cui YH, Guo MY, Shao YX, et al. Effects of SiC on microstructure and properties of plasma sprayed $\mathrm{ZrB}_{2}-\mathrm{ZrC}$ composite coating. Ceram Int 2021, 47: 12753-12761.

[335] $\mathrm{Hu}$ D, Fu QG, Liu T, et al. Structural design and ablation performance of $\mathrm{ZrB}_{2} / \mathrm{MoSi}_{2}$ laminated coating for $\mathrm{SiC}$ coated carbon/carbon composites. J Eur Ceram Soc 2020, 40: $212-219$.

[336] Hu CL, Tang SF, Pang SY, et al. Long-term oxidation behaviors of $\mathrm{C} / \mathrm{SiC}$ composites with a $\mathrm{SiC} / \mathrm{UHTC} / \mathrm{SiC}$ three-layer coating in a wide temperature range. Corros Sci 2019, 147: 1-8.

[337] Jia YJ, Li HJ, Yao XY, et al. Long-time ablation protection of carbon/carbon composites with different$\mathrm{La}_{2} \mathrm{O}_{3}$-content modified $\mathrm{ZrC}$ coating. J Eur Ceram Soc 2018, 38: 1046-1058.

[338] Wang YJ, Li HJ, Fu QG, et al. Ablation behaviour of a $\mathrm{TaC}$ coating on $\mathrm{SiC}$ coated $\mathrm{C} / \mathrm{C}$ composites at different temperatures. Ceram Int 2013, 39: 359-365.

[339] Xu JJ, Sun W, Xu YL, et al. Microstructures and ablation resistance of $\mathrm{WSi}_{2} / \mathrm{ZrSi}_{2} / \mathrm{Zr}_{x} \mathrm{Hf}_{1-x} \mathrm{C} / \mathrm{SiC}$ coating based on a pattern strengthening one-step method. J Eur Ceram Soc 2021, 41: 38-53.

[340] Information on https://Ultramet.Com/Chemical-VaporDeposition/\#Materials-Deposited-Cvd.

[341] Kuriakose AK, Margrave JL. The oxidation kinetics of zirconium diboride and zirconium carbide at high temperatures. J Electrochem Soc 1964, 111: 827.

[342] Wang PP, Li HJ, Ren XR, et al. $\mathrm{HfB}_{2}-\mathrm{SiC}-\mathrm{MoSi}_{2}$ oxidation resistance coating fabricated through in situ synthesis for $\mathrm{SiC}$ coated $\mathrm{C} / \mathrm{C}$ composites. J Alloys Compd 2017, 722: 69-76.

[343] Cai ZY, Zhang DX, Chen XX, et al. A novel ultra-high-temperature oxidation protective $\mathrm{MoSi}_{2}-\mathrm{TaSi}_{2}$ ceramic coating for tantalum substrate. J Eur Ceram Soc 2019, 39: 2277-2286..

[344] Tului M, Lionetti S, Pulci G, et al. Effects of heat treatments on oxidation resistance and mechanical properties of ultra high temperature ceramic coatings. Surf Coat Technol 2008, 202: 4394-4398.

[345] Xu YL, Sun W, Xiong X, et al. Ablation characteristics of mosaic structure $\mathrm{ZrC}-\mathrm{SiC}$ coatings on low-density, porous C/C composites. J Mater Sci Technol 2019, 35: 2785-2798.

[346] Tan ZY, Zhu W, Yang L, et al. Microstructure, mechanical properties and ablation behavior of ultra-high-temperature Ta-Hf-C solid solution coating prepared by a step-by-step plasma solid solution method. Surf Coat Technol 2020, 403: 126405.

[347] Zhang JP, Fu QG, Qu JL, et al. Surface modification of carbon/carbon composites and in situ grown $\mathrm{SiC}$ nanowires to enhance the thermal cycling performance of $\mathrm{Si}-\mathrm{Mo}-\mathrm{Cr}$ coating under parallel oxyacetylene torch. Corros Sci 2016, 111: 667-674.

[348] Xiang Y, Li W, Wang S, et al. Preparation of UHTC based coatings for $\mathrm{C}-\mathrm{SiC}$ composites by slurry and CVD. Mater Technol 2012, 27: 257-260.

[349] Xu L, Cheng J, Li XC, et al. Preparation of carbon/ carbon-ultra high temperature ceramics composites with ultra high temperature ceramics coating. J Am Ceram Soc 2018, 101: 3830-3836.

[350] Loehman RE, Corral EL. Multilayer ultra-high-temperature ceramic coatings. U.S. patent 8137 802, 2012.

[351] Zhou HJ, Gao L, Wang $\mathrm{Z}$, et al. $\mathrm{ZrB}_{2}-\mathrm{SiC}$ oxidation protective coating on $\mathrm{C} / \mathrm{C}$ composites prepared by vapor silicon infiltration process. J Am Ceram Soc 2010, 93: 915-919.

[352] Fu QG, Li HJ, Li KZ, et al. SiC whisker-toughened $\mathrm{MoSi}_{2}-\mathrm{SiC}-\mathrm{Si}$ coating to protect carbon/carbon composites against oxidation. Carbon 2006, 44: 1866-1869.

[353] Ren JC, Zhang YL, Zhang PF, et al. UHTC coating reinforced by $\mathrm{HfC}$ nanowires against ablation for $\mathrm{C} / \mathrm{C}$ composites. Surf Coat Technol 2017, 311: 191-198. 
[354] Cheng CY, Li HJ, Fu QG, et al. Effects of pyrocarbon on morphology stability of $\mathrm{SiC}$ nanowires at high temperatures. J Am Ceram Soc 2018, 101: 3694-3702.

[355] Zhuang L, Fu QG, Ma WH, et al. Oxidation protection of C/C composites: Coating development with thermally stabile SiC@PyC nanowires and an interlocking $\mathrm{TaB}_{2}-\mathrm{SiC}$ structure. Corros Sci 2019, 148: 307-316.

[356] Vogel W. Glass Chemistry. Berlin: Springer-Verlag, Berlin Heidelberg, 1994.

[357] Atkins P, Paula J. Atkins' Physical Chemistry. Oxford: Oxford University Press, 2006: 783-827.

[358] George EP, Raabe D, Ritchie RO. High-entropy alloys. Nat Rev Mater 2019, 4: 515-534.

[359] Xiang HM, Xing Y, Dai FZ, et al. High-entropy ceramics: Present status, challenges, and a look forward. $J A d v$ Ceram 2021, 10: 385-441.

[360] Rost CM, Sachet E, Borman T, et al. Entropy-stabilized oxides. Nat Commun 2015, 6: 8485.

[361] Wright AJ, Wang QY, Huang CY, et al. From high-entropy ceramics to compositionally-complex ceramics: A case study of fluorite oxides. J Eur Ceram Soc 2020, 40: 2120-2129.

[362] Gild J, Zhang YY, Harrington T, et al. High-entropy metal diborides: A new class of high-entropy materials and a new type of ultrahigh temperature ceramics. Sci Rep 2016, 6: 37946.

[363] Zhang Y, Guo WM, Jiang ZB, et al. Dense high-entropy boride ceramics with ultra-high hardness. Scripta Mater 2019, 164: 135-139.

[364] Shen XQ, Liu JX, Li F, et al. Preparation and characterization of diboride-based high entropy $\left(\mathrm{Ti}_{0.2} \mathrm{Zr}_{0.2} \mathrm{Hf}_{0.2} \mathrm{Nb}_{0.2} \mathrm{Ta}_{0.2}\right) \mathrm{B}_{2}-\mathrm{SiC}$ particulate composites. Ceram Int 2019, 45: 24508-24514.

[365] Gu JF, Zou J, Sun SK, et al. Dense and pure high-entropy metal diboride ceramics sintered from self-synthesized powders via boro/carbothermal reduction approach. Sci China Mater 2019, 62: 1898-1909.

[366] Failla S, Galizia P, Fu S, et al. Formation of high entropy metal diborides using arc-melting and combinatorial approach to study quinary and quaternary solid solutions. $J$ Eur Ceram Soc 2020, 40: 588-593.

[367] Chen H, Xiang HM, Dai FZ, et al. Porous high entropy $\left(\mathrm{Zr}_{0.2} \mathrm{Hf}_{0.2} \mathrm{Ti}_{0.2} \mathrm{Nb}_{0.2} \mathrm{Ta}_{0.2}\right) \mathrm{B}_{2}$ : A novel strategy towards making ultrahigh temperature ceramics thermal insulating. J Mater Sci Technol 2019, 35: 2404-2408.

[368] Liu JX, Shen XQ, Wu Y, et al. Mechanical properties of hot-pressed high-entropy diboride-based ceramics. $J A d v$ Ceram 2020, 9: 503-510.

[369] Sarker P, Harrington T, Toher C, et al. High-entropy high-hardness metal carbides discovered by entropy descriptors. Nat Commun 2018, 9: 4980.

[370] Castle E, Csanádi T, Grasso S, et al. Processing and properties of high-entropy ultra-high temperature carbides. Sci Rep 2018, 8: 8609.
[371] Wei XF, Liu JX, Li F, et al. High entropy carbide ceramics from different starting materials. J Eur Ceram Soc 2019, 39: 2989-2994.

[372] Lu K, Liu JX, Wei XF, et al. Microstructures and mechanical properties of high-entropy $\left(\mathrm{Ti}_{0.2} \mathrm{Zr}_{0.2} \mathrm{Hf}_{0.2} \mathrm{Nb}_{0.2} \mathrm{Ta}_{0.2}\right) \mathrm{C}$ ceramics with the addition of SiC secondary phase. J Eur Ceram Soc 2020, 40: 1839-1847.

[373] Qin Y, Liu JX, Li F, et al. A high entropy silicide by reactive spark plasma sintering. J Adv Ceram 2019, 8: 148-152.

[374] Gild J, Braun J, Kaufmann K, et al. A high-entropy silicide: $\quad\left(\mathrm{Mo}_{0.2} \mathrm{Nb}_{0.2} \mathrm{Ta}_{0.2} \mathrm{Ti}_{0.2} \mathrm{~W}_{0.2}\right) \mathrm{Si}_{2} . \quad J$ Materiomics 2019, 5: 337-343.

[375] Chen XQ, Wu YQ. High-entropy transparent fluoride laser ceramics. J Am Ceram Soc 2020, 103: 750-756.

[376] Yan XL, Constantin L, Lu YF, et al. $\left(\mathrm{Hf}_{0.2} \mathrm{Zr}_{0.2} \mathrm{Ta}_{0.2} \mathrm{Nb}_{0.2} \mathrm{Ti}_{0.2}\right) \mathrm{C}$ high-entropy ceramics with low thermal conductivity. J Am Ceram Soc 2018, 101: 4486-4491.

[377] Tallarita G, Licheri R, Garroni S, et al. Novel processing route for the fabrication of bulk high-entropy metal diborides. Scripta Mater 2019, 158: 100-104.

[378] Zhou JY, Zhang JY, Zhang F, et al. High-entropy carbide: A novel class of multicomponent ceramics. Ceram Int 2018, 44: 22014-22018.

[379] Feng L, Fahrenholtz WG, Hilmas GE. Two-step synthesis process for high-entropy diboride powders. J Am Ceram Soc 2020, 103: 724-730.

[380] Feng L, Fahrenholtz WG, Hilmas GE. Processing of dense high-entropy boride ceramics. J Eur Ceram Soc 2020, 40: 3815-3823.

[381] Chicardi E, García-Garrido C, Gotor FJ. Low temperature synthesis of an equiatomic (TiZrHfVNb) $\mathrm{C}_{5}$ high entropy carbide by a mechanically-induced carbon diffusion route. Ceram Int 2019, 45: 21858-21863.

[382] Sedegov A, Vorotilo S, Tsybulin V, et al. Synthesis and study of high-entropy ceramics based on the carbides of refractory metals. IOP Conf Ser: Mater Sci Eng 2019, 558: 012043.

[383] Li F, Lu Y, Wang XG, et al. Liquid precursor-derived high-entropy carbide nanopowders. Ceram Int 2019, 45: 22437-22441.

[384] Feng L, Fahrenholtz WG, Hilmas GE, et al. Synthesis of single-phase high-entropy carbide powders. Scripta Mater 2019, 162: 90-93.

[385] Feng L, Fahrenholtz WG, Hilmas GE. Low-temperature sintering of single-phase, high-entropy carbide ceramics. J Am Ceram Soc 2019, 102: 7217-7224.

[386] Monteverde F, Saraga F, Gaboardi M. Compositional disorder and sintering of entropy stabilized (Hf, Nb, Ta, Ti, $\mathrm{Zr}) \mathrm{B}_{2}$ solid solution powders. J Eur Ceram Soc 2020, 40: 3807-3814.

[387] Gild J, Kaufmann K, Vecchio K, et al. Reactive flash spark plasma sintering of high-entropy ultrahigh temperature ceramics. Scripta Mater 2019, 170: 106-110. 
[388] Zhang Y, Jiang ZB, Sun SK, et al. Microstructure and mechanical properties of high-entropy borides derived from boro/carbothermal reduction. J Eur Ceram Soc 2019, 39: 3920-3924.

[389] Chen L, Wang K, Su WT, et al. Research progress of transition metal non-oxide high-entropy ceramics. J Inorg Mater 2020, 35: 748-758.

[390] Wang K, Chen L, Xu CG, et al. Microstructure and mechanical properties of (TiZrNbTaMo)C high-entropy ceramic. J Mater Sci Technol 2020, 39: 99-105.

[391] Qin M, Gild J, Wang HR, et al. Dissolving and stabilizing soft $\mathrm{WB}_{2}$ and $\mathrm{MoB}_{2}$ phases into high-entropy borides via boron-metals reactive sintering to attain higher hardness. $J$ Eur Ceram Soc 2020, 40: 4348-4353.

[392] Gild J, Wright A, Quiambao-Tomko K, et al. Thermal conductivity and hardness of three single-phase highentropy metal diborides fabricated by borocarbothermal reduction and spark plasma sintering. Ceram Int 2020, 46: 6906-6913.

[393] McClane DL, Fahrenholtz WG, Hilmas GE. Thermal properties of $(\mathrm{Zr}, \mathrm{TM}) \mathrm{B}_{2}$ solid solutions with $\mathrm{TM}=\mathrm{Hf}, \mathrm{Nb}$, W, Ti, and Y. J Am Ceram Soc 2014, 97: 1552-1558.

[394] Wuchina E, Opeka M, Causey S, et al. Designing for ultrahigh-temperature applications: The mechanical and thermal properties of $\mathrm{HfB}_{2}, \mathrm{HfC}_{x}, \mathrm{HfN}_{x}$ and $\mathrm{Hf}(\mathrm{N}) . J$ Mater Sci 2004, 39: 5939-5949.

[395] Wei XF, Liu JX, Bao WC, et al. High-entropy carbide ceramics with refined microstructure and enhanced thermal conductivity by the addition of graphite. $J$ Eur
Ceram Soc 2021, 41: 4747-4754.

[396] Backman L, Gild J, Luo J, et al. Part I: Theoretical predictions of preferential oxidation in refractory high entropy materials. Acta Mater 2020, 197: 20-27.

[397] Wang HX, Cao YJ, Liu W, et al. Oxidation behavior of $\left(\mathrm{Hf}_{0.2} \mathrm{Ta}_{0.2} \mathrm{Zr}_{0.2} \mathrm{Ti}_{0.2} \mathrm{Nb}_{0.2}\right) \mathrm{C}-x \mathrm{SiC}$ ceramics at high temperature. Ceram Int 2020, 46: 11160-11168.

[398] Ye BL, Wen TQ, Liu D, et al. Oxidation behavior of $\left(\mathrm{Hf}_{0.2} \mathrm{Zr}_{0.2} \mathrm{Ta}_{0.2} \mathrm{Nb}_{0.2} \mathrm{Ti}_{0.2}\right) \mathrm{C}$ high-entropy ceramics at 1073-1473 K in air. Corros Sci 2019, 153: 327-332.

[399] Cai FY, Ni DW, Chen BW, et al. Fabrication and properties of $\mathrm{C}_{\mathrm{f}} /\left(\mathrm{Ti}_{0.2} \mathrm{Zr}_{0.2} \mathrm{Hf}_{0.2} \mathrm{Nb}_{0.2} \mathrm{Ta}_{0.2}\right) \mathrm{C}$-SiC high-entropy ceramic matrix composites via precursor infiltration and pyrolysis. J Eur Ceram Soc 2021, 41: 5863-5871.

Open Access This article is licensed under a Creative Commons Attribution 4.0 International License, which permits use, sharing, adaptation, distribution and reproduction in any medium or format, as long as you give appropriate credit to the original author(s) and the source, provide a link to the Creative Commons licence, and indicate if changes were made.

The images or other third party material in this article are included in the article's Creative Commons licence, unless indicated otherwise in a credit line to the material. If material is not included in the article's Creative Commons licence and your intended use is not permitted by statutory regulation or exceeds the permitted use, you will need to obtain permission directly from the copyright holder.

To view a copy of this licence, visit http://creativecommons. org/licenses/by/4.0/. 